
WSRC-TR-90-042-125

\section{MODERATOR CHEMISTRY PROGRAM (U)}

by L. V. Dewitt

Westinghouse Savannah River Company

Savannah River Site

Aiken, South Carolina 29808

Other Authors:

A. Gibbs

(WSRC)

D. P. Lambert

(WSRC)

S. R. Bohrer

(WSRC)

R. L. Fanning

(WSRC)

M. W. Houston

(WSRC)
S. L. Stinson

(WSRC)

R. W. Deible

(WSRC)

S. I. Abdel-Khalik

(WSRC)

This paper was prepared in connection with work done under Contract No. DE-AC09-89SR18035 with the U. S. Department of Energy. By acceptance of this paper, the publisher and/or recipient acknowledges the U.S. Government's right to retain a nonexclusive, royalty-free license in and to any copyright covering this paper, along with the right to reproduce and to authorize others to reproduce all or part of the copyrighted paper. 


\section{DISCL,AIMHL}

This report was prepared as an account of work sponsored by an agency of the United States Government. Neither the United States Government nor any agency thereof, nor any of their employees, makes any warranty, express or implied, or assumes any legal liability or responsibility for the accuracy, completeness, or usefulness of any information, apparatus, product, or process disclosed, or represents that its use would not infringe privately owned rights. Reference herein to any specific commercial product, process, or service by trade name, trademark, manufacturer, or otherwise does not necessarily constitute or imply its endorsement, recommendation, or favoring by the United States Government or any agency thereof. The views and opinions of authors expressed herein do not necessarily state or reflect those of the United States Government or any agency thereot.

This report has been reproduced directy from the best available copy.

Available to DOE and DOE contractors from the Office of Scientific and Technical Information, P.O. Box 62, Oak Ridge, TN 37831; prices available from (615) 576-8401, FTS 626-8.4()1.

Available to the public from the National Technical Information Service, U.S. Department of Commerce, 5285 Port Royal Rd., Springfield, VA 22161. 
WSRC-TR--90-042-125

DE93 004544

\section{MODERATOR CHEMISTRY PROGRAM}

(U)

AUTHORS: L. V. DEWITT, A. GIBBS, D. P. LAMBERT,

S. R. BOHRER, R. L. FANNING, M. W. HOUSTON,

S. L. STINSON, R. W. DEIBLE, S. I. ABDEL-KHALIK

REVIEWERS: H. F. ALLEN, E. W. BAUMANN 
REACTOR ENGINEERING SUPPORT SECTION

SYSTEMS CHEMISTRY GROUP

KEYWORDS:

Moderator

Chemistry

RETENTION:

PERMANENT

CLASSIFICATION:

UNCLASSIFIED

\title{
MODERATOR CHEMISTRY PROGRAM (IJ)
}

\author{
BY \\ SYSTEMS CHEMISTRY GROUP \\ ISSUED: NOVEMBER, 1990
}

APPROVALS

EWBaumanon

Technical Reviewer

Sarny V. Whelits

Manager, Systems Chemistry Group

Hoflem

Manager, Reactor Engineering Support Section $\frac{11 / 15 / 90}{\text { Date }}$

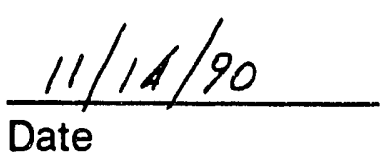

$\frac{11-15-90}{\text { Date }}$ 


\title{
MODERATOR CHEMISTRY PROGRAM
}

\begin{abstract}
Over the past fifteen months, the Systems Chernistry Group of the Reactor Engineering Department has undertaken a comprehensive study of the Department's moderator chemistry program at the Savannah River Site (SRS). An internal review was developed to formalize and document this program. Objectives were as outlined in a mission statement and action plan (page iii). In addition to the mission statement and action plan, nine separate task reports have been issued during ine course of this study. Each of these task reports is included in this document as a chapter.

This document is therefore an organized compilation of the individual reports issued by the Systems Chemistry Group in assessment of SRS moderator chemistry to determine if there were significant gaps in the program as it existed in October, 1989. While these reviews found no significant gaps in that mode of operation, or any items that adversely affected safety, items were identified that could be improved.
\end{abstract}

Many of the items have already been dealt with or are in the process of completion under this Moderator Chemistry Program and other Reactor Restart programs. A complete list of the items of improvement found under this assessment is found in Chapter 9, along with a proposed time table for correcting remaining items that can be improved for the chemistry program of SRS reactors.

An additional external review of the moderator chemistry processes, recommendations, and responses to/from the Reactor Corrosion Mitigation Comrnittee is included as Appendix to this compilation. 


\section{ACKNOWLEDGEMENTS}

The manager of the Systems Chemistry Group during the period of this assessment was L. V. DeWitt. The Moderator Chemistry Program had external direction by S. I. Abdel-Khalik of the Georgia Institute of Technology. An additional external review was commissioned through the Reactor Corrosion Mitigation Committee to Westinghouse Nuclear Services Division (WNSD). Jon Barkich of WNSD was the lead assessor for that study.

The assistance of the Reactor Corrosion Mitigation Committee, particularly E. W. Baumann, in reviewing these documents is gratefully acknowledged. 


\section{MISSION STATEMENT AND ACTION PLAN}

\section{MISSION STATEMENT}

\section{A. OBJECTIVES}

1. To document, and provide the underlying technical bases for the methods, systems, procedures, requirements, and administrative controls currently used at SRS to maintain, control, monitor, analyze, and record moderator quality during all phases of plant operation and lay-up.

2. To examine the adequacy of such methods, systems, procedures, requirements, and administrative controls vis-a'-vis heavy water chemistry state-of-theart, as well as applicable commercial industry practice and guidelines (e.g. INPO good practice and NRC Regulatory Guides).

3. To develop a timely and comprehensive implementation plan for identified items of improvement in the current methods, systems, procedures, requirements, and administrative controls related to moderator chemistry.

4. To implement the plan upon SRS managernent approval.

\section{ACTION PLAN}

\section{A. TASKS}

1. Define the objectives of moderator chemistry control under the following conditions.

a. Normal operation.

b. C \& D operations.

c. Shutdown conditions.

2 Prepare a summary report describing current methods, systems, and procedures used at SRS to maintain, control, monitor, and record moderator quality.

a. Processes, systems, instrumentation and controls.

b. Additives and purification material specifications, material quality maintenance, and material control procedures.

c. Alarms and action levels for abnormal conditions.

d. Responsibilities of various organizations. e. Normal operation, C \& D, extended shutdown, and lay-up conditions.

f. Data collection, evaluation, and record keeping. $g$ Systems and instruments testing and maintenance.

3. Prepare a summary of the technical bases for moderator chemistry requirements currently specified in the plant's Technical Specifications/Standards.

a. Technical Standards/Specifications requirements.

b. Supporting data and/or analyses.

c. Normal operation, C\&D, extended shutdown, and lay-up conditions.

d. Response to out-of-specification conditions.

e. Instruments calibration.

4. Prepare a summary of the requirements for moderator chemistry surveillance and analysis.

a. Required sampling frequency.

b. On-line monitors and manual sampling.

c. Normal operation, C \& D, extended shutdown, and lay-up conditions.

d. Sample handling procedures, lab turn-around time, and reporting.

e. Analysis, evaluation, and trending of data.

f. Response to out-of-specifications conditions.

5. Prepare a summary of operating practices which may adversely impact moderator chemistry.

a. Power ascension; operation; temperature effects.

b. Extended shutdown; drainage.

c. C \& D operations.

d. Air exposure.

e. Deionizer breakthrough.

f. ECS and SSS operation.

g. Rapid shutdown.

$h$. Reactor systems modifications.

6. Examine adequacy of current methods, systems, and procedures; identify items of improvement, and prepare a summary report.

a. State-of-the-art.

b. Commercial industry practice and guidelines (INPO good practice and NRC Reg. guides).

c. Prior experience.

d. Peer review. 
7. Examine adequacy of current Technical Specifications/Standards requirements; identify items of improvement, and prepare a summary report of findings.
a. Supporting data and/or analyses.
b. Prior experience.
c. Peer review.

8. Examine adequacy of current surveillance and analysis requirements and procedures, identify items of improvement, and prepare a summary report of findings.
a. Required versus actual practice.
b. Applicable commercial industry practice.
c. Peer review.

9. Develop a prioritized plan to implement identified items of improvement.

a. Hardware changes.

b. Technical Specifications/Standards revisions.

c. Procedure(s) revisions.

d. Organization and Administration.

e. Resource requirements.

§. Peer/management review and approval.

10. Implement plan upon management approval.

a. Progress reports.

\section{B. PROPOSED TIME TABLE*}

1 Define objectives of moderator chemistry control

2 Summarize cument mahods, systems, and procedures

3. Summarize tectrical basis for Tech. Spec/Standards requirements.

4. Summarize surveillance and analysis requirements

5. blentity adverse operating practices

6. Examine Adequacy of current mothods, systems, and procedures. *apeer Review

7. Examine adequacy of curent Tech. Spoc/Standards requirements * Peer Reviow"*t*

8. Examine adequacy of current sumvillance and analysis * Peer reviow

9. Develop prionitized implementation plan for items of improvement. * Peer/managemert review

10. mplement Plan trapogress Reparts

*Based on a stafing level of two (2) fultime persons 
MODERATOR CHEMISTRY PROGRAM

TABLE OF CONTENTS

SUBJECT

PAGE NUMBER

ABSTRACT

i

ACKNOWLEDGEMENTS

ii

MISSION STATEMENT AND ACTION

PLAN

ii

TABLE OF CONTENTS

SRS MODERATOR CHEMISTRY CONTROL OBJECTIVES (Task 1)

METHODS, SYSTEMS, AND PROCEDURES FOR MODERATOR CHEMISTRY CONTROL AT SRS (Task 2)

Process Systems

Instrumentation

Materials, Material Specifications, and Material Control Procedures

Organizational Responsibility

Data Collection, Evaluation, and Record Keeping

References

Appendix A (Moderator Chemistry Control During Start-up, C\&D, and Shutdown)

2-1

2-1

2-10

2-12

2-15

2-16

$2-17$

$2 \cdot 19$

ASSESSMENT OF M ETHODS, S YSTEMS, AND PROCEDURES FOR MODERATOR CHEMISTRY CONTROL AT SRS (Task 6) Identified Items of Improvement

Recommended Improvements

References

Appendix A (Shutdown Conditions)

TECHNICAL BASES FOR OURRENT REACTOR CHEMISTRY TECHNICAL SPECIFICATION REQUIREMENTS AT SRS (Task 3)

Technical Specifications

Diagnostic Analytes

Discussion of Technical Bases

Monitoring of Moderator Quality

ASSESSMENT OF T ECHNICAL B ASES FOR REACTOR CHEMISTAY CONTIROL AT SRS

(Task 7)

Identified Items of Improvement

Potential Impicvements

References

5-1

$5-1$

5-3
MODERATOR CHEMISTRY SURVEILANCE AND ANALYSIS REQUIREMENTS (TaSk 4)

In-Line Monitoring Requirements

Manual Sampling Requirements

Analysis and Evaluation Requirements 6.6

References

Appendix A (Requirements During

Extended Shutdown Conditions)

Appendix $B$ (Roles of the MPF, HAM, and 400-D Area in Moderator Chemistry Control)

ASSESSMENT OF MODERATOR CHEMISTRY SURVEILLANCE AND ANALYSIS REQUIREMENTS AT SRS (Task 8)

Identified liems of Improvement In-Line Monitoring Manual Sampling Analysis and Evaluation

Recommended Improvements Hardware Related Procedures Related Upgrades in Current Practices References

Appendix A (Recommended Improvements During Shutdown Conditions)

Appendix B (Additional Improvements within Various Procedures)

IDENTIFICATION OF: OPERATING PRACTICES WITH POTENTIALLY ADVERSE IMPACT ON MODERATOR CHEMISTRY (TaSK 5)

8-1

Impacts During Power Operation

Impacts During Startups

8-1

Impacts During Shutdowns

8-3

Impacts During C\&D

Impacts During Outages

Impacts After Emergency Systems

Activation

Recommendations

References

8-4

$8-4$

8.4

8-5

8-5

8-7

IMPLEMENTATION PLAN FOR IDENTIFIED

ITEMS OF IMPROVEMENT IN THE MODERATOR CHEMISTIAY PROGRAM AT SRS (Task 9) 9.1

Recornmended Improvements $9-1$

Prioritized Rankings $9-2$

Implementation Plan 9-5

Referencess $\quad 9-6$

Appendix A (Itemized List of

Reccmmendations from Task

Reports)

Appendix B (Categorized ltems

from Task Reports)

Appendix C \{ltemized List of

Actions for Individual ltems)

APPENDIX "SRS CHEMISTRY OPERATIONS

WALKTHROUGH EVALUATIONFINAL REPORT AND SRS REPLY 


\section{SRS MODERATOR CHEMISTRY CONTROL OBJECTIVES}

(Task 1 Report)

\section{INTRODUCTION}

This report delineates the objectives of moderator chemistry control at SRS. The objectives are defined for both normal reactor operating conditions, including charge and discharge (C\&D) operations, and extended shutdown conditions. The actions required to accomplish each objective are summarized.

\section{OBJECTIVES OF MODERATOR CHEMISTRY CONTROL}

\section{A. NORMAL OPERATIONS}

The objectives of the moderator chemistry program at SRS under normal operating conditions, including $C \& D$ operations, are:

1. To minirnize corrosion of all reactor components and system boundaries in direct contact with the moderator. Accomplishment of this objective involves a compromise between optimum conditions for the stainless steel components (viz. the reactor vessel and process water system boundary) and those for the aluminum-clad fuel and target assemblies. For this purpose, the parameters to be controlled, and measured, are: $p D$, conductivity, and concentrations of nitrates, chlorides, sulfates, dissolved oxygen, mercury, chromium, gold, and siver. The latter four elements are activators for the dissolution of aluminum. Nitrate concemration is measured ior confirmation of oxidation conditions and correct pD. Chlorides and sulfates are important corrosion activators for stainless steol.

2. To maximize the reactor productivity, i.e., minimize parasitic neutron captures, by maintaining the purity and isotopic quality of the moderaır. Accomplishment of this objective involves purification and distillation of the moderator, control of neutron poisons introduced into the system, and removal of fission products. For this purpr se, proper operation of the deionizers and distillation columns. and control of materials which may come in contact with the moderator are required.
3. To minimize the possibility of radioactive releases to the environment. Accomplishment of this objective requires maintenance of conditions which minimize corrosion of reactor components, imposition of operating limits for fission product release, and chemical control of possible activation products which can be absorbed in the aluminum oxide coating and then discharged to the basin.

4. To minimize radiation exposure of personnel. Accomplishment of this objective requires continu. ous monitoring and purification of the moderator, i.e., removal of fission and activation products, if any. Surveillance of turbidity, along with all the parameters inyolved in minimizing corrosion and maintaining purity of the stream (objectives 1 and 2 above), is used to meet this objective.

5. To assure the effectiveness of the supplementary safety system (SS3), if ever needed. Accomplishment of this objective requires a nitrate rich, acidic system to prevent formation and deposition of insoluble gadolinium hydroxide upon actuation of the SSS, and to facilitate cleanup of the moderator through the deionizers following an incident inwhich the SSS is actuated.

\section{II.B EXTENDED SHUTDOWN CONDITIONS}

The objectives of the moderator chemistn program at SRS during extended shutdown conditions are:

1. To minimize corrosion of all reactor components and process water system boundaries. Maintenance of conditions which provide the lowest potentiai for corrosion of the reactor components and system boundaries may involve normal chemistry control operations, authorized supplementary chemical additions, removal of fuel and target assemblies, and/or draining of the reactor vessel.

2. To maintain the moderator in a condition which allows easy and rapid return to the quality levels required for maximum productivity upon resuming operation. Accomplishment of this objective involves control of storage condhions, purification, and control of materials which may potentially come in contact with the moderator.

3. To assure the effectiveness of the SSS, if needed, whenever fuel is present in the reactor. 


\begin{tabular}{c}
\hline METHODS, SYSTEMS, \\
AND PROCEDURES FOR \\
MODERATOR CHEMISTRY CONTROL \\
AT SRS \\
(Task 2 Report)
\end{tabular}

\section{INTRODUCTION}

The purpose of this report is to describe and document the methods, systems, and procedures used at SRS, as of mid-October 1989, to maintain, control, monitor, and record moderator quality. The adequacy of these methods, systems, and procedures, along with suggested items of improvement, will be examined in a later report.

The report is divided into five main sections: process systems, process instrumentation, materials and material specifications, organizational responsibility, and data analyses. A description of the process systems for moderator control, their operation, and their interactions is included in Chapter II. Chapter III discusses current process instrumentation. Control procedures for material to be added to the moderator are contained in Chapter IV. The responsibilities of the various groups involved in chemistry control are outlined in Chapter V. The present methods and systems of data analyses are discussed in Chapter VI.

The material presented in the report pertains to normal reactor operating conditions. Supplementary requirements for start-up, charge and discharge, and shutdown conditions are included in Appendix A.

It should be noted that this report deals only with moderator control requirements within the reactor process water systems. Independent purification facilities such as the Moderator Processing Facility (MPF), the High Activity Mouerator Processing Facility (HAM), and 400-Area are outside the scope of this report. The interfaces between these facilities arid the moderator chemistry control practices within the reactor process water systems are discussed in the Moderator Chemistry Program Task 4 Report, "Moderator Chemistry Surveillance and Analysis Requirements", [1].

\section{PROCESS SYSTEMS}

The processes used to maintain and control moderator quality are separated into four systems: purification, acid addition, oxygen addition, and blanket gas operation. This chapter describes each system in separate sections.

\subsection{Purification}

The purification system removes suspended materials by filtration and evaporation, dissolved ionic impurities by ion exchange (deionization), and light water by isotopic distillation. Filtration and deionization are done in purification cells, evaporation and distillation are done in the distillation area. Operations in the two areas are described separately.

\section{1.a. Fittration and Deionization}

Moderator is taken from the cischarge line of the System 1 heat exchangers and routed to the Purification Area. Valve arrangements in the Purification Area permit the heavy water to be routed through one or more shielded cells in series or in parallel ( $P$ Area has $3, K$ and $L$ Areas each have 2). Each cell contains a prefilter, a deionizer, and an afterfilter. Figure 1 shows a schematic of the flow paths through the Purification Area. The evaporator is contained in one of the purification cells. Operation of the evaporator is discussed in section II.1.b.ii. Normal flow rate through the Purification Area is $30 \mathrm{gpm}$. Two booster pumps (Chempumps) are used to increase flow to and from the Purification Area. The Chempumps are normally used just before and during reactor shutdowns to reduce system radiation levels for work during the shutdown.

The filter assemblies contain filter leaves made from a highly purified asbestos cloth sewn together over expanded metal. The fitters are designed to retain particles larger than 10 microns in diameter. The prefitter removes suspended solids, and the afterfitter retains any resin fines which might leave the deionizer. Solids eventually accumulate, requiring replacement of the filter. Inspection and maintenance of filter assemblies are discussed in section II.1.a.iii.

Dissolved ionic impurities are removed by ion exchange in the deionizers. From the prefilter, heavy water enters the deionizer where ionized 
Figure 1

constituents are removed. The deionizer units contain about $30 \mathrm{tt}^{3}$ of deuterized cation and anion exchange resin. Deionizers are charged, deuterized, and dedeuterized in $\mathrm{K}$ Area. Deionizer preparation is described in section II.1.a.iv.

\section{I1.1.a.i. Purification Operation}

DPSOL 105-1074, "Establishing Purification Flow", [2], describes three sources of moderator for the Purification Area:

Normal flow to the Purification Area is from the System 1 discharge line, taken downstream of the heat exchangers. If at all possible, this source is used. The only requirement is that the reactor plenum be supplied with enough water to keep the System 1 heat exchanger discharge line full. To establish flow, System 1 does not need to be operating, and may be shut down. If the pressure is low, the Purification Chempumps are started. Since System 1 supplies Purification during normal operation, it is desirable to return to this source prior to nuclear start-up to reduce hydraulic transients during that period.

A second flow path is from drain tank EP 208. This flow path is used when flow to the plenum must be stopped. During this operation, reactor overflow must be maintained to keep drain tank 208 full as it pumps to Purification. One advantage of this method is that reactor overflow is maintained while Purification flow continues. The reactor must be full, but it is not necessary for the plenum to have water.

Flow can also be supplied from overflow tank EP 214. This method is used when flow to the plenum must be stopped and drain tank 208 is not available (due to pump draining, etc.). Reactor overflow must be maintained to keep the overflow tank full as it pumps to Purification. Again, the reactor must be full, but it is not necessary for the plenum to have water.

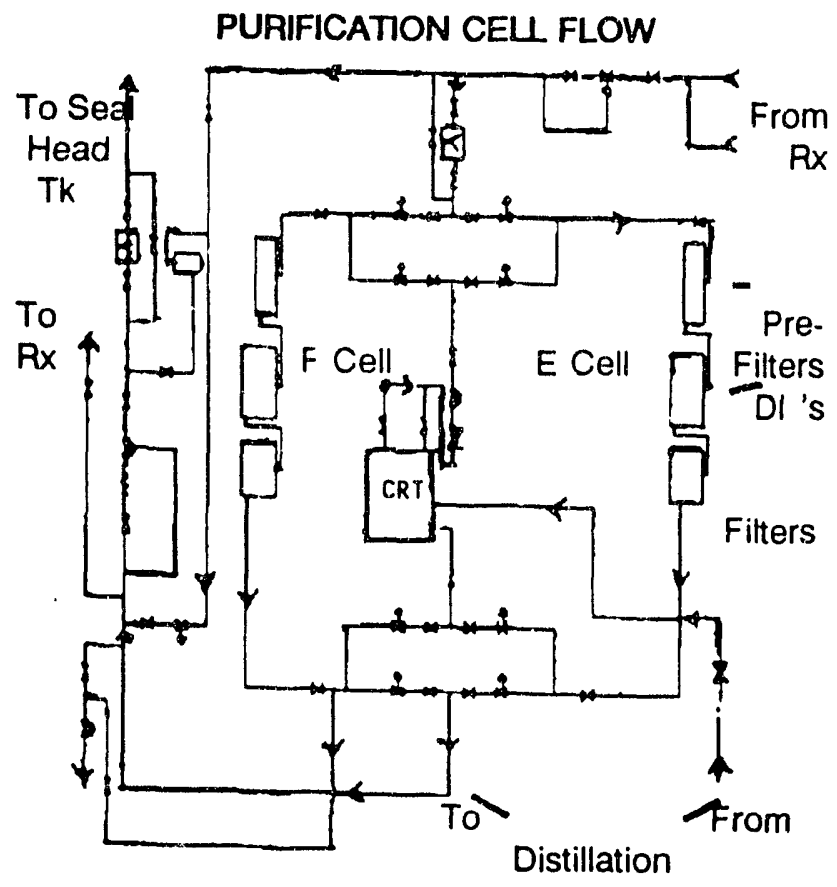

Chempump operation is controlled by DPSOL 105-1295, "Purification "Chempump" Operations and Replacement", [3]. Chempumps may be started prior to a scheduled nuclear shutdown if System 1 pressure is not sufficient to provide the increased flow required. Prior to shutdown, flow is normally increased to hasten reduction of radiation levels around the reactor and to perrnit early entry irito the radiation zones for maintenance work. During $C \& D$ operations, onty one Chempump may be operated at a time. Simultaneous operation of both Chempumps overpressurizes the discharge machine primary D20 system.

Downstream of the deionizer afterfitter, three side streams are diverted, as needed, to separate functions:

1. About $5 \mathrm{gpm}$ is sent to distillation for light water removal.

2. Another stream is routed to the +66-ft level Bingham pump seal head tank to provide a reservoir of coolant for the main process water pump seals. A back pressure of 40 to 44 psig forces water to the seal head tank, which is automatically controlled to a constant water level. Any overflow from the seal head tank is routed to the Purification Area return line. 
3. A side stream is available as a source of heavy water for emergency cooling of irradiated assemblies in the discharge machine.

Flow rates to and from Purification are measured by orifice meters. Results are reccrded in the Central Control Room and in the Purification Control Roorn. If flow to and from the Purification area differs by more than $10 \%$ at a $50 \mathrm{gpm}$ flow rate, an alarm sounds and "Purification D20 Flow Unbalanced" PW-515 annunciators light in the Central Control Room and in the Purification Control Room, [4]. A flow imbaiance indicates a possible leak. If a prolunge $d$ imbalance is indicated, a leak check is initiated. Leakage could result in severe heavy water ioss, gross contamination of operating areas, reactor shutdown, and/ or damage to Bingham pump seals through loss of seal water.

\section{II.1.a.ii. Purification Start-Up and Shutdown}

$\Gamma$ thion/deionization is started up using DPSOL 1. 32, "Cell Start-up, Shutdown, and/or S. ...ilover", [5]. The procedure verifies that equipment is installed correctly and that valves are positioned correctly. At start-up, distillation is left isolated and the cell is recirculated before being placed on-line. Cell oullet moderator samples are taken and analyzed to measure outlet conductivity. Circulation with Center Section is not initiated until effluent conductivity is less than $0.3 \mathrm{umho} / \mathrm{cm}$ for a mixed bed deionizer. This procedure is also used to switch Purification cells. One cell must be running and the other must be on standby at start of operation. Basically, the cell to be placed in operation is placed on line, and then the cell to be removed from operation is taken off line.

Purification flow is shut down using DPSOLs 105326, "Shutdown of Filtration and Deionization System",[6], and 105-1259, "Shutdown of Purification PW Flow", [7]. These procedures cover the valving and shutdown of pumps for purification process water flow shutdown. Discontinuance of al! flow removes the source of supply to the seal head tank. The seal head tank level must be maintained when the Bingham pumps are operating. If seal head tank level is to be maintained, the deionizers are bypassted using DPSOL 105-333, "Deionizer Bypass Operation",[8].

DPSOI 105-333 [R] is initiated, as requested, when all deionizers are plugged, when leakage is being experienced in purification, following injection of SSS solution, and in other cases where purification flow cannot be obtained. The coolant return tank pump must be shut down and flow to and from distillation must be stopped to bypass flow. Operation through this bypass will prevent proper control of moderator chemistry (causing generation of turbidity and corrosion) and increase moderator activity. The procedure contains instructions for valve positioning for bypass flow, and returning the system to normal.

1i.1.a.iii. Filter Assembly Inspection and Maintenance

Filters are inspected prior to installation using DPSOL 105-160, "Inspection of Purification Filter Assembly",[9]. The inspection consists of determining that there are no defects in the filter cloth or edge binding of each leaf. It is verified that there is enough pressure on the assembly to prevent the filter leaves from turning, that new gaskets are used at all joints, and tirat flainge bolts are tightened with a torque wrench.

Fitters (and deionizers) are installed using DPSOL 105-234, "Changing a Prefilter, Afterfilter, and/or Deionizer", [10]. The procedure describes the proper valve positioning, lockouts, and process conditions for the job. Work is performed using the cell crane to remove the filter, rinse it in $\mathrm{H} 2 \mathrm{O}$, and install the new filter. The old filter is packaged and shipped to the burial ground per DPSOL 105-234A, "Packaging and Shipping Process Water Contaminated Prefilters and Afterfilters to the Burial Ground", [11].

\section{II.1.a.iv. Deionizer Preparation}

Deionizers are charged with resin per DPSOL 105-152, "Resin Bed Preparation for Mixed Bed Deionizer", [12]. A normal resin charge is 25 cubic feet of anion resin and 5 cubic feet of cation resin. Ceionizer vessels are examined for defects and labelled prior to charging. Hesin is added to the vessal as a slurn. Deionized water is used to prepare resin slurries and to charge the deionizer. Cation and anion resin slurries from separate drums are pumped into the vessel. The resins are pumped into the deionizer in a two cubic foot anion to one cubic foot cation ratio mixture. After the 5 cubic feet of cation resin is pumped into the deionizer, the remainder of the anion resin is pumped in.

Once the deionizer is charged, water is circulated through it and then sampled and tested for $\mathrm{pH}$ 
and conductivity. If sample results indicate that $\mathrm{pH}$ is $7.00 \pm 0.50$ and conductivity is less than $0.75 \mu \mathrm{mho} / \mathrm{cm}$, the deionizer is pressure tested and prepared for shipment. If sample results do not fall within these limits, the deionizer is alternately flushed and the water is recirculated until they do.

Before a new deionizer can be installed, it must be deuterized (i.e. free light water in the bulk resin must be replaced with heavy water so that isotopic dilution of the heavy water does not occur). Heavy water is introduced slowly into the bottom of the deionizer, and the light water is displaced out the top.

DPSOL 105-153, "Deionizer Resin Bed Deuterization", [13] describes the procedure. $D_{2} \mathrm{O}$ is pumped into the deionizer at a rate of $0.5 \mathrm{gpm}$ until about 235 gallons of $\mathrm{D}_{2} \mathrm{O}$ have been charged. The deionizer effluent is analyzed for $\%$ $\mathrm{D}_{2} \mathrm{O}$ isotopic purity. If sample purity is not within $0.35 \mathrm{~mol} \% \mathrm{D}_{2} \mathrm{O}$ of average mol\% charged to deionizer, an additional 50 pounds of $\mathrm{D}_{2} \mathrm{O}$ is charged. This is repeated until deionizer effluent water sample purity is within 0.35 mol\% $\mathrm{D}_{2} \mathrm{O}$ of average mol\% $\mathrm{D}_{2} \mathrm{O}$ charged to the deionizer.

When the desired sample purity is obtained, the deionizer is allowed to sit for eight hours and the sampling-charging procedure is repeated until the purity limits are obtained. When required analysis has been met and deuterization is complete, 1.5 gallons of $D_{2} \mathrm{O}$ is removed to allow for heat expansion, and the deionizer is prepared for storage and shipment.

The deionizer is replaced when the effluent conductivity exceeds $0.3 \mu \mathrm{mho} / \mathrm{cm}$ using DPSOL 105234, [10]. After placing blinds on all nozzles, the spent deionizer is removed witi she cell crane and loaded into a heavily shielda! cask. Deionizers are then shipped to $K$ Area per DPSOL 105-161, "Shipping Spent Deionizers for Dedeuterization", [14]. DPSOL 105-161 [14] ensures that blind connector seals have been installed on all deionizer inlet and outlet nozzles and that proper accounting procedures for moderator and drum shipment are followed.

Heavy water is recovered from spent deionizers by dedeuterization, which involves displacing heavy water by a downflow of light water. DPSOLs 105-163, "Receiving Spent Deionizers for Dedeuterization", [15], and 105-165, "Operation of Dedeuterization Ham Facility". [16] describe the operation. DPSOL 105-163 [15] requires that proper radiation zone barricading and safety rules are observed. It also provides instructions for logging in a deionizer and receiving the proper documentation. The deionizer is placed in the cell storage area, and its location is entered in the deionizer record log.

Deionizers are dedeuterized by introducing service water into the vessel at a rate of $0.45 \mathrm{gpm}$. The displaced $D_{2} O$ flows to the auxiliary evaporator where solid impurities are removed. The 0 is then sampled and drummed for further pu...wation. When the deionizer effluent is less than 1.25 mol\% $\mathrm{D}_{2} \mathrm{O}$, the deionizer is considered dedeuterized. The deionizer is drained by disconnecting all hoses and pumping the remaining water into drums. A bucket of absorbent material ?oured into the deionizer before the connectc asal assemblies are installed on the inlet and outlet nozzles and the vessel is shipped to the burial ground.

Dedeuterized deionizers are sent to the burial ground per DPSOL 105-164, "Shipping of Dedeuterized Deionizer to Burial Ground", [17]. Before vessel shipment to the burial ground, DPSOL 105164 [17] requires that the radiation activity be measured and the curie content calculated. The procedure gives instructions for the calculation. It also requires the proper Health Protection surveillance and record keeping. Radioactive Solid Waste Burial Ground Record, OSR 7-375 is filled out and carried by the driver to the burial ground.

\section{II.1.b. Distillation}

Light water is removed from the moderator in the distillation unit. A side stream (approximately 5 gpm) from the discharge of the purification cells is sent to the distillation unit. The distillation process separates light water from moderator in two sieve plate columns (columns $A$ and $B$ ) using continuous vacuum distillation. The heavy water rich bottom product from cistillation is returned to the Purification Area via the Coolant Return Tank. It is then pumped through the purification cell supply line for additional filtration and deionization before being returned to the reactor process water system. A portion of the top distillate product, which is richer in light water than the feed, is drummed and returned to the 400-Area for processing. The remainder of the top product is used for reflux. Figure 2 is a schematic of the $L$ Area distillation unit. 
The distillation columns in each area are designed to remove about 1200 pounds of light water a year from the reactor moderator [18]. This rating is based on an operating pressure of 100 $\mathrm{mm} \mathrm{Hg}$ absolute and a refluy, rate of $30010 \mathrm{lb} / \mathrm{hr}$.

\section{II.1.b.i. Reboiler Operation}

Moderator entering distillation goes first to A-reboiler. The function of A-reboiler is to vaporize the moderator and supply the vapor to A-colurnn. It also serves to remove suspended radioactive material from the distillation feed. The moderator level in the reboiler is automatically maintained by a level controller which admits feed to the reboiler at the rate required to keep the level constant. Reboiler purge is pumped to the evaporator for further processing.

DPSOL 105-587, "A-Reboiler Separator Purge to Evaporator", [19] gives instructions for pumping reboiler purge to the evaporator. The normal purging rate is approximately 50 gallons per day. Purging is done only when distillation is operating and on line with Center Section. The procedure verifies equipment and valve position if any work has been done on the system since the last purge. The separator is purged by establishing recirculation flow (back to reboiler) and then opening the valve to the evaporator until it is filled to the desired level. A maximum level of 36 inches is specified in the DPSOL.

\section{I1.1.b.ii. Evaporator Operation}

The evaporator is a 250 gallon stainless steel vessel located in the Purification Area in one of the deionizer cells. Its function is to remove particulate and nonvolatile impurities from the moderator. Process water is normally charged to the evaporator from the reboiler separator in a batch of about 50 gallons. Vapor from the evaporator passes through a condenser and is collected in the Evaporator Condensate Tank. The contents of the Evaporator Condensate Tank can be returned to the coolant return tank or drummed off.

The evaporator is operated per DPSOL 105-454, "Operation of Evaporator \& Evaporator Condens, g System",[20]. After verifying that the level in ie evaporator condensate tank is $5 \%$ or less, steam is supplied to the evaporator. Steam flow is continued until moderator level is reduced to the
Figure 2

Distillation Schematic

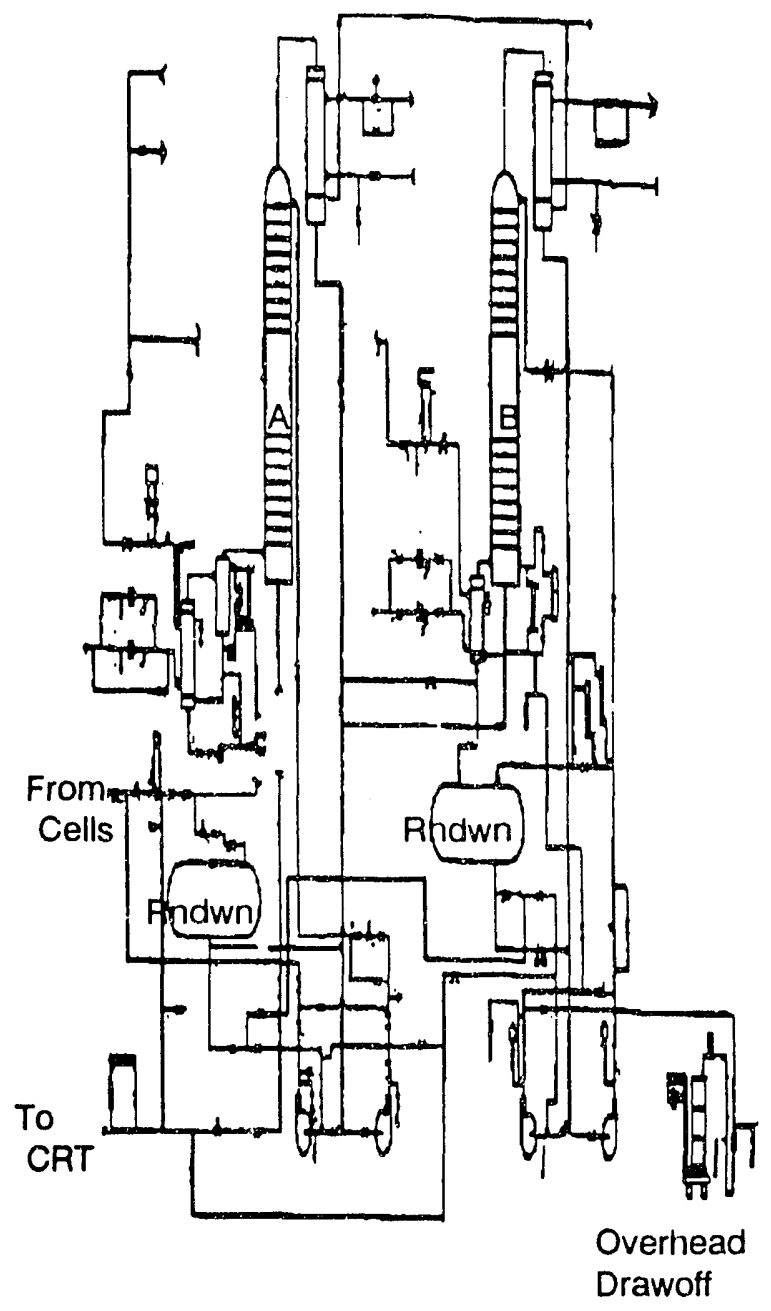

desired, predetermined point. If alarm and annunciatoi plate VR-740, "High Radiation - Evaporator Vapor" is received during evaporator operation, the evaporator will automatically be shut down. Evaporator stearn flow would be discontinued and cooling water would be introduced to the steam coils to stop boilup and prevent radioactive material from getting into the evaporator condensate tank. High radiation in the vapor can be caused by excessive boilup rate, high evaporator level, or by boiling the evaporator dry.

The evaporator condensate tank is emptied using DPSOL 105-455, "Transfer Contents of Evaporator Condensate Tank", [21]. The procedure returns the contents of the evaporator condensate tank to the moderator circulating system after it has been established that the contents meet cur- 
rent Building 105 moderator specifications. The contents may be returned to the system before sample results are received if the latest previous sample results meet specifications. If the requirements are not met, the contents are drummed off for further processing.

DPSOL 105-457, "Drumming Evaporator Condensate Tank Moderator", [22] gives instructions for valving and pump operation to drum out-of-specification moderator. The weight of material transferred to the drum is recorded, and a sample is taken for analysis of conductivity, $\mathrm{pH}$, chloride, boron content, turbidity, $\% \mathrm{D}_{2} \mathrm{O}$, beta-gamma activity, and a!pha activity. If $\mathrm{pH}$ is greater than 9 or less than 4 , supervision is notified.

\section{II.1.b.iii. Distillation Start-Up and Shutdown}

The distillation unit is started up using DPSOLs 105-571, "Distillation Start-Up",[23], and 105-573, "Placing Distillation On-Line, or Off-line",[24]. Start-up entails verifying that process water levels in the rundown tanks and reboilers are adequate, verifying valve positions and equipment conditions, and establishing cooling water and steam flows. Separate sections of DPSOL 105-571 [23] describe start-up for two different shutdown conditions.

Section 1 is used if distillation equipment was shutdown and process water drained to rundown tanks. It gives instructions for establishing condenser cooling water flow, starting vacuum pumps, and start-up of the column reboilers. Column $B /$ reboiler $B$ is started first, then column $A$ reboiler $A$. After both columns are operating on individual reflux, the condenser and bottoms outlet valves are changed to switch to total reflux operation. Steam controllers and $A$ reboiler makeup controllers are switched to automatic, and DPSOL 105-573 [24] is initiated.

Section II is used if distillation was shut down due to equipment failure and subsequent action taken per DPSOL 105-575, "Distillation Fast Shutdown For D2O Leak or Service Failure", [25]. Basically, Section II goes through the same steps as Section I, but certain steps such as vacuum pump or condenser cooling water start-up are included only as necessary.

Distillation is brought on-line or taken of -line using Section I of DPSOL 105-573,[24]. The procedure verifies that distillation is at equilibrium and has been operating on total reflux or bottoms recirculation for at least 24 hours. After ensuring that the coolant return tank is prepared to return column A bottoms moderator to the purification cells, valving is set to initiate moderator flow through distillation. Moderator is introduced as makeup to reboiler $A$ and is metered by reboiler level control. Moderator (column A bottum prod$u c t)$ is returned to purification through the coolant return tank pump. impure moderator (column $B$ overhead product) is drawn off and drummed for further processing using DPSOL 105-34, "BColumn Overhead Drawoff", [26].

Section II of DPSOL 105-753, [24] gives instruction for taking distillation off-line from Center Section. Column B overhead drawoff continues until the concentration reaches $98.0 \mathrm{~mol} \% \mathrm{D}_{2} \mathrm{O}$. The reboiler purge pump is shut down, and the moderator supply and return block valves are closed. Distillation is placed on bottoms recirculation, and coolant return tank operation is discontinued if the tank is not being used for cell recirculation, $\mathrm{pH}$ meter drainage, or dissolved oxygen analyzer return.

Distillation is shut down per DPSOL 105-574, "Routine Distillation Shutdown", [27]. Reboiler A separator purge and column B overhead draw off is discontinued, and distillation is taken off-line. Boil-up is discontinued by stopping steam flow, and reflux circulation is stopped by shutting down the bottoms and condensate pumps. Instructions are also given for shutting down the vacuum pumps and condensate cooling water systems.

In cise of a leak or other emergency, distillation can be shut down using DPSOL 105-575, "Distillation Fast Shutdown For D2O Leak or Senvice Failure", [25]. The procedure provides steps for a fast shutdown of distillation. Only the essential valves and equipment operation are listed to provide for a safe and quick shutdown The last step of the DPSOL specifies that if the system is to be shut down for a long period or if maintenance work is necessary, DPSOL 105-574 [27] should be followed to carry out all steps for a complete shutdown that have not already been done.

\subsection{Acid Addition}

Nitric acid is introduced to the moderator to control $\mathrm{PD}$ and conductivity. This description of the acid addition system first discusses the relationship between $\mathrm{PD}$ and conductivity and the procedures for controlling them. Section II.2.b. contains instructions for operation of the acid addition system equipment. The procedural responses to abnormal conditions are included in Section II.2.c. 
This section also briefly discusses thie interaction between the acid addition and oxygen addition systems.

\section{2.a. Moderator $\mathrm{pD}$ and Conductivity Control}

Moderator $\mathrm{pD}$ and conductivity control are maintained by acid addition. Both $\mathrm{PD}$ and conductivity of the moderator are determined by the concentrations of ions present in the moderator. These are the ions $\mathrm{D}^{+}, O \mathrm{D}^{-}$, and other ions resulting from the presence of unneutralized acid or base or neutral salts derived either from corrosion or chemical addition. Figure 3 shows the relationship betweer $\mathrm{pH}$ and conductivity for water, assuming no neutral salts or impurities are present [28]. The bases for the selection of the pD limits are discussed further in the Moderator Chemistry Program Task 3 Report, "Technical Eases for Reactor Chemistry Control at SRS", [29].

Moderator $\mathrm{PD}$ control is based on the relationship between $\mathrm{pH}$ - and conductivity, using on-line conductivity recorder readings. The $\mathrm{pH}$ as measurec in the moderator is given by the equation: $\mathrm{pH}=$ $\mathrm{pD}-0.4$. The direct measurement of $\mathrm{pD}$ in the moderator is difficult hecause there are no $\mathrm{pD}$ probes. The $\mathrm{pH} / \mathrm{pD}$ relationship is therefore employed, and commerical $\mathrm{pH}$ probes are used. Because the accuracy of $\mathrm{pH}$ measurements in water as nearly pure as reactor moderator is sometimes open to question, it is desirable to have some check on moderator $\mathrm{pH}$ measurement. The moderator conductivity affords such a check.

DPSOL 105-382, "Moderator pD Control", [30] contains procedures for maintaining $P D$ and conductivity control. Table 1 is used as a guide for controlling reactor effluent moderator $\mathrm{pD}$ between 5.0 and 5.2 when only mixed bed deionizers are in purification cell service. Table 2 is used as a guide for controlling on-line moderator conductivity to reactor below $0.3 \mu \mathrm{mho} / \mathrm{cm}$. The corresponding ranges of $\mathrm{pH}$ and conductivity listed in rables 1 and 2 are derived from the curve shown in Figure 1. For operator reference, DPSOL 105382 [30] contains the portion of the curve in Figure 1 encompassing the control range. A page from DPSOL 105-382 [30] containing the curve portion is included as Figure 4. The results are questioned if the values give a point that is not near the line through the following instructions from DPSOL 105-382 [30]:

If conductivity is maintained between 1.9 and 3.0 but $\mathrm{pH}$ can not be maintained between 4.6 and 4.8, notify Reactor Technology Department and day supervision.

If conductivity from purification is less than 0.3 $\mu \mathrm{mho} / \mathrm{cm}$ and $\mathrm{pH}$ is less than 5.6 or greater than 7.6, have $\mathrm{E} \&$ I calibrate $\mathrm{pH}$ meter.

If moderator conductivity is within limits but moderator $\mathrm{pH}$ is out of opera.ing limits, verify proper positioning of moderator per monitoring system per DPSOL 105-381, "In-Line pH Meter Operation", [31].

\section{2.b. Acid Addition System Equipment}

\section{Operation}

The procedure to add acid is contained in DPSOL 105-1197C, "Nitric Acid Injection System Operation", [32]. Dilute nitric acid solution $(0.1 \mathrm{~N})$ is added to the heavy water by pumping from a drum into the system 1,5, or 6 Bingham pump suction lines. The acid drum and control panel are located in the purification makeup room. The makeup room nitric acid facility consists of a metering pump, alternate hand pump, solenoid valve, flow switch and drum cap connector with a flexible verit hose, recirculation hose and pump suction hose. The drum cap connector is fitted with quick disconnects and only the pump suction hose can be connected to the drum dip tube.

The acid addition procedure is begun by selecting a pump system for acid injection (only one system can be selected at a time) and pressing the "Start" button. When the metering pump start button is pressed the pump "ON" light will illuminate. The acid addition light will illuminate and? $(\mathrm{PL})$ or $2.5(\mathrm{~K})$ liters of dilute acid will be injected automatically into the selected system in a four $(\mathrm{PL})$ or five (K) minute interval. The metering pump will stop after operating the four or five minutes. This procedure can be repeated as necessary to inject the desired total liters.

The hand pump will be used only if the metering pump fails. The hand pump may be operated by pulling the handle outward and pushing it inward (one cycle). Thirty cycles will inject one liter from the dilute acid drum. 
Figure 3

\section{RELATIONSHIP BETWEEN CONDUCTIVITY AND PD}

Conquativity, $u \mathrm{mho} / \mathrm{cm}$

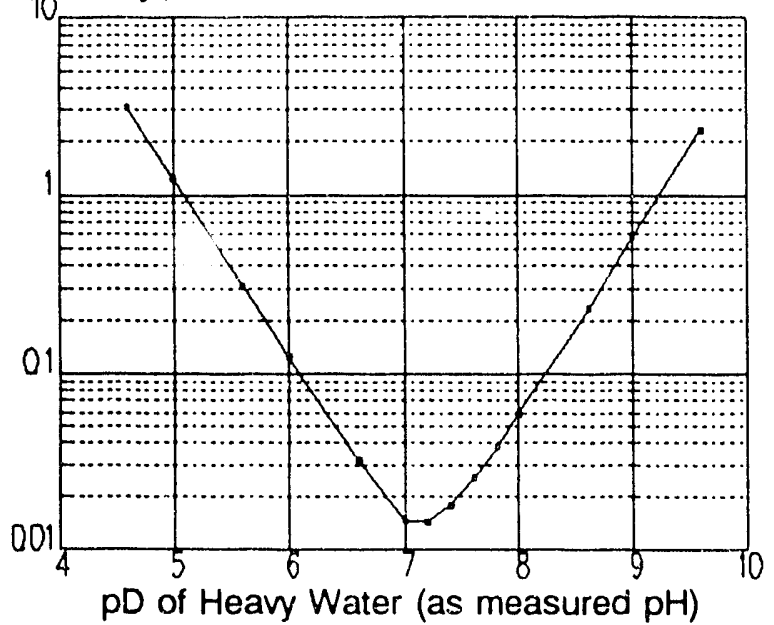

Table 1

\begin{tabular}{lllll}
\hline $\begin{array}{l}\text { Reactor } \\
\text { Effluent }\end{array}$ & & $\begin{array}{l}\text { Purification } \\
\text { Flow }\end{array}$ & $\begin{array}{c}\text { Acid } \\
\text { Addition }\end{array}$ \\
\hline Cond & $\mathrm{pD}$ & $\mathrm{pH}$ & & \\
$\begin{array}{c}\text { Above } \\
3.0\end{array}$ & $\begin{array}{l}\text { Below } \\
5.0\end{array}$ & $\begin{array}{l}\text { Below } \\
4.6\end{array}$ & Full & None
\end{tabular}

Between Between Between

$\begin{array}{llll}1.9-3.0 & 5.0-5.2 & 4.6-4.8 & 30 \pm 5 \mathrm{gpm} \text { As }\end{array}$

$\begin{array}{cccc}\text { Below } & \text { Above } & \text { Above } \\ 1.9 & 5.2 & 4.8 & 30 \pm 5 \mathrm{gpm} \text { As } \\ \end{array}$

\section{Table 2}

Cond pD pH Action

Less than

0.3 umho/cm $6.0 \cdot 8.0 \quad 5.6 \cdot 7.6 \quad$ None

Less than Less than Less than Verify $0.3 \mu \mathrm{mho} / \mathrm{cm} \quad 6.0 \quad 5.6 \quad$ proper

value

positioning

per

105-381.PLK

\begin{tabular}{ccc}
$\begin{array}{c}\text { Greater than } \\
0.3 \mu \mathrm{mho} / \mathrm{cm}\end{array}$ & $\begin{array}{c}\text { Less than } \\
6.0\end{array}$ & $\begin{array}{r}\text { Less than } \\
5.6\end{array} \begin{array}{r}\text { Switch } \\
\text { cell and } \\
\text { change out } \\
\text { deionizer }\end{array}$ \\
\hline
\end{tabular}

Figure 4

\section{RELATIONSHIP BETWEEN CONDUCTIVTY AND PD \\ (Expanded Scale) \\ Conductivity, $\mu \mathrm{mho} / \mathrm{cm}$}

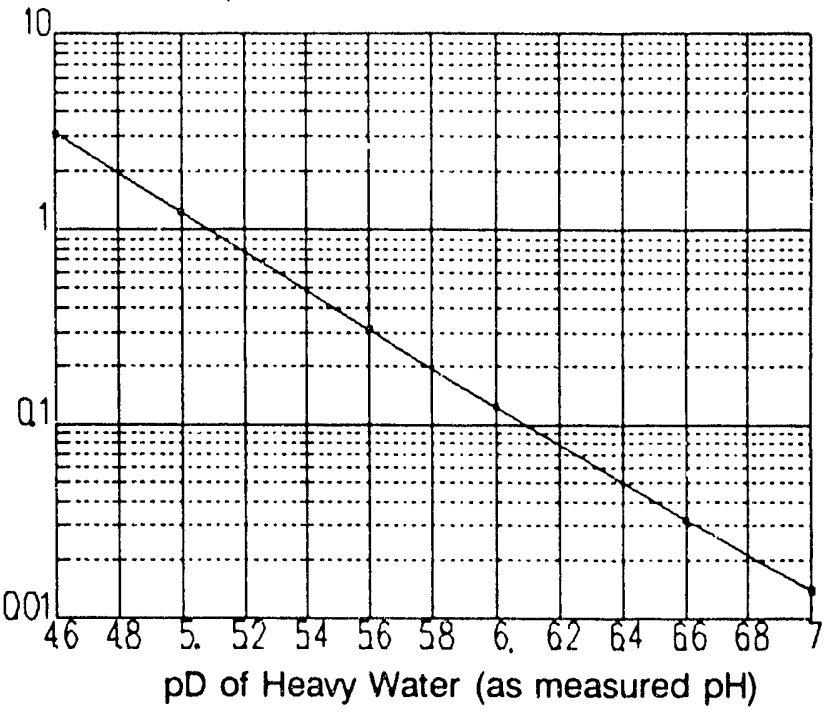

\section{II.2.c. Abnormal Condition Control}

Acid addition is also controlled through abnormal condition control DPSOLs. Responses to $\mathrm{pH}$ alarms (DPSOL 105-PW-730, "pH Abnormal", [33]) and out of range conductivities (DPSOLs 105-PW-702, "High or Low Conductivity - Moderator From Reactor", [34], and 105-PW-724, "High Conductivity - Moderator to Reactor", [35]) specify appropriate acid addition conditions. DPSOL 105-756A, "Reactor Oxygen Control", [36] also gives instructions for acid addition (along with oxygen addition) during acid instability conditions.

The procedural response to a high or low $\mathrm{pH}$ alarm (DPSOL 105-PW- 730 [33]) is to check the conductivity recorders to determine if moderator conductivity is outside of the following range:

Normal Conductivity Range, umhos/cm

To Reactor:

$0.3 \max$.

From Reactor: $\quad 3.0 \mathrm{max} .-1.9 \mathrm{~min}$.

*Day Supervision may specify more restrictive limits.

If conductivity is outside of the above limits, the appropriate DPSOL is initiated:

To Reactor: DPSOL 105-PW-724 [35]

From Reactor: DPSOL 105-PW-702 [34] 
Both procedures require that the conductivity reading be confirmed by comparing purification and central control room conductivity recorders. If they do not agree, an additional conductivity reading for moderator conductivity to purification is taken using DPSOL 105-6120, "Moderator Conductivity Analysis", [37].

Per DPSOL 105-PW-724 [35], if the moderator to the reactor conductivity is greater than $0.3 \mu \mathrm{mho} /$ $\mathrm{cm}$ under normal purification cell operation, purification cells are switched, and the depleted deionizer is replaced. If conductivity remains high $(0.3 \mu \mathrm{mho} / \mathrm{cm})$ for more than 30 minutes, distillation is isolated per DPSOL 105-573 [24].

Per DPSOL 105-PW-702 [34], if the conductivity of the moderator from the reactor is greater than $3.2 \mu \mathrm{mho} / \mathrm{crn}$, purification flow is maximized and acid addition is discontinued. If the conductivity is greater than $4.5 \mu \mathrm{mho} / \mathrm{cm}$ or greater than 3.2 $\mu \mathrm{mho} / \mathrm{cm}$ after one day of the maximum purification flow, reactor shutdown is required per division B of DPSOL 105-1205, "Lowering Reactor Power to Shutdown Conditions", [38].

For low conductivity, the rate of decrease is first determined. If the rate of decrease is less than $0.2 \mu \mathrm{mho} / \mathrm{cm} / \mathrm{hr}$, acid is added per DPSOL 105$1197 \mathrm{C}$ [32]. If the rate is greater than $0.2 \mu \mathrm{mho} /$ $\mathrm{cm} / \mathrm{hr}, 6$ liters of acid are added, and oxygen addition to the moderator is begun per DPSOL 105-754, "Oxygen Addition to Moderator System", [39].

Oxygen and acid addition is continued as long as conductivity remaiı is between 1.9 and $1.2 \mu \mathrm{mho} /$ $\mathrm{cm}$. If conducivity drops below $1.2 \mu \mathrm{mho} / \mathrm{cm}$ or the moderator to purification $\mathrm{pH}$ meter shows $\mathrm{pH}$ greater than 5.0, $\mathrm{PD}$ control is regained using DPSOL 105-756A [36]. DPSOL 105-756A [36] requires that blanket gas $\mathrm{O}_{2}$ concentration be maintained at $0.2 \%$ and oxygen be added to the moderator at the maximum rate of $2360 \mathrm{cc} / \mathrm{min}$. Initially, 6 liters of acid are added. After ten minutes, if the conductivity is less than $2.1 \mu \mathrm{mho} / \mathrm{cm}$, 6 more liters of acid are added. if, after ten more minutes, the conductivity has not increased by at least $0.4 \mu \mathrm{mho} / \mathrm{cm}$ and $\mathrm{PD}$ is greater than 5.7 , the reactor is shut down. If conductivity has increased ai least $0.4 \mu \mathrm{mho} / \mathrm{cm}$ and $\mathrm{pD}$ is less than $5.7,6$ liter acid additions continue under the following guidelines:

1. Do not exceed 24 liters acid addition without day supervision and Reactor Engineering approval.
2. Verify that conductivity is increasing at least $0.4 \mu \mathrm{mho} / \mathrm{cm}$ for each addition and that moderator $\mathrm{pD}$ value is less than 5.7 .

3. Reduce additions to 2 liters whenever the conductivity rises to $2.0 \mu \mathrm{mno} / \mathrm{cm}$.

4. Continue 2 liter acid additions until the conductivity is in the range of 2.6 to $3.0 \mu \mathrm{mho} / \mathrm{cm}$, and then continue as required to maintain that range.

\subsection{Oxygen Addition}

Oxygen is consumed in moderator due to the formation of aluminum oxide on the reactor assemblies. It is consumed in the blanket gas as it recombines with $D_{2}$ to form $D_{2} O$. Some oxygen is required to be in the moderator to inhibit the reduction of nitrates to ammonia. The production of ammonia wculd interfere with moderator $\mathrm{pD}$ control. Oxygen is added directly to moderator and/ or indirectly through the blanket gas.

Dissolved oxygen concentrations are maintained at a minimum during reactor operation to reduce the potential of oxygen-induced corrosion cracking in stainless steel. DPSOL 105-756A [34] specifies addition requirements. Instructions for adding oxygen are contained in DPSOLs 105-753, "Oxygen Addition to Blanket Gas System", [40], and 105-754 [39].

Oxygen is added to the blanket gas to maintain free $D_{2}$ below explosive levels. Oxygen is added to the moderator to control the rate of nitric acid elimination as an aspect of moderator $\mathrm{pD}$ control. During acid instability conditions (rate of conductivity decrease is greatar than $0.2 \mu \mathrm{mho} / \mathrm{cm} / \mathrm{hr}$ ), increased oxygen is added to the blanket gas in addition to the moderator to help control the rate of nitric acid elimination. Because of the high rate of aluminum oxide formation on fresh assemblies during start-up, oxygen is commonly added directly to the moderator during start-up and power ascensions.

\section{I1.4 Blanket Gas}

The blanket gas system has several functions related to moderator chemistry. These include maintaining oxygen levels during acid instability conditions (oxygen addition to blanket gas), removing gases evolving from the moderator, and preventing heavy water degradation by moisture in air. 
As described in the Acid Addition and Oxygen Addition sections, oxygen is added to the blanket gas during an acid instability condition. DPSOL 105-753 [40] describes the proper valve positions for oxygen addition. DPSOL 105-756A [36] specifies that oxygen be added to blanket gas using DPSOL 105-753 [40] until blanket gas $\mathrm{O}_{2}$ concentration is $0.2 \%$. The $\mathrm{O}_{2}$ addition to blanket gas is then stopped. The blanket gas $\mathrm{O}_{2}$ concentration is monitored and controlled by moderator oxygen addition rate and acid addition rate.

The blanket gas system removes gases evolving from the moderator by sweeping helium over the surface of the moderator in the reactor vessel. During reactor operation, the moderator is subjected to intense radiation which partially decomposes it into oxygen and deuterium gases. Deuterium gas is also generated as a byproduct of the chemical reaction between heavy water and aluminum cladding on assemblies. The $D_{2}$ evolution rate is greatest during the first week of an irradiation cycle as aluminum oxide film builds up on the surface of new aluminum clad assemblies. The oxygen and deuterium that do not recombine within the reactor vessel evolve from the heavy water in the moderator space and collect in the gas plenum.

Entrained moderator is removed from the blanket gas after it exits the reactor gas plenum in separators and collected in the overflow receiver tank and coolant return tank. The recovered moderator is added to that withdrawn from the reactor system and is treated along with the bulk of the heavy water undergoing purification. The blanket gas system is shown in Figure 5.

Figure 5

BLANKET GAS SYSTEM

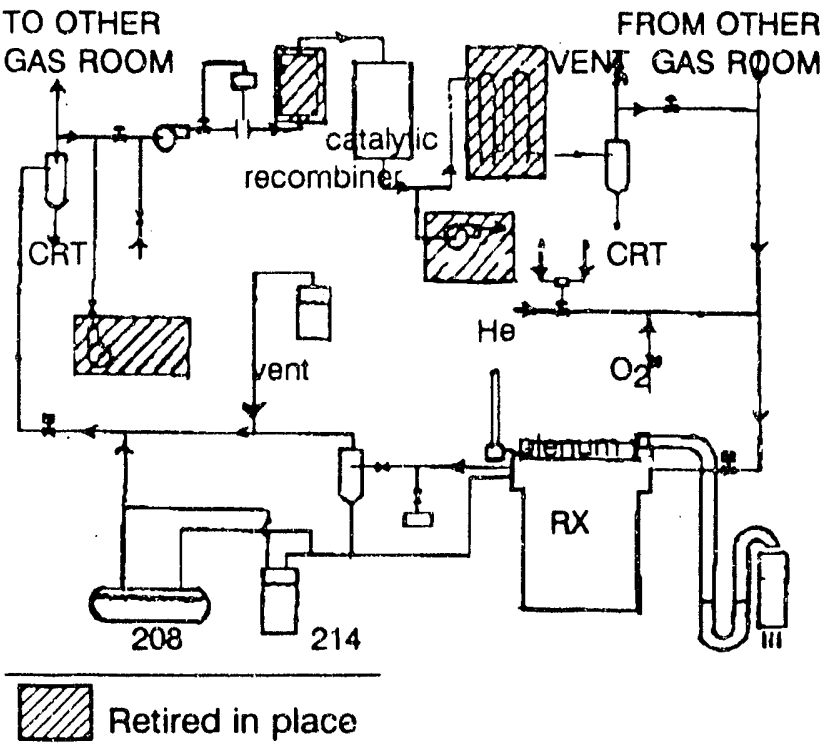

To prevent an explosive mixture of deuterium and oxygen from accumulating in the gas plenum, helium gas is circulated in a closed system through the reactor gas plenum and Purification Area gas room recombiners. Blanket gas is catalytically recombined to reduce free $\mathrm{D}_{2}$ and $\mathrm{O}_{2}$ concentrations to prevent explosive levels from occurring. DPSOL 105-756A [36] requires that blanket gas $\mathrm{D}_{2}$ concentration be controlled to less than $0.5 \mathrm{~mol} \%$. Blanket gas $\mathrm{O} 2$ concentration is maintained at $0.1 \cdot 0.2 \%$.

The free $D_{2}$ and $O_{2}$ form heavy water in the Purification Area gas room catalytic recombiner. This heavy water is removed from the gas stream by a spray separator. Heavy water that collects in the gas room spray separator drains into the coolant return tank, where it enters purification with the other moderator recovered from the blanket gas.

Blanket gas prevents heavy water degradation from moisture in the air by insuring that moderator vessels are vented to an inert atmosphere (helium blanket gas). Moisture degradation is the introduction of $\mathrm{H}_{2} \mathrm{O}$ into the moderator due to contact with ambient air.

\section{INSTRUMENTATION}

Moderator instrumentation measures and records conductivity, $\mathrm{pH}$, and dissolved oxygen. All monitoring is done continuously and in-line with the exception of portable conductivity meters used to verify in-line results. No automatic controls are associated with the instrumentation. Monitoring, surveillance requirements, and procedural response to abnormal conditions are discussed in the Moderator Chemistry Program Task 4 Report [1]. Requirements for monitoring, evaluating, and recording instrumentation output are discussed in the Data Collection section. A description of the instrumentation follows.

\section{II.1. Conductivity}

Moderator conductivity is measured by four probes. Two cells are in the $-20 \mathrm{ft}$. level process water lines to and from the Purification Area and indicated on a recorder in the Central Control Room. Two celis are in the $-14 \mathrm{ft}$. level hot tunnel process water lines to and from the Purification Area and indicated on a recorder in the Purification Control Room. The cells employ a Wheatstone bridge circuit to measure the specific conductivity of the moderator.

Portable conductivity meters are used at the 
sample sink to verify on-line probe performance and to provide an alternate method for measuring moderator conductivity [41]. The performance of the four on-line condurtivity probes is verified monthly against portable meter readings per DPSOL 105-306, "Comparing Purification and Center Section Conductivity Recorder Readings",[42]. Operability of the portable conductivity meter is confirmed monthly per DPSOL 105 306 [42] to ensure that an alternate method for moderator conductivity measurement is available in the event on-line instrumentation is inoperable. DPSOL 105-PW-702 [34] requires that moderator conductivity measurements be made with a portable meter in the event that on-line conductivity recorder readings differ by more than $0.2 \mu \mathrm{mho} /$ $\mathrm{cm}$.

\section{III.2. $\mathrm{pH}$}

Heavy water $\mathrm{pD}$ (recorded as $\mathrm{pH}$ ) to and from the Purification Area is monitored by in-line $\mathrm{pH}$ meters located in the purification makeup room. The in-line $\mathrm{pH}$ system is a dual installatior of identical units consisting of duplicate flow assemblies and associated electrodes, indicating $\mathrm{pH}$ meters, recorders and annunciators. Manifold valving can be manipulated so that each meter can monitor each stream, either from the reactor or from the Purification Area. Moderator flow exiting the $\mathrm{pH}$ units is directed to the Coolant Return Tank.

DPSOL 105-381 [31] contains vatving and operating information. Normal process water flow to $\mathrm{pH}$ Unit 1 is from the reactor. Normal process water flow to $\mathrm{pH}$ Unit 2 is from Purification to the reactor. Supervision must approve any flow changes to these units. The procedure contains instructions for changing sample feed sources (with an approved job plan). It also specifies that process water flow to the pH meters should be discontinued during reactor shutdowns and/or when proc. ess water flow to purification has been discontinued, unless othenwise specified by day supervision. Shutdown under these conditions protects the electrodes from damage due to pressure variations.

The $\mathrm{pH}$ meter recorders and alarm annunciators are located in the Purification Control Room. An alarm sounds and a "pH Abnormal" annunciator lights for a high pH of 5.0 or a low pH of 4.4 for flow to the Furification Area and for a high $\mathrm{pH}$ of 7.4 and a low pH of 5.4 for flow from the Purification Area. The alarm is characterized and appropriate action taken per DPSOL 105-PW-730 [33].
The first step required by DPSOL 105-PW-730 [33] is to determine which unit caused the alarm and whether $\mathrm{pH}$ is high or low. Next, moderator conductivity is checked-if conductivity is out of range, subsequent action is taken per DPSOL 105-PW-702 [34] or DPSOL 105-PW-724 [35].

If conductivity is within normal range, the meters are checked. In-line valving is checked per DPSOL 105-381 [31]. E \& I is requested to check the meter and make necessary repairs or calibrate the meter. If only one meter is operative, the $\mathrm{pH}$ of moderator from the reactor is monitored. If both meters are taken out of service, the moderator is sampled at least once each shift and anatyzed for $\mathrm{pH}$.

In $L$ and $K$ Areas only, if the out of range $\mathrm{pH}$ meter sample source is from the discharge of the Coolani Return Tank, distillation is taken off-line per DPSOL 105-573 [24]. When pH is returned to normal range, distillation is returned to on-line operation per DPSOL 105-573 [24].

\section{III.3 Dissolved Oxygen}

The dissolved oxygen monitor is also located in the makeup room. The monitor is an Orbisphere membrane/electrode type oxygen analyzer. Normal moderator oxygen readings at level operation are from 0.2 to $1.0 \mathrm{ppm}$.

The monitor loop is supplied with moderator from the reactor using the same header as the $\mathrm{pH}$ meters. After exiting the analyzer, the moderator is returnet to the Coolant Return Tank.

The analyzer is operated per DPSOL 105-380, "Dissolved Oxygen Analyzer Operation",[43]. DPSOL 105-380 [43] specifies the correct valve positioning to obtain moderator flow and proper operating pressure of $10-20 \mathrm{psig}$. It also requires once per shift monitoring of operating pressure and moderator oxygen condition, as well as completion of the appropriate control room data sheets.

The cutput from the monitor is sent to a recorder in the Purification Control Room. An annunciator for high oxygen level (2.0 ppm) is also located in the Purification Control Room. Response to the alarm is through DPSOL 105-PW-722, "Dissolved Oxygen Abnormal", [44], which has three directives:

1. Verify that the requirements for DPSOL 105$756 \mathrm{~A}$ [36] are being met. 
2. Request $E \& \mid$ to calibrate the analyzer.

3. Notify day supervision if dissolved oxygen remains high for longer than 24 hours.

IV. MATERIALS, MATERIAL SPECIFICATIONS, AND MATERIAL CONTROL PROCEDURES

\section{IV.1. Materials}

The materials currently used to control moderator quality are deionizer resins, nitric acid, and oxygen. Deionizer resins are used to remove dissolved ionic impurities from the moderator. Nitric acid is added to control moderator $\mathrm{pD}$ and conductivity within established limits. Oxygen is added whenever the conductivity rate of decrease (acid elimination rate) exceeds a value which would require the addition of 6 liters of $0.1 \mathrm{~N} \mathrm{ni-}$ tric acid every 3 hours.

The addition of deionizer resins and deionizer preparation is discussed in Chapter $\|$ of this report. The guidelines for adding nitric acid are contained in DPSOL 105-382 [30], and the guidelines for adding oxygen are contained in DPSOL 105-756A [36]. These guidelines are discussed in more detail in the Moderator Chemistry Program Task 4 Report [1], Section II.3.

Other additives not used for moderator chemistry control purposes will contact or potentially contact the moderator. These additives are helium, gadolinium nitrate, and polyborate solution. Helium is used in the blanket gas system to sweep away dangerous (explosive) levels of deuterium and oxygen. The blanket gas system is discussed in more detail in Chapter II of this report. Gadolinium nitrate and polyborate solution are neutron poisons used for rapid shuidown of the reactor. The solutions are part of the Supplementary Safety System (SSS) and the Emergency Cooling System (ECS), respectively.

\section{IV.2. Material Specifications}

\section{IV.2.a. Moderator Chemistry Control Material}

Specifications for the deionizer resins, nitric acid, and oxygen are contained in DPSOP 116, "Essential Material Specifications", [45]. A summary of these specifications is given below.

\section{IV.2.a.i. Anion Exchange Resin}

1. Shall be Rohm \& Haas "Amberlite" IRA-400C or equivalent in hydroxide $\left(\mathrm{OH}^{-}\right)$form.

2. Carbon dioxide $\left(\mathrm{CO}_{2}\right)$ absorption capacity must be at least 1.0 milliequivalent/milliliter (meq/ $\mathrm{ml)}$ of wet resin.

3. Exchangeable chloride $\left(\mathrm{Cl}^{-}\right)$content of resin must be less than $0.015 \mathrm{meq} / \mathrm{ml}$ of wet resin.

4. Moisture content should be at least $40 \%$.

5. Resin shall meet the following wet screen analysis limits for particle size:

\begin{tabular}{|cc|}
\hline $\begin{array}{c}\text { J.S. Standard } \\
\text { Screen * }\end{array}$ & $\begin{array}{c}\text { Cumulative } \\
\text { Retained }\end{array}$ \\
\hline 10 & 2 max \\
\hline 60 & 99 min \\
\hline
\end{tabular}

6. Exchangeable sulfate content of the resin must be less than $0.1 \mathrm{meq} / \mathrm{ml}$ of wet resin.

7. Resin shall be packed in watertight containers. Each container shall hold $5 \mathrm{tt}^{3}$ of drained resin packaged in polyethylene.

\section{iv.2.a.ii. Cation Exchange Resin}

1. Shall be Rohm \& Haas "Amberlite" IR-120 or equivalent in hydrogen ion $\left(\mathrm{H}^{+}\right)$form.

2. Cation exchange capacity must be at least 1.8 $\mathrm{meq} / \mathrm{ml}$ of wet resin.

3. Moisture content shall be at least $40 \%$.

4. Resin shall meet the following wet screen analysis limits for particle size:

\begin{tabular}{|cc|}
\hline $\begin{array}{l}\text { U.S. Standard } \\
\text { Screen }\end{array}$ & $\begin{array}{r}\text { Cumulative } \% \\
\text { Retained }\end{array}$ \\
\hline 10 & 2 max \\
\hline 60 & 99 min \\
\hline
\end{tabular}

5. Resin shail be packed in watertight containers. Each container shall hold $5 \mathrm{tt}^{3}$ of drained resin in sealed polyethylene.

\section{IV.2.a.iii Nitric Acid}

1. Actual wt. $\%$ of nitric acid shall be $+/-1 \%$ of 
nitric acid \% specified.

2. The following parameters shall meet the corresponding limits:

\begin{tabular}{|lc|}
\hline Parameter & wt. \% max \\
\hline Nitrogen oxides & 0.050 \\
Chlorides & 0.001 \\
Sulfates & 0.001 \\
ron & 0.001 \\
Residue on evaporation & 0.020 \\
Residue on ignition & 0.005 \\
(depending on \% nitric acid) & or \\
& 0.010 \\
\hline
\end{tabular}

\section{IV.2.a.iv. Oxygen}

Oxygen content shall be a minimum of $99.5 \%$. DPSOP 116 [45] doesn't specify whether the limit is mole, weight, or volume percentage.

\section{IV.2.b. Moderator Contacting Material}

A summary of material specifications for those items not used for moderator chemistry quality control (helium, gadolinium nitrate, polyborate solution), but which contact the moderator is contained in this section.

\section{IV.2.b.i. Gadolinium Nitrate}

1. The following species shall meet the corresponding limits:

\begin{tabular}{|lc|}
\hline Species & wt. \% \\
\hline Gadolinium nitrate, $\mathrm{Gd}\left(\mathrm{NO}_{3}\right)_{3} \mathrm{GH}_{2} \mathrm{O}$ & $99.50 \mathrm{~min}$ \\
Total rare earth oxides & $39.50 \mathrm{~min}$ \\
& \\
Rare earth composition: & \\
& \\
Gadolinium oxide, $\mathrm{Gd}_{2} \mathrm{O}_{3}$ & $99.00 \mathrm{~min}$ \\
Samarium oxide, $\mathrm{Sm}_{2} \mathrm{O}_{3}$ & $0.70 \mathrm{max}$ \\
Neodymium oxide, $\mathrm{Nd}_{2} \mathrm{O}_{3}$ & $0.10 \max$ \\
Europium oxide, $\mathrm{Eu}_{2} \mathrm{O}_{3}$ & 0.01 max \\
Yttrium oxide, $\mathrm{Y}_{2} \mathrm{O}_{3}$ & $0.10 \max$ \\
Other rare earth oxides & 0.01 max \\
\hline
\end{tabular}

2. Material shall be contained in polyethylene lined packages to prevent absorption of moisture and carbon dioxide.

\section{IV.2.b.ii. Polyborate}

1. The following species shall meet the corresponding limits:

\begin{tabular}{|c|c|}
\hline Species & \\
\hline $\begin{array}{l}\text { Polyborate, } \mathrm{Na}_{2} \mathrm{~B}_{8} \mathrm{O}_{13} 4 \mathrm{H}_{2} \mathrm{O} \\
\text { Boron trioxide, } \mathrm{B}_{2} \mathrm{O}_{3} \\
\text { ron oxide, } \mathrm{Fe}_{2} \mathrm{O}_{3} \\
\text { Con } \\
\text { Copper, } \mathrm{Cu} \\
\text { Mercury, } \mathrm{Hg} \\
\text { in/ } \mathrm{B} / \mathrm{B} \text { ratio }\end{array}$ & $\begin{array}{l}99.0 \% \mathrm{~min} \\
>60.0 \% \\
\quad 0.1 \% \mathrm{max} \\
<150 \mathrm{ppm} \\
<10 \mathrm{ppm} \\
<15 \mathrm{ppm} \\
18.0 \% \mathrm{~min}\end{array}$ \\
\hline
\end{tabular}

2 Each shipment must include product from only one production run.

\section{IV.2.b.iii. Helium}

1. Shall be Grade A, Bureau of Mines.

2. Shall be $99.99+\mathrm{mol} \%$.

\section{IV.3. Material Control Procedures}

All material control procedures that impact moderator quality control are contained within DPSOL 105-1845 [46]. This DPSOL has the following features:

--An information section describing the criteria for which each applicable material will be judged to determine its suitability.

-An approved materials list containing material name, use, and applicable procedure (if any).

-A procedure for the analysis of a material for potential approval.

-A data sheet to document the approval of a new material.

-A data sheet to document that all parties required to review this DPSOL have done so.

-A data sheest to document the use of a volatile organic material.

Each of these features are discussed in greater detail in this section.

\section{IV.3.a. Information Section}

The purpose of this section is to provide guidelines to be used in the process of determining a particular material's suitability. These guidelines, or criteria, are broken down into nine (9) areas: neutron poisoning, corrosion, neutron activation, carbon filter poisoning, foaming agents, hazards 
to personnel, hazards to the environment, degradation of disassembly basin water, and degradation by radiation.

Materials contributing to a neutron absorption factor of 1000 or greater are not to be added to the reactor. Materials contributing to a neutron absorption factor of greater than 50 but less than 1000 are to be added to the reactor only after the approvals of Reactor Operations (ROD) and Reactor Engineering (RED) managers (except where authorized by approved procedures). Elements to be avoided are boron, cadmium, dysprosium, europium, gadolinium, lithium, and samarium.

Chemicals containing any of the following corrosive species are to be avoided whenever possible: mercury, silver, gold, copper, and chlorides (acids, bases, and oxygen play a role in corrosion, and DPSOL 105-1845 [46] gives reference to other applicable DPSOLs for their usage). Table 3 shows the maximum allowable concentrations of the above mentioned species per DPSOL 105-1845 [46].

\begin{tabular}{lc} 
& Table 3 \\
\hline Species & Maximum Concentration \\
\hline Mercury & $10 \mathrm{ppb}$ \\
Silver & $50 \mathrm{ppb}$ \\
Gold & $50 \mathrm{ppb}$ \\
Copper & $50 \mathrm{ppb}$ \\
Chlorides & $100 \mathrm{ppb}$ in moderator, \\
& $250 \mathrm{ppm}$ on outside of \\
& stainless steel equipment
\end{tabular}

It is not specified whether "Maximum concentration" means the concentration of the species in the actual material in question or whether it means the concentration of the species in the moderator. Also, it is not clear whether "100 ppb of chlorides in the moderator" means materials which are in the moderator that contain $100 \mathrm{ppb}$ chlorides or whether it is actually $100 \mathrm{ppb}$ chlorides in moderator.

The usage of materials containing elements that are highly subject to neutron activation should be avoided. Particular attention should be given to avoiding the following elements: argon, bromine, cesium, chlorine, chromium, cobalt, copper, io- dine, krypton, manganese, phosphorus, and sulfur. Compounds containing these elements must not enter the reactor tank or annular cavity without prior RED approval.

Soaps and other foaming agents must not enter the process water system. Foam causes undesirable liquid carryover during distillation and/or evaporation.

Materials that are subject to degradation when exf used to radiation should not be used if failure would compromise system integrity or where products of decomposition would upset moderator chemistry or stainless steel/alurninum corrosion resistancs. The control criterion for chemicals hazardous to personnel, chemicals hazardous to the environment, carbon filter poisons, and chemicals that degrade disassembly basin water are not discussed here since these materials do not impact the objectives and fall outside the scope of the Moderator Chemistry Program.

\section{IV.3.b. Authorized Materials List}

This part is actually a subsection of the Information Section discussed above. The list is divided into four different categories:

--Category I - Name brand products (to be used per manufacturer's recommendations).

--Category II - Acutely hazardous materials, reference should be given to Material Safety Data Sheets (MSDS) for usage.

--Category III - Chemical compounds (use requires written procedure or joi plan).

-Categury iV - Prohibited without approval (materials prohibited in the 105 buildings without proper approval).

wach approved material has an approved use documented on the list along with any applicable procedure numbers.

\section{IV.3.C. Analysis Procedure}

The analysis procedure gives guidelines for the approval of new materials for use in the 105 buildings. Each new material intended for use in the 105 buildings must have a Data sheet 1 filled out and approved by RED, ROD, and Health Protection (HP). A copy of the Data sheet 1 should be sent to EES, Materials Consultation if the material is to be used on process water equipment. A copy 
of the MSDS inust be obtained, and a copy must be sent to the Reactor Department Hazardous Materials Coordinator, if appropriate. If a sample is requested by the Special Services Department Coordinator, the following steps are performed:

1. Submit a one liter sample of material in ouestion to EES.

2. Send a filled out Analysis request form with cost code.

3. Request weight percent of each of the following species on the request form:

\author{
Phosphate $\left(\mathrm{PO}_{4}\right)$ \\ Chloride ( $\mathrm{Cl})$ \\ Copper (Cu) \\ Mercury $(\mathrm{Hg})$ \\ Gold (Au) \\ Silver (Ag) \\ Sulfate $\left(\mathrm{SO}_{4}\right)$ \\ Chromium (Cr)
}

4. Report results to Reactor Department Coordinator.

5. Reactor Department Coordinator shall review results with RED and notify requestor if material is acceptable or not by sending a copy of the Data Sheet 1 . If the material is approved, the data sheet will list any restrictions for further use.

The Department Coordinator shall maintain records of all materials approved for use (Data Sheet 15). All newly approved materials should be added to the approved materials list of this DPSOL by a procedure change.

Data Sheet 2 is used to document review of this DPSOL. All applicable personnel are required to review this DPSOL semiannually, and their supervisors are required to sign Data Snet 2 testifying to this. A description of applicable personnel is contained in the Frequency Section of the DPSOL. All groups should respond to this review by stating whether the approved materials list is accurate and up-to-date.

Data Sheet 3 is to be filled out any time an approved volatile organic is used in the 105 buildings. All approved volatile organics are contained under Category III of the approved materials list of DPSOL 105-1845 [46]. The DPSOL gives references for the definition of a volatile organic. The purpose of the data sheet is to document the quantity of the volatile organic used along with which fitter compartments are on-line. Then a determination can be made as to the risk of carbon fitter degradation from use of the organic material. A copy of the data sheet is then sent to the Reactor Department Filter Coordinator.

\section{ORGANIZATIONAL RESPONSIBILITY}

A definitivr description of the organizational responsibilities and interfaces is not readily available. Moderator chemistry control activities are carried out as required by a plethora of individual procedures. A SRS Reactor Chemistry Policy statement has been proposed, but is still in draft form [47]. The following discussion of organizational responsibility is based largely upon an analysis of these procedures and common knowledge of standard operating practices.

Responsibility for control of moderator quality is divided over several organizations. Reactor Operations (ROD) has ultimate responsibility in that it operates purification and chemical addition equipment, and responds to out-of-limit conditions. ROD also samples moderator, monitors and records data, and controls material use in the reactor area. Reactor Maintenance (RM) supports equipment repair and calibration services. Reactor Engineering (RED) provides technical oversight and troubleshooting, as well as recommendations for improvement.

The Analytical Laboratories (AL) of the Environment, Safety, Health and Quality Assurance Division, or other laboratories contracted by $A L$, anatyze samples delivered by $R O D$ and report the results. Technical Standards/Specifications are developed by the Savannah River Laboratory. Health Protection monitors high activity samples before shipment to $\mathrm{AL}$.

\section{V.1. Reactor Operations}

ROD's various operational activities are defined in the 105 series DPSOL's. The majority of these activities are discussed in other chapters throughout this report. Operation of purification and chemical addition equipment as well as instrumentation operation are detailed in Chapter II. On-line instrument monitoring and data collection are covered in Chapter III. Material control procedures are examined in Chapter IV. Sampling and data recording requirements are included in Chapter VI.

In addition, $R O D$ has the authority to initiate projects to upgrade reactor chemistry and authorize overtime as needed to obtain necessary information on reactor chemistry. ROD may also require additional sampling or specify different analytical 
methods to obtain chemistry information.

\section{V.2. Reactor Maintenance}

RM, specifically Electrical \& Instrumentation (E\&l), maintains and calibrates the measurement equipment and instruments used to monitor moderator conditions. "80000 series" DPSOLs contain calibration frequencies and procedures for most instrumentation. Many operational DPSOLs specify that E\&l be requested to calibrate an instrument when results are quostionable. DPSOLs 105-306 [42], $105-380$ [43], and 105-381 [30] are examples of operational DPSOLs that specify E\&l activities.

\section{V.3. Reactor Engineering}

RED is the primary technical resource for moderator chemistry control. RED maintains surveillance of process and equipment performance and assists in implementing technical programs in the reactor areas. As a roubleshooting aid, RED is charged with recognizing, defining, and providing technical assistance in solving problems that arise. RED also acts as the communications liaison between ROD and the laboratories.

Operating DPSOLs call for FED approval in many cases when responses to abnormal conditions are necessary. For instance, DPSOLs 105-756A [36] and 105-756B, "Reactor Oxygen ControlData" [48] specify RED approval for acid addition and oxygen additions when the additions exceed certain rates. All materials approved for use in the reactor area under DPSOL 105-1845 [46] are to be approved by RED. In addition, any deviation from the requirements of DPSOL 105-1845 [46] must be approved by RED.

RED formally cornmunicates with ROD through Reactor Technology Reports (RTR's) and Reactor Technology Memoranda (RTM's). The RTR is used to document findings or the results of a study conducted by RED personnel. The RTR has recently been redefined as a Technical Report (WSRC-TR-YR-42-XXX). An RTM is used primarily to transmit recommendations and is usually the result of a RED study.

\section{V.4. Analytical Laboratories}

Analytical Laboratories (AL) are located in $D, F$, $H$, and $M$ Areas. Samples are delivered by $R O D$ to the appropriate laboratory indicated in DPSOL 105-6101A, "Sample Analysis Schedule and Control-Routine" [49]. The laboratories report the results back to the reactor areas and for inclusion in the computer generated SANSCO reports. AL maintains their own approved procedures and training program and documents training and analytical results.

\section{DATA COUECTION, EVALUATION, AND RECORD KEEPING}

The bulk of moderator chemistry data is collected by the Sample Analysis Schedule and Control System (SANSCO). The SANSCO program generates a sample schedule for each reactor area which specifies frequency, sample point, and required analysis for normal conditions. Other data are collected regularly by ROD through the use of on-line data sheets. Data evaluation is performed in the short term by ROD's response to out-of-limit conditions. Long term evaluation is performed by RED responses to chronic problems. At present, no routine trending of moderator chemistry data is being performed. Record keeping is done primarily with the SANSCO data base. The on-line data sheet retention periods range from one month to one year.

\section{V1.1. Data Collection}

A complete discussion of sampling locations, frequencies, procedures, and handling requirements are contained in the Moderator Chemistry Task Force Task 4 Report, "Moderator Chemistry Surveillance and Analysis Requirements" [1]. A brief summary is included in this section.

Data for the purpose of moderator quality assessment are obtained as the results of laboratory analysis conducted under the SANSCO routine. The SANSCO computer program prepares a schedule of required sampling for each reactor area. Printouts are provided for each area prior to their use date. Labels for each sample are preprinted and received with the schedule printouts. DPSOL 105-6101A [49] provides a reference for determining all required samples, frequencies, and analyzes information. It specifies that whenever moderator is in the process water system, regardless of reactor operating status, samples must be taken in order to maintain moderator chemistry within normal operating limits.

Samples are taken by ROD personnel and transported to the approp iate analytical laboratory. Results are reported by FAX to the Central Control Room where they are picked up by Purification Control Room personnel and recorded on DPSOL 105-6101C, "Sample Analysis Schedule 
and Control-Data Sheet 1 Sample Schedule" [50]. The results are also submitted for entry into the SANSCO computer program data base by the laboratory.

Data from on-line instrumentation are recorded by ROD in data sheet DPSOL's. DPSOL 105-82,"Purification Control Room Data Sheets" [51] requires that moderator $\mathrm{pH}$ and conductivity to and from Purification and dissolved orygen content be monitored and recorded every two hours. Isotopic purity of moderator is recorded each shitt in DPSOL 105-83, "Moderator System Data Collection" [52]. Dissolved oxygen content is recorded every eight hours in DPSOL 105-99, "Purification Field Data Sheets" [53]. DPSOL 105-1106, "Graphic Panel Data Sheets" [54] requires that moderator ccnductivity to and from Purification be monitored every two hours and recorded every eight hours.

\section{V1.2. Data Evaluation}

ROD evaluates moderator chemistry data on a regular basis, using SANSCO reports and monthly moderator system reponts (DPSOL 10583 [52]. DPSOL 105-84, "Analyzing 100-Area Moderator System Reprt" [5ت] provides definitions and instructions for analyzing the 100-Area Moderator System Report. Trends are established by referring to previous reports.

A more immediate evaluation of data by ROD is done when out-of-limit values are reported or recorded. Out-of-limit values are circled when recorded and reported to supervision. Out-of-limit values are responded to using Abnormal Condition Control (ACC) DPSOLs. The appropriate ACC DPSOLs for moderator chemistry control include 105-PW-702 [34], 105-PW-722 [44], 105-PW-724 [35], and 105-PW-730 [33].

In general, the ACC DPSOLs verify the out-of-limit reading by comparing with ther instruments or calibrating the instrument in question. If an outof-limit value is confirmed, the instructions are given to address the abnormal condition.

As part of its technical support service, RED evaluates moderator chemistry data, atthough no routine trending is currently being done. RED also participates in troubleshooting abnormal conditions. RED is consulted when ACC procedurss do not bring a value back within limits and when oxychen or acid addition rates exceed preset limits.

\section{V1.3. Record Keeping}

The bulk of moderator chemistry data recor: keeping is done with the SANSCO data base. The results of all laboratory analyses are entered into the computer program data base. The program prints out two reports. The "Daily Laboratory Analysis Report" reports routine analysis results for each sample run by the laboratory each day. The "Monthly Summary Laboratory Analysis Report" reports all analysis results for each sample taken during the month. Data can be extracted as needed by users having access to the data base. In addition, Special Sample reports are issued weekly.

Moderator chemistry data is also kept by ROD as DPSOLs retained on file. DPSOLs 82 [51] and 105-99 [53] are retained for one year. DPSOL $105-1106$ [54] is retained for one month.

\section{REFERENCES}

1. "Moderator Chemistry Surveillance and Analysis equirements", S. R. Bohrer and S .I. AbdelKhalik, OPS-RCD-890246, SAS Report (12/27/89).

2. "Establishing Purification Flow", SRS ROD Procedure DPSOL 105-1074-PLK, Revision 11 (8/17) 87).

3. "Purification "Chempump" Operations and Replacement", SRS ROD Procedure DPSOL 1051295-PLK, Revision 9 (7/9/87).

4. "Systems Analysis Heavy Water and Blanket Gas Purification Area of the Savannah River Reactors", W. S. Durant, DPSTSY-100-2, August, 1973.

5. "Cell Startup, Shutdown, and/or Switchover", SRS ROD Procedure DPSOL 105-302-LK, Revision $24(9 / 11 / 87)$.

6. "Shutdown of Filtration and Deionization System", SRS ROD Procedure DPSOL 105-326-LK, Revision 11 (8/15/83).

7. "Shutdown of Purification PW Flow", SRS ROD Procedure DPSOL 105-1259-PLK, Revision 10 (2/ 23/90).

8. "Deionizer Bypass Operation", SRS ROD Procedure DPSOL 105-333-LK, Revision 9 (8/19/83).

9. "Inspection of Purification Filter Assembly", SAS ROD Procedure DPSOL 105-160-PLK, Revision $4(7 / 23 / 82)$. 
10. "Deionizer or Deionizer Filter Replacement", SRS ROD Procedure DPSOL 105-234-LK, Revision $21(1 / 23 / 90)$.

11. "Packaging and Shipping Process Water Contaminated Prefilters and Afterfilters to the Burial Ground", SRS ROD Procedure DPSOL 105-234A, Revision 2 (2/13/84).

12. "Resin Bed Preparation for Mixed Bed Deionizer", SRS ROD Procedure DPSOL 105-152-K, Revision 9 (1/19/90).

13. "Deionizer Resin Bed' Deuterization", SRS ROD Procedure DPSOL 105-153-K, Revision 10 $(6 / 04 / 87)$.

14. "Shipping Spent Deionizers for Dedeuterization", SRS ROD Procedure DPSOL 105-161-PLK, Revision 11 (5/3/82).

15. "Receiving Spent Deionizers for Dedeuterization", SRS ROD Procedure DPSOL 105-163-K, Revision 6 (3/15/85).

16. "Operation of Dedeuterization HAM Facility", SRS ROD Proredure DPSOL 105-165-K, Revision $9(1 / 29 / 88)$.

17. "Shipping Dedeuterized Deionizer to Burial Ground", SRS ROD Procedure DPSOL 105-164-K, Revision 10 (3/15/85).

18. "Distillation Handbook," E. C. Bertsche, DSPSPU 57-11-29, July 9, 1957.

19. "A-Reboiler Separator Purge to Evaporator", SRS ROD Frocedure DPSOL 105-587-PLK, Revision $19(5 / 12 / 86)$.

20. "Operation of Evaporator \& Evaporator Condensing System", SRS ROD Procedure DPSOL 105-454-PLK, Revision 14 (2/13/84).

21. "Transfer Contents of Evaporator Condensate Tank", SRS ROD Procedt a DPSOL 105-455-PLK, Revision 21 (9/30/85).

22. "Drumming Evaporator Condensate Tank Moderator", SRS ROD Procedure DPSOL 105457-PLK, Revision 17 (5/12/86).

23. "Distillation Startup", SRS ROD Procedure DP. 'L 105-571-K, Revision 18 (6/6/85).

24. "Placing Distillation Online or Offline", SRS
ROD Procedure DPSOL 105-573-K, Revision 9 (11/25/81).

25. "Distillation Fast Shutdown for D2O Leak or Service Failure", SRS ROD Procedure DPSOL 105-575-LK, Revision 14 (5/07/87).

26. "B-Column Overhead Drawoff", SRS ROD Procedure DPSOL 105-34-PK, Revision 15 (11/ 84).

27. "Routine Distillation Shutdown", SRS ROD Procedure DPSOL 105-574-PLK, Revision 17 (1/ 27/84)

28. "Moderator pH vs. Conductivity", F. B. Longtin, RTM 1802, June 15, 1959.

29. "Moderator Chemistry Program - Technical Bases for Reactor Chemistry Control at SRS", A. Gibbs and S. I. Abdel-Khalik, OPS-ROD-900081 $(3 / 7 / 90)$.

30. "Moderator $p D$ Control", SRS ROD Procedure DPSOL 105-382-PLK, Revision 16 (6/9/88).

31. "In-Line $\mathrm{pH}$ Meter Operation", SRS ROD Procedure DPSOL 105- 381-PLK, Revision 8 (5/2/88).

32. "Nitric Acid injection System Operation", SRS ROD Procedure DPSOL 105-1197C-PLK, Revision $4(9 / 20 / 88)$.

33. " $\mathrm{pH}$ Abnormal", SRS ROD Procedure DPSOL 105-PW-730-PLK, Revision 1 (1/12/83).

34. "High or Low Conductivity $\mathrm{D}_{2} \mathrm{O}$ From Reactor", SRS ROD Procedure DPSOL 105-PW-702PLK, Revision 1 (1/27/83).

35. "High Conductivity - Moderator to Reactor", SRS ROD Procedure DPSOL 105-PW-724-PLK, Revision 1 (1/27/83).

36. "Reactor Oxygen Control", SRS ROD Procedure DPSOL 105-756A-PLK, Revision 4 (7/15/85).

37. "Moderator Conductivity Analysis", SRS ROD Procedure DPSOL 105-6120-PLK, Revision 5 (7) 28/88).

38. "Lowering Reactor Power to Shutdown Conditions", SRS ROD Procedure DPSOL 105-1205PLK, Revision 46 (4/88).

39. "Oxygen Addition to Moderator System", SRS ROD Procedure DPSOL 105-754-PLK, Revision 5 
(3/5/86).

40. "Oxygen Addition to Blanket Gas System", SRS ROD Procedure DPSOL 105-753-PLK, Revision $7(9 / 25 / 85)$.

41. "Standardized Portable Conductivity Meters in the 100 Areas", D. L. Ferguson, RTM 4900, April 25, 1988.

42. "Comparing Purification and Center Section Conductivity Recorder Readings", SRS ROD Procedure DPSOL 105-306-PLK, Revision 10 (8/8/88).

43. "Dissolved Oxygen Analyzer Operation", SRS ROD Procedure DPSOL 105-380-PLK, Revision 10 $(3 / 30 / 88)$.

44. "Dissolved Oxygen Abnormal", SRS ROD Procedure DPSOL 105-PW-722-PLK, Revision 2 (9/ 83).

45. "Essential Material Specifications", DPSOP 116, Revision 76, July, 1988.

46. "Chemicals and Non-radioactive Hazardous Materials Control", SRS ROD Procedure DPSOL 105-1845-PLK, Revision 10 (10/22/87).

47. "SRS Reactor Chemistry Policy (Draft)", F. Beranek, OPS- RTD-900144, March 13, 1990.

48. "Reactor Oxygen Control - Data", SAS ROD Procedure DPSOL 105-756A-PLK, Revision 2 (10/ 17/83).

49. "Sample Analysis Schedule and Control - Routine", SRS ROD Procedure DPSOL 105-6101APLK, Revision 12 (9/27/89).

50. "Sample Analysis Schedule and Control - Data Sheet 1 Sample Schedule", SRS ROD Procedure DPSOL 105-6101C-PLK, Revision 3 (3/7/88).

51. "Purification Control Room Data Sheets", SRS ROD Procedure DPSOL 105-82-LK, Revision 40 $(2 / 19 / 88)$.

52. "Moderator System Data Collection", SRS ROD Procedure DPSOL 105-83-PLK, Revision 7 $(2 / 14 / 83)$.

53. "Purification Field Data Sheets", SRS ROD Procedure DPSOL 105-99-L.K, Revision 43 (8/15/ 89).

54. "Graphic Panel Data Sheets", SRS ROD Pro- cedure DPSOL 105- 1106-PLK, Revision 67 (5/25/ 89).

55. "Analyzing 100-Area Moderator System Report", SRS ROD Procedure DPSOL 105-84-PLK, Revision 3 (1/27/83).

56. "PW Flow Reduction - 6 DC to 3 DC Throttled", SRS ROD Procedure DPSOL 105-1231-PLK, Revision $28(1 / 11 / 89)$.

57. "Moderator Chemistry Control During Shutdown", SRS Procedure DPSOI 105-6133-PLK, Revision $O$ (10/12/89).

\section{APPENDIX A}

Moderator Chemistry Control During Start-Up, Charge \& Discharge, and Shutdown

As indicated earlier, all moderator chemistry control practices described in Chapters II through VI of the report apply to normal reactor operating conditions. Requirements unique to start-up, C\&D, and shutdown conditions are summarized in this appendix.

\section{Start-up}

The formation of aluminum oxide on freshly charged assemblies causes high oxygen consumption during start-up. The rate of oxide formation increases with increasing temperature. Prior to each power rise, the moderator oxygen addition rate is increased to the maximum allowable (2360 cc/min) per DPSOL 105-756A [36]. After each power rise, the oxygen addition rate is readjusted as required to keep the blanket gas oxygen concentration between $0.1 \%$ and $0.2 \%$. DPSOL 105-382 [30] advises that, during start-up and power ascension of a cold clean charge, increase surveillance of $\mathrm{pD}$ and conductivity because there is a high probability of $\mathrm{pD}$ instability.

During nuclear start-up and power ascensions, conductivity may be allowed to decrease to 1.5 umho/cm per DPSOL 105-PW-702 [34]. If conductivity decreases below 1.5, acid is added only as 
necessary to stay within the range of 1.5 to 1.9 $\mu \mathrm{mho} / \mathrm{cm}$.

\section{Charge and Discharge}

Normal chemistry control limits are in effect during C\&D operations. Since purification flow is a source of cnoling water to the discharge machine, some restrictions on changes to the flow pattern are observed. These restrictions are contained in DPSOLS 105-1074 [2], 105-1259 [7], and 1051295 [3].

1. If C\&D of heat-generating assemblies is to be started during reactor shutdown, use only one Chempump because the cooling water hoses for the D-machine will be overpressurized if two pumps are used.

2. Notify $\mathrm{CH}$ (Charge Handling) supervision of any change that affects process water flow to D-machine, e.g., changing of number of Purification Chempumps online, opening of valve 86 , etc.

3. C\&D Operations must not be in progress during shutdown of purification PW flow. C\&D operations may be started after $\mathrm{CH}$ supenision is notified of any change that has been made that has affected process water flow to D-machine and that reactor overflow has been established.

4. When changing Chempump operation, notify $\mathrm{CH}$ supervision that purification Chempump operation is to be changed and that C\&D operation must be stopped if process water is required for the D-machine. Inform CH supervision of changes that were made in: purification Chempump operation.

An additional requirement is that process water flow be reduced to prevent splashing and assembly displacement. DPSOL 105-1231, "PW Flow Reduction - $6 D C$ to $3 D C$ Throttled", [56] describes the steps necessary to reduce flow to the normal C\&D flow conditions. The major steps include ensuring there has been adequate cooling time since shutdown and that three nonadiacent or any four DC motors are operating. Rotovalves are then throttled to reduce reactor overflow to approximately $10 \mathrm{gpm}$.

\section{Shutdown}

Moderator chemistry control requirements during shutdown conditions are described in DPSOL 105 \$133, "Aloderater Chemistn' Control During
Shutdown",[57]. The procedure was approved October 12, 1989. The requirements include:

1. The reactor must be drained and discharged of heat generating assemblies if purification is offline for more than two weeks.

2 If the moderator in any process water system, including the reactor tank and heat exchangers, cannot be circulated and sampled for a period of two weeks, that system should be drained.

3. Distillation and purification flow should be on at all times.

4. Moderator chemistry control should be maintained as usual per DPSOL 105-6101A [49] in both the reactor tank and the storage tanks. If the conductivity, $\mathrm{pH}$, and chlorides cannot be maintained within limits, the system should be drained and discharged of heat generating assemblies.

5. If the moderator has been drained to the storage tanks, it must be sampled as usual per DPSOL 105-6101A [49] and circulated through purification. If the chlorides, conductivity, and $\mathrm{pH}$ cannot be maintained within limits in the storage tanks, the Reactor Engineering Department must be notified for further action.

The above requirements are to be accomplished through the following practices:

1. Maintain moderator chemistry as usual by following DPSOLs 105-6101A [49] and 105-6101C [50].

2 Complete the data sheets of DPSOL 105-6133 [57] to keep an updated status of the process water system (i.e. whether pumps, heat exchangers, etc. contain moderator and/or are circulating the moderator).

3. Given the current status of the process water system, a decision is made as to any actions required based on the requirements above (i.e., if the moderator in a certain process water loop has been docurnented in the data sheets as not having been circulated in over two weeks, then a decision is made to drain the system). 


\section{ASSESSMENT OF METHODS, SYSTEMS, AND PROCEDURES FOR MODERATOR CHEMISTRY CONTROL AT SRS}

\author{
(Task 6 Report)
}

\section{INTRODUCTION}

As a part of the SRS Moderator Chemistry Program conducted by the Reactor Engineering Department, current moderator chemistry control methods, systems, and procedures used at SRS have been documented (Task 2 Report) [1]. The adequacy of these methods, systems, and procedures has been assessed and documented in this report.

The purpose of this report is to document the identified items of improvement in chemistry control methods, systems, and procedures. The recommended actions to enhance these items, along with the rationale behind recommendations, are given.

The report is divided into two main chapters, viz. identified items of improvement and recommendations. The items of improvement identified in Chapter II are grouped into three areas: (1) Process Systems, (2) Instrumentation, (3) Materials, Material Specifications, Material Control Procedures, (4) Organizational Responsibility, and (5) Data Collection, Evaluation, and Record Keeping. The organization of Chapter II of the report parallels that of the Task 2 Report [1] on which this assessment has been based. Chapter III summarizes the recommended enhancements to upgrade identified items, along with the bases for such recommendations. In order to allow easy follow up and cost-benefit analysis of the recommendations, they have been grouped into three categories: (1) hardware-related recommendations, (2) procedures-related recommendations, and (3) upgrades in current practices.

It should be noted that the material presented in Chapters II and III pertains to normal reactor operating conditions. Recommended improvements relating to requirements for extended shutdown are discussed in Appendix $A$.
It should also be noted that this report deals only with moderator chemistry control methods, systems, and procedures within the reactor process systems. Independent purification facilities such as the Moderator Processing Facility (MPF), the High Activity Moderator Processing Facility (HAM), and the 400-Area are outside the scope of this report.

\section{IDENTIFIED ITEMS OF IMPROVEMENT}

This chapter documents identified items of improvement in current methods, systerns, and procedures used at SRS to maintain, control, monitor, and record moderator quality. It is based on an assessment of methods, systems, and procedures as of mid-October 1989 which have been documented in Reference 1 (Task 2 Report). The organization of this chapter parallels that of Reference 1 in order to assure consistency and allow easy comparison between the two reports. Each of the five sections below, namely process systems; instrumentation; riaterials, material specifications, material contıol procedures; organizational responsibilities; and data collection, evaluation, and record keeping, corresponds to one of the chapters in Reference 1.

\subsection{Process Systems}

This section describes items of improvement related to the processes used to maintain and control moderator quality within the reactor process water system.

\section{a. Purification System}

1. The fitter assembly design is obsolete. Spare part availability has become a problem. Chloride leaching is suspected of the current filters.

2 One-time use of deionizer vessels contributes to hazardous waste and expense.

\section{b. Acid Addition System}

1. The system is not automated and requires an operator.

2 The relationship between $\mathrm{pD}, \mathrm{pH}$, and conductivity is not clear in the operational procedures.

3. The "possible" and "impossible" regions of the pD-conductivity relationship are not clear in the operational procedures. 


\section{c. Blanket Gas System}

1. Several moderator storage tanks are not blanketed with an inert gas.

\section{II. instrumentation}

This section describes items of improvement related to in-line instrumentation used to monitor moderator quality.

\section{a. Conductivity}

1. Existing cells have no on-line calibration capability.

2. There are no conductivity alarms in the Central Control Room.

3. Correlation of on-line readings with sample analyses has been inconsistent.

\section{b. $\mathrm{pH}$}

1. Current instrument configuration does not give accurate readings at low flow (shutdown) conditions.

2 Correlation of on-line readings with sample analyses has been inconsistent.

3. The meters have no redundant back-ups. In the event of a meter failure, only the reactor effluent can be analyzed.

\section{c. Dissolved Oxygen}

1. Maintenance record of current equipment is inadequate.

\section{d. Ionic Species}

1. No instrumentation instailed for ionic species.

\subsection{Materials, Material Specifications, Material} Control Procedures

This section describes items of improvement related to materials, material specifications, and material control procedures related to moderator chemistry control within the reactor process water systems.

\section{a. Materials:}

No items of improvement were identified.

\section{b. Material Specifications:}

1. In DPSOP 116, "Essential Material Specifications" [2], the oxygen specification states that oxygen content shall be a minimum of 99.5 percent. However, it doesn't specify whether this percentage is by mole, weight, or volume.

2. The gadolinium nitrate specification in DPSOP 116 specifies that gadolinium nitrate shall be at least 99.50 weight percent; however, it also specifies that the total rare earth oxide content in the gadolinium nitrate shall be at least 33.50 weight percent, which is impossible. The specification, as written, does not make it clear that the specified percentage of rare earth oxides is only applicable after supplying heat to the gadolinium nitrate in the laboratory

3. The polyborate specification in DPSOP 116 specifies that polyborate shall be at least 99.0 percent; it doesn't specify whether the percentage is by mole, weight, or volume. It also specifies that the boron trioxide content in the polyborate shall be at least 60.0 percent (doesn't specify by mole, weight, or volume). This figure on boron trioxide content is misleading, it only applies after supplying heat to the polyborate in the laboratory.

4. The deionizer resin specifications do not require that the resins be "nuclear grade".

\section{c. Material Control Procedures:}

1. The information section of DPSOL 105-1845, "Chemicals and Non-Radioactive Hazardous Materials Control" [3], does not present the proper guidelines for determining the suitability of new chemical materials for usage in the 105 buildings.

The limits for chloride, mercury, gold, silver, and copper fail to take into account that the quantity of these species is dependent on the total quantity of material used. Also, it is not made clear whether these limits refer to the concentration of the species in the material in question or whether it is the actual concentration of the species in the moderator.

2 There are several approved materials contained in the authorized materials list that should require a written procedure or a job plan for usage but are not designated as such. Also, the list does not contain any columns for usage restric- 
tions, MSDS number, whether the material is approved for use on or in the process water system, etc.

3. The analysis procedure of DPSOL 105-1845 lends itself to various interpretations; it lacks the specific guidelines that allow consistent decisions of a chemical material's suitability for use. The guidelines that do exist are contained in the information section and do not have well documented technical bases.

4. The chemical control program does not have a vehicle for encouraging compliance; that is, there exists no disciplined control over how chemical materials are obtained in the ficld. Also, there is no systern in place in the field for informing workers of the usage restrictions associated with each chemical material and for ensuring that workers use chemical miaterials according to established restrictions and guidelines.

\subsection{Organizational Responsibility}

This section describes items of improvement related to the organization used to implement moderator control methods, systems, and procedures.

1. A definitive description of the organizational responsibilities and interfaces is not readily available.

2 Control and direction of moderator quality control are spread thinly over a diverse collection of departments.

\subsection{Data Collection, Evaluation, and Record Keeping}

This section describes items of improvement related to the moderator chemistry data system in use at SRS.

1. Hard copy reports from the SANSCO data base are not timely or well distributed.

2 The SANSCO data base is not readily accessible or particularly "user friendly".

3. No routine trending of chemistry parameters is currently being done.

\section{RECOMMENDED IMPROVEMENTS}

This chapter summarizes the recommended enhancements to upgrade the identified items in Chapter II, along with the rationale for such recommendations. In order to allow easy follow-up and cost-benefit analysis of the recommendations, they have been grouped into three categories, namely, hardware-related recommendations, procedures-related recommendations, and up. grades in current practices.

The listed recommendations within each category are ranked in order of importance; the categories themselves are not prioritized. Clearly, the decision to implement any, or all, of these recommendations may need to await estimates of resource requirements and cost-benefit analyses. Development and delivery of appropriate training to operations personnel should follow that decision. Several of the recommendations have been previously documented in the Task 7 [4] or Task 8 [5] report. For completeness, they are included in this chapter as well.

\section{III.1. Hardware-Related Recommendations}

The following hardware-related improvements are recommended. The underlying rationale for each recommendation is also given. The recommendations are listed in order of priority and importance, with " $a$ " being the highest priority.

a Install an additional in-line $\mathrm{pH}$ meter to function as a redundant back-up to either existing $\mathrm{pH}$ meter.

Rationale: Currently, if a $\mathrm{pH}$ meter fails, only one process water stream $\mathrm{pH}$ can be measured, that of the reactor effluent. The $\mathrm{pH}$ of the stream from Purification must be measured by laboratory sample. Installation of a third meter will provide redundancy so that both streams can be measured in the event of a meter failure.

b. Replace existing conductivity instrumentation with state of the art equipment.

Rationale: Current equipment does not allow for on-line calibration. Due to the hard-wire type of connection to indicators and controllers, the addition of extra alarms is not possible. Replacement with microprocessor controlled instrumentation will improve reliability and versatility. 
c. Replace the dissolved oxygen instrument.

Rationale: The existing dissolved oxygen instrument is not designed for radiation senvice and has experienced numerous maintenance problems.

d. Replace the filter assemblies used in the Purification System pre-filter and after-iilters.

Rationale: Current equipment is outdated and obsoiete. Difficulty has been experienced in obtaining spare parts. The filter material is asbestos and contains leachable chloride and sulfate. Lowchloride filter material should now be available.

e. Determine the feasibility of automating the acid addition system.

Rationale: Autornatic addition will allow for closer process control of $\mathrm{pH}$.

f. Reconfigure the flow sampling technique used in the make-up room to provide more flow to the $\mathrm{pH}$ meters.

Rationale: Current set-up can give misleading readings when process water recirculation pumps are not operating.

g. Modify sampling lines and acquire proper portable instrumentation with flow-through cells for surveillance of conductivity and $\mathrm{pH}$ of the moderator.

Rationale: The difficulty of obtaining cross-check analyses for $\mathrm{pH}$ and conductivity of the pure waters between the laboratory and in-line instruments has caused the power reactor industry to install multi-redundant instruments in-line. Portable instruments are also temporarily installed in a flowing stream rather than using grab samples when checking the accuracy of the in-line in struments. This philosophy of operation would be beneficial for reactor chemistry control and reactor operations at SRS.

h. Install in-line, ion-specific, instrumentation for chloride.

Rationale: Such instrumentation would provide additional information on a specific anionic impurity with great poiential impact on IGSCC.

i. Install cation conductivity apparatus in-line.

Rationale: The use of in-line cation conductivity to monitor the anionic impurity levels would improve reactor operations' ability to monitor deionizer resin performance, improve the margin of protection from intergranular stress corrosion cracking (IGSCC) from anions, and provide assurance thatt the acidic, nitrate-rich concitions necessary to prevent gadolinium hydroxide precipitation are met.

j. Test and install ion chromatography equipment after reliability is improved, and proven, in commercial reactors.

Rationale: Such an installation would avoid the need for pulling and iransportation of grap samples. The use of in-line ion chromatography is increasing in the power industry as a diagnostic tool. At the present time the instruments are expensive, bulky, and must receive almost constant expert maintenance for continuous operation [6]. Improved durability, and decreasing maintenance requirements should make them feasible for installation in the SRS reactors during the next 5 years. Because of operational and installation problems unique to the SRS reactors, installation at SRS should be tested in a simulated reactor flow stream. Consideration should be given to the tritium content of the moderator as well as the radioactivity levels to be encountered, before purchase of systems for all reactors. Information returned from an ion chromatograph in-line does not improve safety or operability of the reactor. It does, however, provide diagnostic information more rapidly without transportation of samples to a laboratory.

\subsection{Procedures-Related Recommendations}

The following procedures-related improvements are recommended. The underlying rationale for each recommendation is also given. The recommendations are listed in order of priority and importance, with " $a$ " being the highest priority.

a Modify the method in which limits on undesirable species found in chemical materials (i.e. chloride, copper, mercury, etc.) are calculated. Document the technical bases for the new method and the bases for the corresponding limits in a Technical Report. Incorporate these new limits into DPSOL 105-1845.

Rationale: The limits for chloride, mercury, gold, silver, and copper are reported as mass per volume. Consequently, they fail to take into account that the total quantity of these species is 
dependent on the quantity of overall material used. Estabiishing a limit on the total quantity of species that a particular material can potentially contribute to the moderator will give a more accurate picture of the risks associated with using various materials. This new method would ultimately translate into limits on the total quantity of material used. Without using this method, potentially serious consequences can result from using material approved per the present method, i.e., using a material where all species are less than their respective designati:d 'quantity per volume' limits, but using large enough quantities of the material such that some species are present in damaging quantities.

b. Revise DPSOL 105-1845. Ensure that the information section has correct criteria for determining the suitability of potentially new chemical materials. Revise the authorized materials list so that each approved chemical material has documented usage restrictions, MSDS number, applicability to process water system, and that all materials requiring written procedure or job plan for usage are designated as such. Revise the Analysis Procedure section with clear step-bystep instructions that result in correct consistent decisions of a new chemical material's suitability for use.

Rationale: DPSOL $105-1845$ is vague and often results in contrasting interpretations. Also, the information is incomplete, resulting in loopholes and 'judgemerit calls' where specific step-by-step guidelines should exist. For example, the information section does not properly communicate the guidelines for determining the suitability of new chemical materials for usage in the 105 buildings: It is not made clear whether limits given for corrosive species (i.e. chloride, copper) refer to the concentration of the species in the material in question or whether it is the actual concentration of the species in the moderator. There are several approved materials cortained in the authorized materials list that should require written procedure or job plan for usage but are not designated as such. Also, the list does not contain any columns for usage restrictions, MSDS number, whether the material is approved for use on or in the process water system, etc. Many materials are used in critical applications (i.e. lubricants, pipe sealants), but DPSOL 105-1845 conveys that indiscriminate usage is not improper.

The laboratory analysis section of DPSOL 1051845 also lends itself to various interpretations; it lacks the specific guidelines that allow consistent decisions of a chemical material's suitability for use. The guidelines that do exist are contained in the information section and are not properly communicated. These guidelines should be transferred into specific steps for those responsible for approving new chemical materials.

c. Revise DPSOP 116 so that the material specification for oxygen reads 99.5 mole percent and that the material specification for polyborate reads 99.0 weight percent.

Rationale: DPSOP 116 doesn't specify whether these percentages are by mole, weight or by volume. Gases are usually presented as mole percent, solids as weight percent. Specifying as such will eliminate possible confusion and inconsistencies when evaluating the quality of new shipments.

d. Revise DPSOL. 105-382 [7] to explain the relationship between $\mathrm{PD}$ and conductivity.

Rationale: This information is not currently included. The graph included with the procedure includes a region where it is theoretically impossible for a data point to be located, but is not labelled as such.

e. Rewrite specifications for deionizer resins so that the specifications require "nuclear-grade" resin.

Rationale: The resin currently being used is not nuclear-grade. The usage of nuclear-grade resin will yield more efficient removal of ions from the process water, resulting in lower corrosion tendencies and lower radiation exposure.

f. Revise the gadolinium nitrate specification so that the minimum total oxides are at least 39.75$40.44 \%$.

Rationale: Calculation of the weight percent of total oxides from the known formula weights of the species and the known stoichiometry of the reaction involved when gadolinium nitrate hexahydrate is dehydrated and oxidized gives a result of approximately $40 \%$.

g. Revise DPSOP 116 so that it is made clear that the specifications for those species (oxides) that become present only after dehydration and oxidation of the original material (gadolinium nitrate hexahydrate, polyborate) are designated as such. 
Rationale: The specification, as written, does not make it clear that the specified percentage of rare earth oxides is only applicable after oxidation of the gadolinium nitrate in the laboratory. The same is true for polyborate specification. Its figure on boron trioxide content is misleading, it also only applies after oxidation of the polyborate in the laboratory.

\section{III.3 Upgrades in Current Practices}

a. Restructure the SANSCO computer program so that it is more "user friendly". Determine required samples and sample frequencies for various process conditions (e.g. operation, shutdown, start. up, extended shutdown, etc.). Incorporate new changes into the program. Alternatively, purchase or develop new software to better perform the required functions currently performed by SANSCO.

Rationale: The SANSCO sample schedule computer program contains no provisions for conditions when systems are out-of-service. There is no interaction between the user and the program concerning process conditions.

b. Develop a computer network to report analysis results to all appropriate personnel in a timely manner. Eliminate phone calls (except as a last resort) as a means of reporting results to Purification Control Room and Central Control Room personnel.

Rationale: The hard copy SANSCO daily reports are not timely. They are distributed three or four days after the analysis results are obtained.

c. Implement a trending program to track key chemistry parameters.

Rationale: Regular trending is necessary to characterize existing moderator quality, identify areas for improvement, and preclude out of limit conditions.

d. Develop a formal reactor chemistry policy to define goals and responsibilities for maintaining moderator quality.

Rationale: Current responsibilities and interfaces are not clear. A specific written policy implementing appropriate guidelines is needed to have a successful managernent plan for chemistry control. e. Perform a study to determine how control can be exercised over the way chemicals are obtained and used in the field. This involves coming up with ways to make sure workers are aware of the proper usages and usage restrictions associated with each chemical material and that only authorized chemical materials are used in the 105 buildings. Document the findings of this study.

Rationale: There exists no control over how chemical materials are obtained and used in the field. There is no system in place in the field for informing workers of the usage restrictions associated with each chemical material and for ensuring that workers use chemical materials according to established guidelines and in a disciplined manner. Without exercising this control, workers are not aware of and do not appreciate the importance of chemical control. By itself, DPSOL 1051845 (a category 2 procedure) has not been enough to remind workers of the proper usages and use restrictions of approved materials, and it has not been enough to keep unapproved chemicals from the reactor building.

f. Determine the feasibility of establishing helium blankets on the moderator storage tanks currently vented to atmosphere.

Rationale: Moderator stored in atmospherevented storage tanks undergoes light water degradation due to interaction with water vapor.

g. Determine the feasibility of controlling $\mathrm{pH}$ and conductivity using cation and anion resin beds instead of acid addition.

Rationale: This method would eliminate the addition of nitrates into the system as nitric acid. Higher levels of moderator purity could be gained.

h. Determine the feasibility of regenerating purification deionizers or reusing deionizer vessels.

Rationale: The current practice of disposing deionizers when spent creates hazardous waste that could be reduced by reg ineration. 


\section{N. REFERENCES}

1. Moderator Chemistry Control Methods, Systems, and Procedures, R. L. Fanning, S. R. Bohrer, and S. I. Abdel-Khalik, OPS-RES-90-0141, $(5 / 18 / 90)$.

2. Essential Material Specifications, DPSOP 116, Revision 76, July, 1988.

3. Chemicals and Non-Radioactive Hazardous Materials Control, SRS ROD Procedure 105-1845PLK, Revision 10 (10/22/87).

4. Assessment of Technical Bases for Reactor Chemistry Control at SRS, A. Gibbs and S. I. Abdel-Khalik, OPS-ROD-900082 (3/7/90).

5. Assessment of Moderator Chemistry Surveillance and Analysis Requirements at SRS, S. R. Bohrer and S. I. Abdel-Khalik, OPS-ROD-900073 $(2 / 21 / 90)$.

6. In-Plant Measurement of Corrosive lons in Water, T. O. Passell, EPRI NP-6308, Electric Power Research Institute (1989).

7. Moderator $P D$ Control, SRS ROD Procedure DPSOL 105-382-PLK, Revision 16 (6/9/88).

8. Moderator Chemistry Control During Shutdown, SRS ROD Procedure DPSOL 105-6133-PLK, Revision $O(10 / 12 / 89)$.

\section{RECOMMENDED IMPFOVEMENTS IN MODERA- TOR CHEMLSTRY CONTROL. METHODS, SYS- TEMS, AND PROCEDURES DURING SHUT- DOWN CONDITONS}

As indicated earlier, all moderator chemistry control practices and recommendations described in Chapters II and III of this report apply to normal reactor operating conditions. The identified items of improvement for moderator chemistry control during shutdown are:

1. Although a procedure has been approved for shutdown chemistry control [8], no formal lay up program exists.

2 Insufficient planning is practiced for equipment outages that affect the operability of moderator chemistry control systems.

The following action is recommended:

Establish a comprehensive lay up program. Sufficient resources will be necessary to allow preshutdown planning and project/operations interfaces to maintain moderator chemistry quality during maintenance activities and outage conditions. 


\section{TECHNICAL BASES \\ FOR CURRENT REACTOR CHEMISTRY TECHNICAL SPECIFICATION REQUIREMENTS AT SRS}

(Task 3 Report)

\section{INTRODUCTION}

Reactor chemistry has been controlled at SRS since the reactors began operation. It has evolved, however, from a very simple surveillance of conductivity, gross radioactivity, and $\mathrm{D}_{2} \mathrm{O}$ content of the moderator to one where the interactions among systems such as the blanket gas, supplementary safety system, and deionizer performance are assessed and monitored.

The reasons for control of reactor chemistry began with the recognition that impurities would degrade reactor efficiency and that low conductivity water did not decompose significantly. Experience, laboratory, and reactor tests at SRS, as well as at commercial power reactors and national laboratories, have shown that currosion of components and replacement costs can be minimized by chemistry control.

The purpose of this report is to document the technical bases for the current reactor chemistry technical specification requirements at SRS. This effort corresponds to Task 3 of the SRS Moderator Chemistry Program conducted by the Reactor Engineering Department as outlined in reference 1.

The control analytes for moderator chemistry are specified in SRS Technical Standards DPSTS. 105-2.07, "Heavy Water Quality", [2] and DPST105-3.08, "Fission Product Activity in Heavy Water", [3]. These analytes, along with their stated bases, are summarized in Chapter II of this report. Additional analytes are used for reactor chemistry diagnostics; these are discussed in Chapter III. Much of the information presented in Chapter III is obtained from RTR-1806, "Reactor Chemistry and Radioactivity Manual", [4]. Chapter IV provides an expanded discussion of the physical and chemical laws, along with the reactor and laboratory tests, which provide the un- derlying technical reasons for surveillance of reactor chemistry at SRS. Chapter $V$ provides a summary of the monitoring done to meet the needs for moderator chemistry control.

\section{MODERATOR CHEMISTRY TECHNICAL SPECIFICATIONS}

The analytes specified for monitoring and control under the current technical specifications $[2,3]$ are listed in Table II.1. These Technical Standards apply to all phases of operation at SRS during which moderator is present in the reactor vessel, including extended shutdown of the reactors.

The bases of these standards are operating experience and published information concerning the corrosion of aluminum and stainless steel, particularly in heavy-water reactor systems, and the decomposition of heavy water by radiolysis. A summary of the bases as provided in the SRS Technical Specifications $[2,3]$ is given below.

TABLE II.1

TECHNICAL SPECIFICATIONS UMTTS FOR MODERATOR CHEMISTRY PARAMETERS

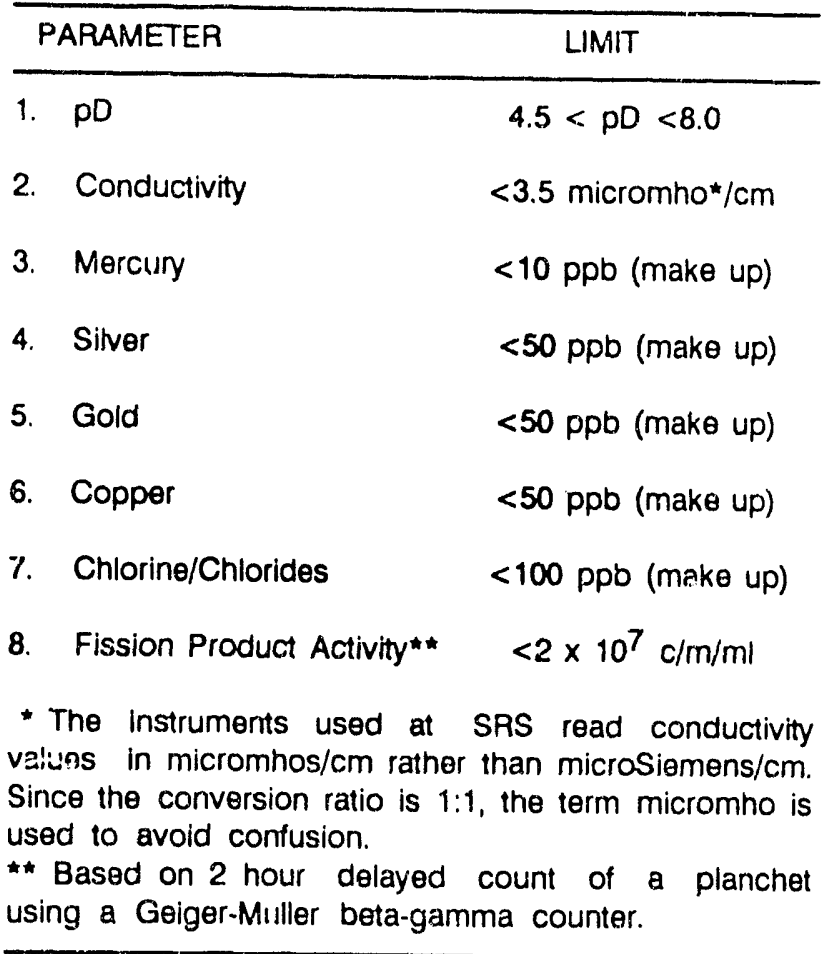

\subsection{Bases for $P D$ Standard}

The bases for the $P D$ standard are provided in the SRS Technical Specifications [2]: 
1. "It has been demonstrated during sustained reactor operation at the Savannah River Plant that the corrosion rate of aluminum components, and the associated problems of high radioactivity and turbidity in the process systems, is substantially reduced by control of the acidity of the moderator. This is confirmed by information obtained from other sites. It was found that the aluminum corrosion decreased as the $p D$ was decreased to 4.7 . No tests have been made at SRP with $p D$ less than 4.7; however, since the aluminum corrosion rate does not change rapidly with $p D$ when operating near the minimum value of aluminum corrosion, a limit on $p D$ of 4.5 was chosen for the maximum acidity for this Standard. This is to provide flexibility in writing operating procedures and to allow a working margin for instrument errors.

The upper limit on $p D(8.0)$ is established to:

a. Provide flexibility during periods when the reactor is not operating.

b. Ensure gadolinium solubility if the Supplementary Safety System is used. Formation of insoluble gadolinium hydroxide would be minimal $(<1 \%)$ at moderator $p D<9.5$. The upper $p D$ limit of 8.0 provides a large margin from significant gadolinium precipitation."

\subsection{Bases for Conductivity Standard}

The bases for the conductivity standard provided in the SRS Technical Specifications [2] are:

"The control of moderator $p D$ requires that conductivity be perrnitted to increase in accordance with the physicochemical relationships between ionic content of moderator and the ionic mobility of the ions present in the moderator. For $p D=$ 5.0 the corresponding conductivity of the moderator, provided all of the conductivity is a result of the deuterium-anion pair, is $3.0 \mathrm{micromho} / \mathrm{cm}$. Because a small amount of salt ions would some. times be present in the moderator as a result of corrosion, a slightly higher conductivity than the acid contribution is desirable for control purposes. A conductivity limit of $3.5 \mathrm{micromho} / \mathrm{cm}$ is chosen to provide sufficient excess to allow for a small amount of corrosion products $10.5 \mathrm{mi}$ cromho/cm) when maintaining the $p D$ at 5.0 . A conductivity of $3.5 \mathrm{micromho} / \mathrm{cm}$ corresponds to $p D=4.8$ (approximately) if all of the ionic material is the deuterium-anion pair; therefore, the conductivity is the limiting variable."
II.3. Bases for Mercuny, Silver, Gold, Copper and Chlorine/ChlorideStandards

The bases for the mercury, silver, gold, copper, and chlorine/chloride standards provided in the SRS Technical Specifications [2] are:

"The presence of the following materials are undesirable in the reactor system:

a. Metals thai establish large electrochemical potentials with aluminum and stainless steel.

b. Elements such as chlorine (or chlorides) which are corrosive to stainless steel.

Because the mechanism by which these undesirable impurities may concentrate in the reactor system is not known, the consequences of these types of corrosive action can be minimized by limiting the amount of impurities shat may be added to the reactor system to negligible quantities."

\subsection{Bases for Fission Product Activity Standard}

The bases for the fission product activity standard provided in the SRS Technical Specifications [3] are:

1. "Release of fission products can result in high activity levels

a. in the moderator, thus interfering with early detection of subsequent failures,

b. in the external hydraulic system of the reactor, rendering maintenance difficult,

c. On the surfaces of the fuel, target, or housing assemblies, leading to contamination of the disassembly basin, and

d. in the blanket gas, leading to atmospheric releases of radioactivity.

It is necessary to monitor for fission product release to pormit corrective action before the 'evels become excessive. Two of the following instruments, or suitable equivalents, shall be operable whenever the reactor is operating above low power.

Gas chromatograph

Low energy gamma monitor 


\section{Blanket gas monitor}

10-minute delay system

2. Failures which cause fuel or target swelling can be located by flow and/or temperature indications. Prompt shutdown of the reactor to discharge the assembly containing the located fuel or target failure minimizes the total release of fission product and fissionable material.

Many reactor charges with uranium-aluminum fuel have been operated with minor cladding failures which cannot be located during reactor operation. These failures usually do not cause swelling, and cannot be located by the radioactivity which they release because both the radioactivity and the uranium producing it spread rapidly throughout the reactor. Fission product activity in the moderator builds up very gradually over a long period of time. Operation of these charges has demonstrated that releases of activity to the environment resulting from such minor cladding failures can be kept wel" below established release standards and that all necessary operating functions can be performed while keeping radiation exposure to operating personnel within established limits.

3. A few reactor charges have been operated with fission product activity in the moderator resulting in 2-hour beta-gamma planchet activities in the range from $5 \times 10^{6}$ to $1 \times 10^{7} \mathrm{c} / \mathrm{m} / \mathrm{ml}$. In these instances high radiation levels were encountered in some working areas. Additional shielding reduced these levels so that in the more recent instances only minor accornmodations were needed to continue normal work. Deionizer life was shorteried and stack releases were increased, but practicable methods were available to meet these problems. Radioactivity transferred to the disassembly basins was controlled by the basin deionizer filter system with little or no increase in liquid releases to the environment.

The choice of an upper limit for fission product activity is judgmental. However, it is not apparent that operation at levels significantly in excess of those already experienced is warranted. Instead, continued effort will be made to maintain activity levels at values as low as practicable by quality control measures in the fabrication process, prompt discharge of known failures, and periodic discharge of semipermanent lattice components. A 2-hour planchet value of $2 \times 10^{7} \mathrm{c} / \mathrm{m} / \mathrm{m} /$ corresponds to a specific activity value slightly less than $10^{5}$ curies, the activity release limit specified as the criterion for $B O S F_{N}$ Technical Limits in DPSTS-105-1.02. The highest planchet value observed during regular operation was $10^{7} \mathrm{c} / \mathrm{m} /$ mll.

At beta-gamma planchet activities above $2 \times 10^{6}$ $\mathrm{c} / \mathrm{m} / \mathrm{ml}$ there are occasional errors in determining the beta-gamma activity. It is not intended that the reactor be shut down because of a single erroneous measurement. High aciivity levels should be confirmed by two or more evaluations. It is recognized that up to 48 hours elapse from time of sampling until the analytical results are obtained."

\section{DLAGNOSTIC ANALYTES FOR REACTOR CHEMISTRY}

In addition to the major analytes listed in Chapter II, there are many other elements and compounds in the moderator and related systems which are monitored to determine the state of the chemistry in the SRS reactors. Some of these analytes are:

Lithium
Boron
Gadolinium
Heavy water (mol \%)
Rare Earth metals
Nitrate
Nitrite
Culfate
Phosphate
Oxalate
Dissolved Oxygen
Blanket Gas Composition
Uranium
- Urhidity
Traisition metals
Alpha
Specific Radionuclides
Tritium

\section{N. DISCUSSION OF TECHNICAL BASES}

This chapter provides an expanded discussion of the physical and chemical laws, along with the reactor and laboratory tests, which provide the underlying technical reasons for surveillance of reactor chernistry at SRS.

\section{IV.1. $\mathrm{pH}$ and Conductivity}

The $\mathrm{pH}$ and conductivity for heavy water are directly related as expressed by Kohlrausch's law [5] according to the equation:

$$
\begin{aligned}
& L=0.250\left[D^{+}\right]+0.142\left[O D^{-}\right]+0.055\left\{\left[D^{+}\right]-\right. \\
& \left.\left[O D^{-}\right]\right\}+0.110 \mathrm{n}
\end{aligned}
$$




$$
\mathrm{pH}=-\log \left[\mathrm{D}^{+}\right]-0.4
$$

where $L$ is the conductivity in mho/cm, and $[X]$ is the molar concentration of $X$. The value of $n$ is independent of $\mathrm{pH}$, which is unaffected by the presence of neutral salts.

The above relationship is shown graphically in Figure 1. It should be noted that the $\mathrm{pH}$ as measured in the SRS heavy water reactors is given by:

$$
\mathrm{pH}=\mathrm{pD}-0.4
$$

\section{FIGURE 1}

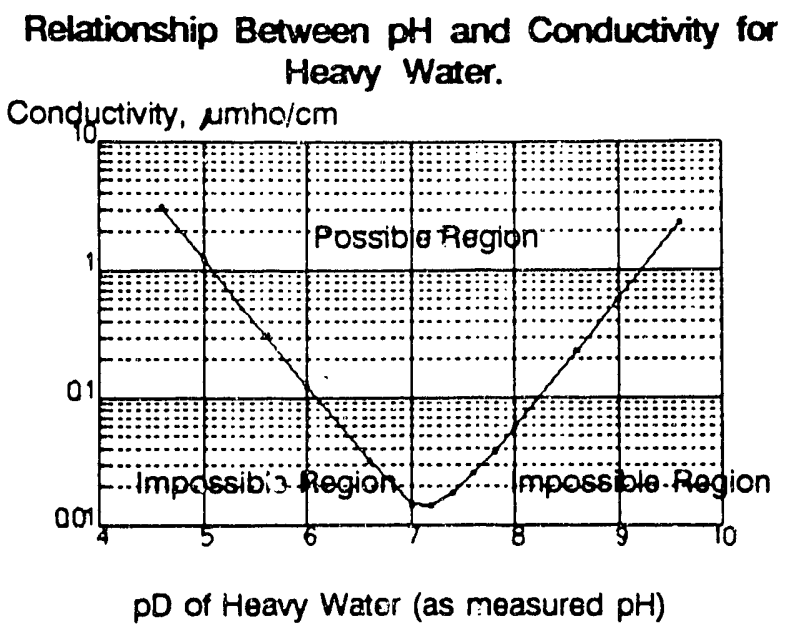

The conductivity of the moderatcr is controlled since it is recognized that impurities, which directly affect the condistivity, would degrade the neutronics of the reactor and produce unwanted activities. The conductivity is th erefore $\mathrm{dsed}$ as a means of regulating flow through the deionizers and monitoring deionizer performance to ensure moderator purity.

In the late 1950's it became obvious that excess corrosicri of aluminum cladding was taking place in SRS reactors and that this could be remedied by controlling the $\mathrm{pH}$ of the moderator [6]. Institution of $\mathrm{pH}$ control resulted in a rapid reduction of turbidity in the moderator and subsequent reduction of radiation exposure to personnel [7]. The relationship between $\mathrm{pH}$ of heavy water and corrosion of aluminum is shown in Figure 2 [8]. The moderator $\mathrm{pH}$ in the SRS reactors had to be adjusted to a higher value than is optimum for minimization of aluminum corrosion in order to keep the corrosion of the stainless steel vessel and components at a minimum. It is well known that general corrosion of steel accelerates at acidic $\mathrm{pH}$ due to the dissolution of iron.

\section{FIGURE 2}

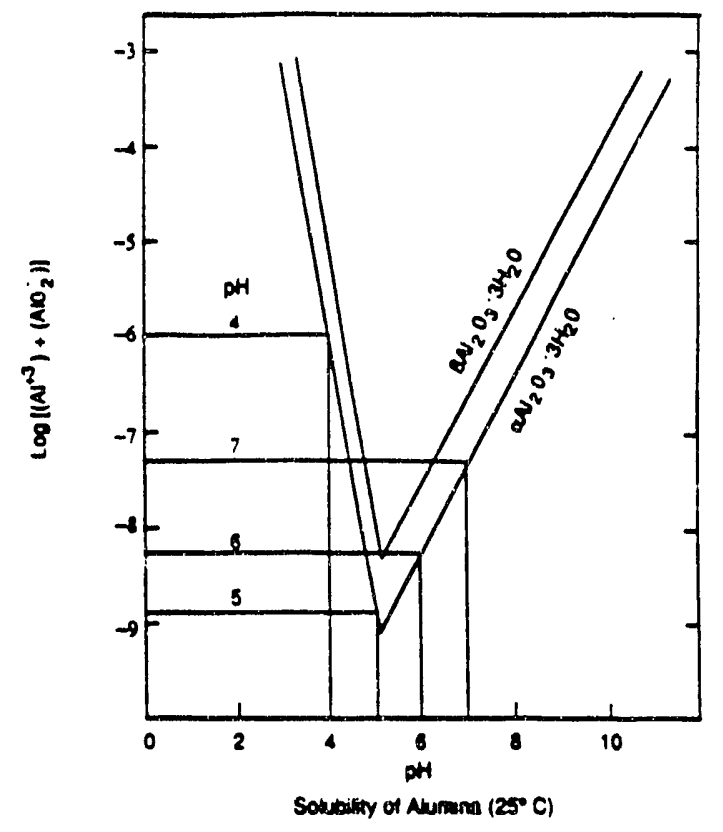

Actual in-reactor tests were run at SRS [6] to study the effects of $\mathrm{pH}$ control it different le:els using different means of adjustment. For example, carbonic acid was used as a pH adjustment by adding carbon dioxide to the blanket gas. Although the $\mathrm{pH}$ was controlled, the concentration of carbonic acid needed was more than 10 times that of nitric acid for the same control. The increased concentration of carbonic acid dissolved in the moderator and its subsequent radiolysis caused more peroxides to be formed. There was evidence of increased stainless steel corrosion at the concentration of peroxides achieved. After lengthy tests, it was determined that the current operating conditions using nitric acid additions and mixed bed deionizers with the moderator $\mathrm{pH}$ at $4.7+/-0.1$ were optimal for minimization of stainless steol and aluminum corrosion and resulted in the best control at the lowest cost. Iricreasing the $\mathrm{pH}$ to 5.5 in order to save deionizer costs resulted in increased corrosion of the aluminum.

$\mathrm{pH}$ control is also essential for operation of the gadolinium nitrate supplementary safety system (SSS). Difficulty in cleanup of the moderator and startup of the reactor after an injection of the SSS in 1977 was thoroughly studied [9-15]. The conclusion of these reports is that to maintair the gadolinium nitrate in solution without precipitation to the hydroxide form, the moderator must be acidic and nitrate rich. Gadolinium nitrate will begin precipitation at a pH somewhere between 5.6 to 7.4 (at $25^{\circ} \mathrm{C}$ ) [16]. The equations relating $\mathrm{pH}$ and gadolinium solubility are: 


$$
\begin{gathered}
\log K_{\text {so }}=-21.5 \text { to }-26.95 \text {, and } \\
\mathrm{pH}=14+1 / 3 \log K_{\text {so }}-1 / 3 \log \left[\mathrm{Gd}^{+++}\right]
\end{gathered}
$$

A graphical relationship of gadolinium hydroxide precipitation and $\mathrm{pH}$ is presented in Figure 3. The amounts of gadolinium subject to deposition in the reactor can be calculated from the concentration of the element in the SSS (approximately $1 \mathrm{M})$ and the moderator concentration of approximately $0.001 \mathrm{M}$.

\section{FIGURE 3}

\section{Relationship Between pH of Heavy Water and Gadolinium Hydroxide Precipitation.}

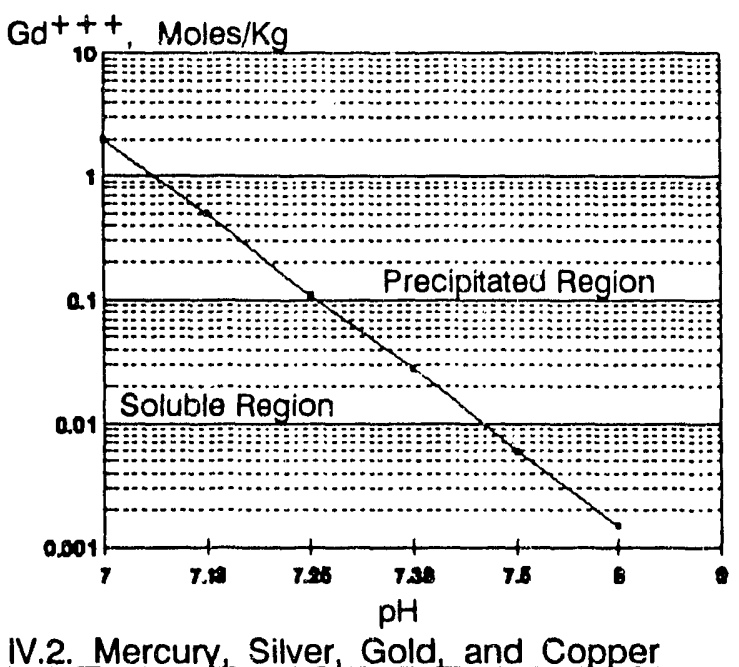

These elements, particularly mercury, are known to be activators for corrosion of aluminum in aqueous systems [17]. The mechanism for corrosion is the galvanic cell formed because of the significant difference of the elements' electronegativity values from that of aluminum [18]. There is no source of these elements in the reactor system provided that materials testing and control procedures are followed. In addition, there is no known mechanism for concentration of these elements in the reactor system. Therefore, the control is placed on makeup water and materials which may be introduced into the reactor chemisiry system. The limits are set to reflect and control the concentrations in the reactor below those which are known to cause pitting corrosion in the aluminum cladding.

\section{IV.3. Chlorine/Chloride}

The chloride ion is extremely corrosive to siainless steel at high temperatures and has been shown to be the usual cause of intergranular stress corrosion cracking (IGSCC) in the SRS reactor nozzles and piping. A potential source of chloride in the reactor system is from the deionizer resins; gaskets, filters, and packing are also suspect, although all of these sources are checked before introduction into the system. Chloride has also been shown to concentrate in the alumina films formed on the surfaces of the reactor system [8]. This chloride can be released to the moderator system to initiate IGSCC when the alumina coating is disturbed by $\mathrm{pH}$ changes or sudden temperature changes. The limits on chloride concentration were set to reflect the analytical capabilities at the time, plus a margin of error to allow for continued operations. The actual analytical results have been improved and the concentration limits have been lowered in operating procedures.

IV.4. Fission Product Activity, Alpha, and Specific Radionuclides

Analysis of fission product activity in the coolant/ moderator is common to all reactors as a means of monitoring fuel integrity. In SRS reactors there is a high level of $\mathrm{Na}^{24}$ activity always present in the moderator because of the $A 1^{27}$ ( $n$, alpha) $\mathrm{Na}^{24}$ reaction. The quantity of $\mathrm{Na}^{24}$ is related to the power level of the reactor and the deionizer flow rates. An analysis of the noderator (and deionizer effluent) activity at 2 hours after sampling is made to indicate trends in fission product or corrosion product activities. This gross activity in c/ $\mathrm{m} / \mathrm{ml}$ (calibrated on a $\mathrm{Cs}^{137}$ standard) has an approximate $5 \%$ efficiency for the total radionuclide inventory in the moderator. The deionizer efficiency, as well as the form of the activity (ion or particulate) can be calculated from these values.

Gross alpha counts are also done on the moderator streams to identify the source of the activity (fuel or target). These counts are in $\mathrm{d} / \mathrm{m} / \mathrm{ml}$ with a $100 \%$ efficiency for calculation of activity of alpha activity in the reactor system. The use of multichannel analyzers and high resolution detectors now allows rapid analysis of specific radionuclides with minimal sample preparation and chemical separations. These analyses are very useful in determining the source of fission products (target or fuel), corrosion of reactor componerits, activation products resulting from introduction of unusual materials into the reactor and cleanup capacity of the deionizers. Chemical separationis are still performed so analyze for pure beta emitters such as $s^{35}$ and $p^{32}$, which result from activation of ion exchange resin degradation 
products. The values obtained from these analyses are in $d / \mathrm{m} / \mathrm{ml}$ calibrated using National Institute of Standards and Technology (NIST) standards. Using these sample results and the known ratio of fission product yields (or cross sections, in the case of unusual materials introduced) one can calculate the inventory of released fissionable or other material circulating in the reactor, the extent of the problem, the inventory of radionuclides accumulating on the deionizer resins, and the need for additional resources for cleanup.

\section{IV.5. Lithium, Boron, Gadoliniurn, Uranium, Trit-} ium, and Heavy Water

All of these analytes are monitored for indications of leaks or failures of systems connected to the reactor moderator system. The presence of lithium and excess tritium, for example, would indicate a failure of a lithium target. A decrease in the heavy water concentration would indicate inleakage of a light water system. The common characteristic for all these analytes is their deleterious effect on reactor neutronics due to neutron absorption or reduced moderation.

\section{IV.6. Rare Earth Metals}

The makeup moderator is analyzed for the presence of rare earth metals in order to prevent their introduction into the reactor system because of their adverse impact on reactor operation.

\section{IV.7. Nitrate and Nitrite}

Nitrate should be present in the moderator system at a level of $390-630 \mathrm{ppb}$ if the $\mathrm{pH}$ is in the proper range. The presence of the nitrate at these levels indicates that the correct acid has been added to the system in the proper amount. The absence of nitrite confirms that the system is still an oxidizing atmosphere, rather than a reducing atmosphere. A reducing atmosphere involving the reduction of nitric acid would cause loss of $\mathrm{pH}$ control. This, in turn, would cause increased corrosion of the aluminum cladding. The absence of nitrate and nitrite in the deionizer effluent indicates that deionizer exchange is operating properly. Tilie presence of nitrate, but an absence of $\mathrm{Na}^{24}$ activity indicates that the anion resin has become depleted, although cation capacity is still available.

\section{N.8. Dissolved Oxygen and Peroxides}

The concentration of dissolved oxygen in a reac- tor has been shown to be related to IGSCC of stainless steel. The initiating concentration is dependent upon temperature and pressure and formation of peroxides. For this reason many power reactors are now operating with hydrogen injection to produce a reducing atmosphere. At SRS this cannot be done because it would result in rapid corrosion of the aluminum in the assemblies. SRS therefore operates with a blanket gas of helium and a dissolved oxygen concentration of $0.5-1.5 \mathrm{ppm}$. This concentration range is needed to maintain $\mathrm{pH}$ control of the reactor chemistry. It has not been demonstrated that this concentration of dissolved oxygen has a significant effect upon IGSCC at the SRS operating temperatures and other conditions.

Special analysis of peroxides is requested when there are indications from the dissolved oxygen monitor, corrosion product tests or other monitors that chemistry control has been compromised in some manner. Routine analysis of peroxides provides a baseline for reference and maintains the expertise of the laboratory analysts.

\section{IV.9. Blanket Gas Composition}

The helium blanket gas is analyzed continually to insure that an explosive concentration of deuterium does not build up. The SRS Technical Specifications [19] require that the volumetric concentrations of deuterium and oxygen in the blanket gas do not exceed $3.8 \%$ and $21 \%$, respectively. Additional information gained from the blanket gas system include the rate of radiolysis of nitric acid and the rate of aluminum corrosion. Trending of this information can anticipertio problems with reactor chemistry control.

\section{IV.10. Transinion Metals}

The moderator is analyzed for transition metals concentrations periodically in order to monitor the rate of stainless steel corrosion in the reactor system. The activation product activities are also monitored on a more frequent basis for the same reason. These analyses provide a cross-check for quality assurance purposes.

\section{IV.11. Turbidity}

Turbidity is monitored frequently as a check on the aluminum cladding corrosion. It is a fairly sensitive monitor of $\mathrm{pH}$ control in the reactor and

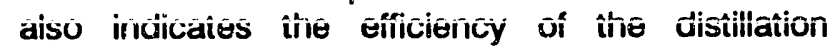
towers. 


\section{IV.12. Sulfate and Phosphate}

The presence of sulfate and/or phosphate in the moderator indicate the presence of resin fines (non-fitterable) or soluble non-ionic materials, the introduction of foreign materials, and/or depletion of the anion resin in the deionizer beds.

\section{MONITORING OF MODERATOR QUALTYY}

This chapter summarizes the methods by which the various moderator chemistry parameters at SRS are monitored. Additional details on moderator chemistry surveillance and analysis requirements may be found in reference 20 .

The conductivity is monitored in-line in SRS reactors at two poinis. In an operating reactor, the moderator conductivity is controlled at 1.9-3.0 micromho/cm, while that of the deionizer effluent is controlled at less than $0.3 \mathrm{micromho} / \mathrm{cm}$. Control is accomplished by addition of nitric acid, flow through the deionizers, and the replacement of deionizers. There is also a portable conductivity meter available in each reactor area for use if an in-line meter fails or gives questionable results. Grab samples for laboratory analysis are run routinely to check in-line results and to provide backup for in-line meter failure.

The $\mathrm{pH}$ is monitored in-line as bulk moderator and at the deionizer effluent. The moderator $\mathrm{pH}$ operating control conditions are 4.6-4.8, while the deionizer effluent $\mathrm{pH}$ conditions are 5.6 to 7.4 . $\mathrm{pH}$ control is accomplished by the same means as conductivity control.

Dissolved oxygen is monitored in-line and is controlled by addition of gaseous oxygen to the moderator during startup and to the blanket gas, as needed, during operation.

The blanket gas composition is monitored continuously on-line using gas chromatographs. Although the primary concern has been the $D_{2}$ concentration limits, it is possible to use the data collected for diagnostic evaluation of the moderator system. For example, increased nitrogen, deuterium or oxygen levels might indicate increased radiolysis of the moderator and nitric acid, and an increase in $\mathrm{D}_{2}$ alone might indicate an increase in corrosion of aluminum cladding in the moderator according to the simplified reaction:

$$
2 \mathrm{Al}+6 \mathrm{D}_{2} \mathrm{O} \rightarrow 2 \mathrm{Al}(\mathrm{OD})_{3}+3 \mathrm{D}_{2}
$$

Laboratory backup analyses of grab samples of the blanket gas are performed periodically by mass spectrometric techniques.

Gross radioactivity is monitored continuously by various detectors around the reactor. Some of the streams are monitored after time delays for trend analysis. Actual analysis of the moderator for fission product and activation product activities is done in the laboratory using grab samples. Abnormally high results on the field monitors are indicative of fuel or target failures and corrosion products entering the moderator stream; this necessitates rapid sampling and laboratory analysis to find the cause.

The remaining analytes are monitored through laboratory analysis of grab samples. The metals (cations) are determined using spectroscopic or polarngraphic methods having sensitivities in the low ppb range. The chlorides have been determined by spectrophotometric methods with a sensitivity of $30 \mathrm{ppb}$; ion chromatographic methods with a sensitivity of $<10 \mathrm{ppb}$ are currently used. Ion selective electrodes identical to those used in commercial power reactors have been ordered to develop backup methods sensitive to about $10 \mathrm{ppb}$ for chlorides. Other anions are determined using ion chromatography methods with sensitivities in the $10 \mathrm{ppb}$ range.

\section{REFERENCES}

1. "Moderator Chemistry Program - Mission Statement and Action Plan", L. V. DeWitt and S. I. Abdel-Khalik, OPS-ROD-890236, SRS Report (12/ 7/89).

2."Heavy Water Quality" ,DPSTS-105-2.07, Technical Standards for SRS Reactors (4/1/75).

3. "Fission Product Activity in the Heavy Water", DPSTS-105-3.08, Technical Standards for SRS Reactors (4/1/75).

4. "Reactor Chemistry and Radioactivity Manual", F. B. Longtin, RTR-1806, SRS Report (1978).

5. "Moderator pH vs. Conductivity", F. B. Longtin, RTM-1802, SRS Report (1959).

6. "Works Technical Monthly Progress Reports", DPSP-59-1-6-R through DPSP-61-1-6-R, SRS Reports (1959-1961). (Secret) 
7. "Works Technical Monthly Progress Reports", DPSP-59-1-12, SRS Report (Dec. 1959). (Secret)

8. "A Mechanism for Stress Corrosion Cracking of Stainless Steel in Reactor Systems", R. S. Ondrejcin, DP-1089, SRS Report (1969).

9. "Analysis of Deionizer Resins Used for Cleanup of Gadolinium Nitrate in P-Reactor", E. W. Baumann, DPST-77-484, SRS Report (1977).

10. "Analysis of Moderator and Resin from Cleanup of Gadolinium Nitrate in C-Reactor", E. W. Baumann, DPST-78-239, SRS Report (1978).

11. "Mechanisms of Gadolinium Deposition in SRP Reactor Systems: A Literature Study", E. W. Baumann, DPST-78-602, SRS Report (1978).

12. "Identification and Determination of NitrateDeficiency in Moderator Containing Gadolinium Nitrate", E. W. Baumann, DPST- 78-626, SRS Report (1978).

13. "Conductivity of $\mathrm{DNO}_{3}$ and $\mathrm{Gd}\left(\mathrm{NO}_{3}\right)_{3}$ in $\mathrm{D}_{2} \mathrm{O}$ at $25^{\circ} \mathrm{C} "$, E. W. Baumann, DPST-79-235, SRS Report (1979).

14. "Radiolysis of Gadolinium Nitrate Solutions and Deposition of Gadolinium on Aluminum", E. W. Baumann, DPST-79-420, SRS Report (1979).

15. "Analysis of 105-P Moderator After Gadolinium Nitrate Injection", E. W. Baumann, DPST-79583, SRS Report (1979).

16. "Gadolinium Salts for Liquid Shut-Off Systems--Their Chemistry and Behavior", N. D. Haworth, WNRE-235, Canadian AECL Report (1975).

17. "The Radiochemistry of Aluminum and Gallium", J. E. Lewis, NAS-NS-3032, National Academy of Sciences Report (1961).

18. "Handbook of Chemistry and Physics", CRC Press, 67th Edition (1987).

19. "Blanket Gas", DPSTS-105-2.05, Technical Standards for SRS Reactors (4/1/75).

20. "Morderator Chemistry Surveillance and Analysis Requirements", S. R. Bohrer and S. I. AbdelKhalik, OPS-ROD-890246, SRS Report $(12 / 27 / 89)$. 


\section{ASSESSMENT OF TECHNICAL BASES FOR REACTOR CHEMISTRY CONTROL AT SRS}

(Task 7 Report)

\section{INTRODUCTION}

As a part of the SRS Moderator Chemistry Program conducted by the Reactor Engineering Department, current SRS moderator chemistry technical bases have been documented [1]. The moderator chemistry program and technical specifications are aimed at preserving the cladding and process water system boundaries. They are also aimed at maintaining conditions which assure the effectiveness of the supplementary safety system (SSS) if it is required.

An assessment of the technical bases presented in reference 1 has been made. Based on that assessment, several minor items of improvement have been identified. The purpose of this report is to document these items of improvement and the underlying rationale behind each item. The improvements are based on the results of studies more recent than the SRS technical standards (1978), as well as EPRI guidelines for primary water chemistry in commercial reactors. The identified areas of improvement are listed in Chapter II. The underlying rationale behind each item is given in Chapter III.

\section{Ii. IDENTIFIED TIEMS OF IMPROVEMENT}

In evaluating the technical bases for reactor chemistry control at SRS, the following areas of improvement have been identified.

1. The upper limit for moderator $\mathrm{pH}$ specified in the SRS Technical Standards [2] is 8.0. This value may result in significant gadolinium hydroxide precipitation onto the reactor surfaces following actuation of the SSS.

2. The limits for diagnostic analytes such as chloride and sulfate are judged to be high, inasmuch as they are based on the capabilities of older technology (current at the tirne of Technical Standards writing).
3. A basic misunderstanding concerning the chemistry laws as they apply to very pure water has led to an erroneous perception that grab samples analyzed off-line will give similar results to the in-line monitors. Redundant in-line and/or proper portable instrumentation can eliminate this problem.

4. Organic analysis of the moderator is not currently specified.

\section{POTENTIAL IMPROVEMENTS}

Based on the above list of improvement items, the following actions are recommended. The rationale behind each recommendation is also given. It should be noted that all of these changes are minor in nature; they will not atter the chemistry conditions currently maintained in the SRS reactors and will not significantly affect the safety and operation of the reactors. The decision to implement any, or all, of these changes will depend on resource availability and cost/benefit analyses.

1. Lower the maximum $\mathrm{pH}$ limit for the moderator from 8.0 to 7.2 .

Rationale: Tests and subsequent laboratory work done since the last revision of the SRS Technical Specification in 1973 indicate that sufficient gadolinium hydroxide precipitates from a solution with a $\mathrm{pH}$ of 8.0 to cause deposition on the reactor surfaces. This means that in the event of SSS discharge, problems could be encountered during subsequent reactor restart until all the deposited gadolinium is depleted. To reduce the likelihood of this occurrence, all six process water pumps are operated to provide moderator circulation until the gadolinium is removed by the deionizers. By lowering the maximum $\mathrm{pH}$ limit to 7.2 the probability of such occurrence would be reduced by nearly three orders of magnitude.

The behavior of gadolinium nitrate in the SRS reactor system was studied and documented after difficulty in cleanup and startup was experienced in 1977. The conclusion of these studies and others was that gadolinium hydroxide will begin to precipitate at a pH somewhere between 5.6 and 7.4 (at $25^{\circ}$ C) [2]. The relationship between $\mathrm{pH}$ and gadolinium nitrate solubility is shown in Figure 1. Examination of Figure 1 shows that lowering the $\mathrm{pH}$ upper limit to 7.2 will reduce the probability of gadolinium precipitation on reactor 
surfaces by a factor of approximately 1000 while maintaining reactor operation with a margin encompassing instrumerit measurement precision.

FIGURE 1

$\mathrm{pH}$ vs. Gadolinium Solubility

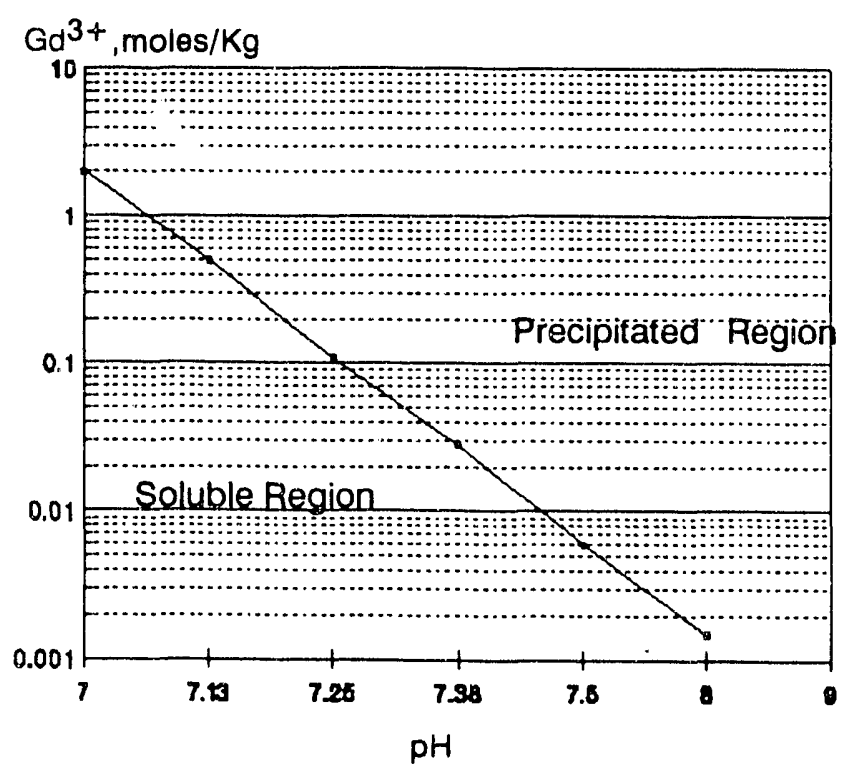

This change in the maximum $\mathrm{pH}$ limit is not essential for reactor safety or material protection. Sufficient gadolinium nitrate circulates in the system even at a $\mathrm{pH}$ of 8.0 to maintain the safety of the reactor; when the reactor is restarted, the precipitated gadolinium hydroxide will absorb neutrons until it is depleted.

2. Current guidelines on limits for diagnostic analytes such as chloride and sulfate should be lowered to reflect the improved analytical procedures in the laboratory. Actual values should be reported rather than "less than" values.

Rationale: The current guidelines for limits on impurities in the moderator and makeup systems match the analytical capabiiities of the SRS laboratories at the time when the guidelines were originally set. With improvement of the instrumentation, these limits can now be lowered. This will bring the reporting of results into line with current practice at commercial reactors, and improve the diagnostic abilities of the reactor technical organizations. Reporting of lower values will assure a larger margin of protection against intergranular stress corrosion cracking (IGSCC).

The current technical specification limit of 100 ppb for chloride is for makeup water only. The current operating limit of $10 \mathrm{ppb}$ in the moderator was set to allow laboratory operation with then current instrumentation. The use of ion chromatographs and ion selective electrodes now gives better sensitivity and higher precision at the lower levels than was possible earlier. Reporting of the actual values would allow trending of the results versus conditions so that one can forecast and prevent problems before they occur. In the same manner, operational limits for chloride, sulfate, oxalate, peroxide and other anionic and cationic impurities in the moderator and makeup should be reconsidered in the light of laboratory improvements.

All of the above impurities are used for diagnostic purposes and do not involve reactor safety. Lower impurity levels are associated with lower probabilities of IGSCC occurring in stainless steel. Operational limits for different leve's should be set to allow continued reactor operation while remedial actions to lower the concentrations within the limits are taken.

3. Analysis of total organic carbon in the moderator should be required.

Rationale: An additional analytical capability that could be added to bring the SRS reactor chemistry parameters into agreement with current practice at commercial reactors is that of total organic carbon. This would provide information not currently available on the presence of organics circulating in the reactor.

Examination of available INPO and EPRI documents [3-5] and discussions with reactor chemistry personnel at Georgia Power Company's Plant Vogtle and INPO headquarters indicate that the reactor chemistry parameters at SRS are in good agreement with those analyzed in commercial reactors (allowing for the differences in reactor types and operation). A possible additional parameter for analysis at SRS that is done in power reactors is that of total organic carbon. In the past, this analysis has been inferred by permanganate demand analysis at SRS; no correlation with operating conditions has been found. Analysis of total organic carbon would provide SRS operations with an additional diagnostic parameter to prevent loss of $\mathrm{pH}$ control resulting from reduction of nitric acid by organic carbon, similar to the occurrence in the L-2 cycle in 1964. Bicarbonate is also a major exhaustant of the deionizers. Additional instrumentation in the laboratory with corresponding training and personnel would be necessary to implement this analysis. 
4. Install redundant in-line instrumentation, and/or modify sampling lines, and acquire proper portable instrumentation with flow-through cells for surveillance of conductivity and $\mathrm{pH}$ of the moderator.

Rationale: The impossibility of obtaining crosscheck analyses for $\mathrm{pH}$ and conductivity of the pure waters between the laboratory and in-line instruments has caused the power reactor industry to install multi-redundant instruments in-line. Portable instruments are also temporarily installed in a flowing stream rather than using grab samples when checking the accuracy of the in-line instruments. This philosophy of operation would be beneficial for reactor chemistry control and reactor operations at SRS.

5. Install cation conductivity apparatus in-line.

Rationale: The use of in-line cation conductivity to monitor the anionic impurity levels, and installation of in-line ion-specific electrode for chloride (and possibly nitrate) would improve reactor operations' ability to monitor deionizer resin performance, improve the margin of protection from IGSCC from anions, and provide assurance that the acidic, nitrate-rich conditions necessary to prevent gadolinium hydroxide precipitation are met.

6. Install in-line, ion-specific, instrumentation for chloride.

Rationale: Such instrumentation would provide additional information on a specific anionic impurity with great potential impact on IGSCC.

7. Test and install ion chromatography equipment after their reliability is improved, and proven, in commercial reactors.

Rationale: Such an installation would avoid the need for pulling and transporting grab samples. The use of in-line ion chromatography is increasing in the power industry as a diagnostic tool. At the present time the instruments are expensive, bulky, and must receive almost constant expert maintenance for continuous operation [6]. The durability, size, and maintenance are improving and should make them feasible for installation in the SRS reactors during the next 5 years. Because of operational and installation problems unique to the SRS reactors, installation at SRS should be completely mocked up on a prototype, with consideration for the tritium content of the moderator as well as the radioactivity levels to be encountered, before purchase of systems for all reactors. Information returned from the ion chromatograph in-line does not improve safely or operability of the reactor. It does, however, provide diagnostic information more rapidly without transportation of samples to a laboratory.

\section{iv. References}

1. "Technical Bases for Reacto" Chemistry Control at SRS," A. Gibbs and S. 1. Abuel-Khalik, OPS-HOD-900081, SRS Repoit (03/01/0).

2. "Gadulinium Salts for Liquid Snut-u.t SystemsTheir Chemistry and Behaviour," N. D. Haworth, WNRE-235, Canadian AECL Report (1975).

3. "BWR Normal Water Chemistry Guidelir.es: 1986 Revision," W. Bilanin, EPRI NP-4946-SR, Electric Power Research Institute (1988).

4. "PWR Primary Water Chemistry Guidelines: Revision 1," C. J. Wood, EP!il NP-5960-SR, Electric Power Research Institute (1988).

5. "Guidelines for Chemistry at Nuclear Power Stations," INPO 88-021, Institute for Nuclear Power Operations (1988).

6. "In-Plant Measurement of Corrosive lons in Water," T. O. Passell, EPRI NP-6308, Electric Power Research Institute (1989). 
MODERATOR CHEMISTRY SURVEILANCE AND ANALYSIS REQUIREMENTS

\author{
(Task 4 Report)
}

\section{INTRODUCTION}

The purpose of this report is to describe and document the SRS moderator chemistry surveillance and analysis requirements as of mid-October 1989. The adequacy of such requirements, along with suggested items of improvement, will be examined in a later report. The report is divided into three main sections, viz. in-line monitoring, manual sampling, and data analyses. Requirements related to in-line monitoring of moderator quality parameters are discussed in Chapter II of this report. The parameters to be continuously monitored, along with the monitor types, sensor locations, alarm setpoints, calibration requirements, observation frequencies, operability determination, and responses to out-ofservice and out-of-limits conditions, are presented. Chapter III describes all requirements related to manual sampling of the moderator for chemistry control purposes. The sampling loca. tions and frequencies, along with the precautions and requirements for pulling and transporting of samples, and laboratory turn-around time, are given. Requirements related to the evaluation, trending, and reporting of the analyses results, along with response to out-of-limits conditions, are presented in Chapter IV.

It should be noted that the material presented in Chapters II through IV pertains to normal reactor operating conditions, including $C \& D$ operations. Supplementary requirements for extended shutdown conditions, as defined in the recently adopted DPSOL 105-6133 procedure entitled: "Moderator Chemistry Control During Shutdown", [1] are discussed in Appendix A.

It should also be noted that this report deals only with moderator control requirements within the reactor process water systems. Independent purification facilities such as the Moderator Processing Facility (MPF), the High Activity Moderator Processing Facility (HAM), and the 400-Area are outside the scope of this report; the interfaces between these facilities and the moderator chemistry control practices within the reactor process water systems are briefly discussed in Appendix B.

\section{IN-LNNE MONITORING REQUIREMENTS}

This chapter describes all requirements related to in-line monitoring of moderator quality parameters within the reactor process water systems. Five parameters are continuously monitored: (1) conductivity of the reactor effluent stream, (2) conductivity of the reactor influent stream, (3) $\mathrm{pH}$ of the stream to purification (reactor effluent), (4) $\mathrm{pH}$ of the stream from purification (reactor influent), and (5) dissolved oxygen in the process water system. The monitor types, sensor locations, and alarm setpoints for each of the five parameters monitored are given in Table II.1.

Table II.1

\begin{tabular}{|lllr|}
\hline \multicolumn{4}{|c|}{$\begin{array}{c}\text { IN-LNE MONITORS OF MODERATOR QUALTY } \\
\text { (Normal Operating }\end{array}$} \\
\hline Conditions)
\end{tabular}


The alarm settings in Table 11.1 have been obtained from DPSOL 105-75-PLK "Purification Control Room Settings" [2].

The output from each sensor listed in Table $I 1.1$ is indicated in the Purification Control Room (PCR) by a chart recorder with an associated alarm. Two additional conductivity sensors are placed in the reactor effluent and influent streams; the outputs from these two sensors are indicated in the Central Control Room (CCR) by shart recorders.

\section{II.1. Reading And Calibration Frequencies}

Each recorder for the five parameters listed in Table II.1 is required to be checked once every two hours by Purification Control Room personnel according to DPSOL 105-82 "Purification Control Room Data Sheets" [3]. The operability of each recorder is checked "on the spot" by observation and investigation of suspect readings such as offscale values or no indications. Formal operability determinations are made by periodic maintenance and calibrations. Table II.2 lists the applicable Reactor Maintenarice Procedures used to calibrate and check the operability of the various in-line monitors and the frequencies by which these calibrations are to be performed.

Table 11.2

\begin{tabular}{|c|c|c|}
\hline \multicolumn{3}{|c|}{$\begin{array}{c}\text { CALIBRATION AND OPERABILTY CHECKS } \\
\text { FOR INLUNE MONT ORS }\end{array}$} \\
\hline $\begin{array}{l}\text { MONITORED } \\
\text { PARAMETER }\end{array}$ & $\begin{array}{l}\text { REACTOR } \\
\text { MAINTENANCE } \\
\text { PROCEDURE }\end{array}$ & $\begin{array}{l}\text { RECORDER } \\
\text { CALIBRATION } \\
\text { FREQUENCY }\end{array}$ \\
\hline Conductivity & DPSOL $80802[4]$ & Unspecified \\
\hline $\mathrm{pH}$ & DPSOL 81401 [5] & Monthly \\
\hline Dissolved $\mathrm{O}_{2}$ & DPSOL 81406 [6] & Monthly \\
\hline
\end{tabular}

As indicated in Table 11.2 , the $\mathrm{pH}$ and dissolved oxygen meters are to be calibrated on a monthly basis. No calibration frequency is currently specified for the conductivity monitors. However, DPSOL 105-306-PLK, "Comparing Purification and Center Section Conductivity Recorder Readings", [7] is penformed monthly. The PCR and $C C R$ in-line conductivity monitors readings are compared to each other and to a portable meter.
Discrepancies greater than $10 \%$ for reactor effluent monitors are to be resolved by $E$ \& I. The portable monitor is to be operated per DPSOL 105-6120-PLK, "Moderator Conductivity Analysis", [8].

The purification control room alarms for all the monitors listed in Table 11.1 are to be checked annually by $E \&$ I per DPSOL 105-75-PLK [2], while the annunciator plate bulbs are to be checked each shift per DPSOL 105-82 [3].

\subsection{Response to Out-of-Service Conditions}

When only one $\mathrm{pH}$ monitor is in service, it must be set to monitor the reactor effluent $\mathrm{pH}$. If both $\mathrm{pH}$ monitors are inoperable, laboratory grab samples must be obtained ar.d submitted for analysis once per shift so that the $\mathrm{pH} /$ conductivity relationship contained in DPSOL 105-382 [9] can be verified.

If the dissolved oxygen monitor is inoperable, the inlet throttle valve must be closed while the vent valve is to be opened. The purification control room dissolved oxygen charts should be marked "shutdown for repairs", with time and date indicated. An E \& I mechanic must be requested to make any necessary repairs.

Currently, no procedures exist which give instructions in case of inoperable conductivity monitor(s).

\subsection{Response to Out-of-Limits Conditions}

This section describes the various actions to be taken when any of the in-line monitored parameters falls outside the limits given in Table II.1. Specific responses are given for five cases: (a) high reactor effluent stream conductivity, (b) low reactor effluent stream conductivity, (c) high reactor influent stream conductivity, (d) $\mathrm{pH}$ values out of limits, and (e) high dissolved oxygen. In addition to the actions listed below for these conditions, all out-of-limits data recorded from the PCR panels per DPSOL 105-82 [3] should be circled and reported to supervision. Table II.3 lists all applicable procedures in response to out-oflimits data from in-line monitors. 
Table II.3

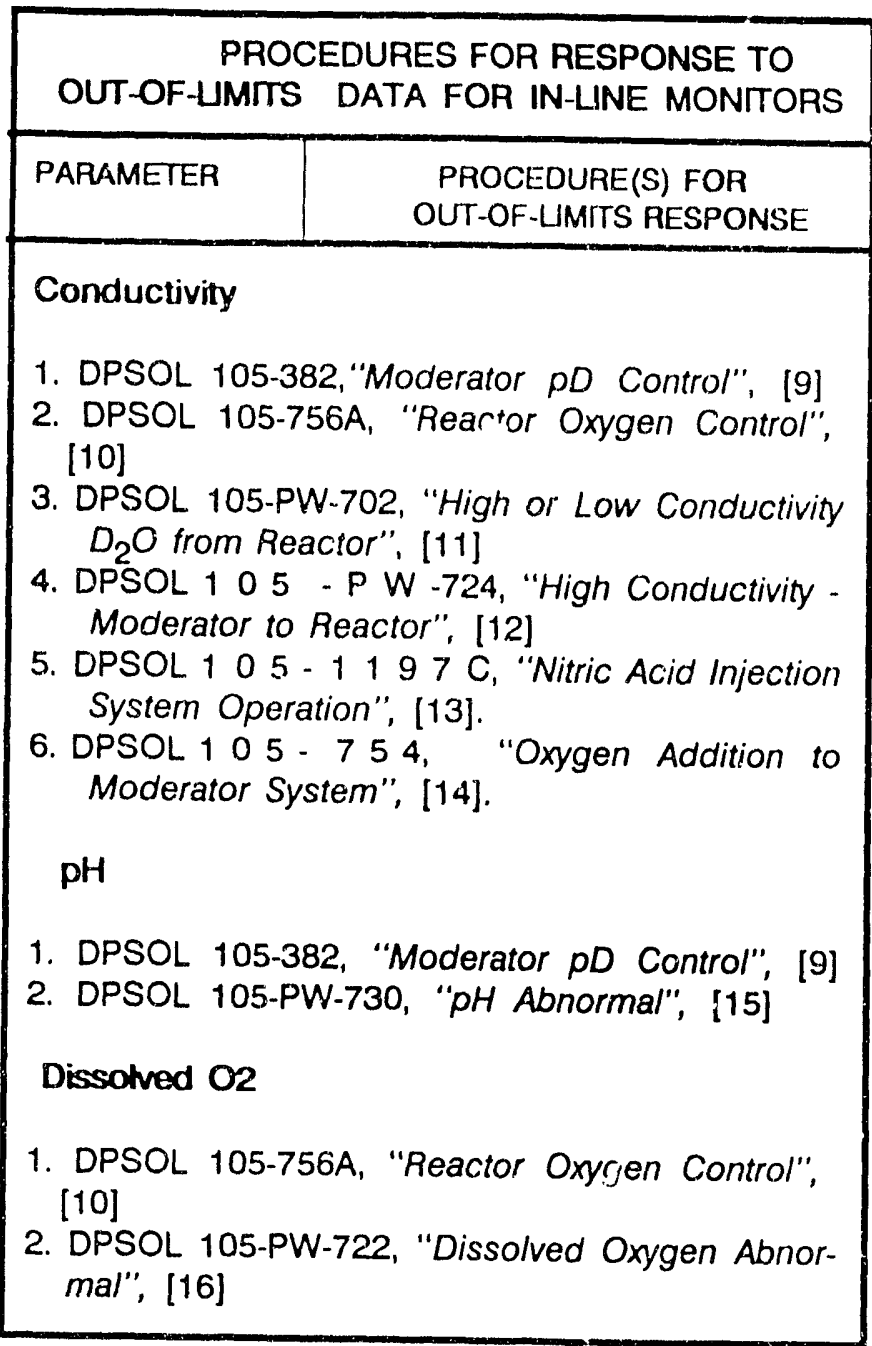

\section{a. High Reactor Effluent Stream Conductivity:}

When the conductivity of the reactor effluent stream exceeds the high alarm setpoint (3.2 $\mu \mathrm{mho} / \mathrm{cm})$, the following actions are to be taken per DPSOL 105-PW-702, "High or Low Conductivity D2O from Reactor", [11].

1. Compare the recorders readings in the Central Control Room (CCR) and the Purification Control Room (FCR). If the difference between inese readings is greater than $0.2 \mu \mathrm{mho} / \mathrm{cm}$, determine the conductivity of the moderator stream to purification using a portable conductivity meter per DPSOL 105-6120, "Moderator Conductivity Analysis", [8].

2. If two of the three readings are greater than the high alarm setpoint $(3.2 \mu \mathrm{mho} / \mathrm{cm})$, purification flow should be increased to its maximum value and acid addition should be discontinued.
3. The reactor should be shutdown per DPSOL 105-1205, "Lowering Reactor Power to Shutdown Conditions", [17] if conductivity remains above $3.2 \mu \mathrm{mho} / \mathrm{cm}$ for more than 24 hours with maximum purification flow and no acid addition or when two of the readings are greater than 4.5 $\mu \mathrm{mho} / \mathrm{cm}$ at any time.

\section{b. Low Reactor Effluent Stream Conductivity:}

When the conductivity of the reactor effluent stream drops below the low alarm setpoint (1.7 $\mu m h o / c m)$, the following actions are to be taken per DPSOL 105-PW-702, "High or Low Conductivity $\mathrm{D}_{2} \mathrm{O}$ From Reactor", [11]:

1. If both the PCR and CCR conductivity recorders indicate a conductivity decrease rate of more than $0.2 \mu \mathrm{mho} / \mathrm{cm} / \mathrm{hr}$, add six liters of nitric acid per DPSOL 105-PW-702, "High or Low Conductivity D2O From Reactor", [11], using DPSOL 105. 1197C, "Nitric Acid Injection System Operation". [13]. Verify that a positive response of at least 0.4 $\mu \mathrm{mho} / \mathrm{cm}$ is obtained. Also, add oxygen to the moderator using DPSOL 105-754, "Oxygen Addition to Moderator System" [14]. Continue oxygen and acid additions as long as conductivity remains between 1.2 and $1.9 \mu \mathrm{mho} / \mathrm{crn}$. If the con ductivity drops below $1.2 \mu \mathrm{mho} / \mathrm{cm}$ or the in-line $\mathrm{pH}$ meter reads more than $5.0(5.4 \mathrm{pD})$, and if reactor power is ascending, reduce power to $20 \%$ and regain pD control using DPSOL 105-756A, "Reactor Oxygen Control" [10]. During full power continue maximum moderator oxygen addition rate for at least five hours. Attempt to regain $\mathrm{pD}$ control once every hour by adding six liters of nitric acid, or more if response is at least 0.4 $\mu \mathrm{mho} / \mathrm{cm}$. If $\mathrm{pD}$ control is not regained within five hours, notify Reactor Engineering. It should be noted that the two procedures, DPSOL 105-756A and DPSOL 105-PW-702, appear to be inconsistent regarding the criteria for determining the quantities of oxygen and acid to be added. For DPSOL 105-756A the amount of oxygen to be added is a function of purification flow while acid is added until the conductivity returns to the 2.6 $3.0 \mu \mathrm{mho} / \mathrm{cm}$ range. On the other hand, for DPSOL 105-PW-702, oxygen addition is independent of purification flow while acid is added only until an increase of $0.4 \mu \mathrm{mho} / \mathrm{cm}$ is observed).

2. If both PCR and CCR recurders do not show a rapid conductivity decrease, compare readings. If they are within $0.2 \mu \mathrm{mho} / \mathrm{cm}$, add acid as described in 1 above. Verify that increase is at least 
$0.4 \mu \mathrm{mho} / \mathrm{cm}$. If the readings are not within 0.2 $\mu \mathrm{mho} / \mathrm{cm}$, initiate DPSOL 105-6120, "Moderator Conductivity Analysis" [8]. If any two of the three recorders indicate less than $1.7 \mu \mathrm{mho} / \mathrm{cm}$, add oxygen and acid as described in 1 above.

3. The reactor should be shutdown per DPSOL 105-1205, "Lowering Reactor Power to Shutdown Conditions" [17], if the conductivity does not increase by at least $0.4 \mu \mathrm{mho} / \mathrm{cm}$ after acid addition and the $\mathrm{pD}$ is greater than 5.7.

\section{c. High Reactor Influent Stream Conductivity:}

When the conductivity of the reactor influent stream exceeds the high alarm setpoint, the following actions are to be taken per DPSOL 105PW-724, "High Conductivity - Moderator to Reactor" [12].

1. Compare the CCR and PCR conductivity recorder readings. If they do not agree, the conductivity should be measured using a portable meter using DPSOL 105-6120-PLK [8].

2. If the conductivity of the cell effluent is greater than $0.3 \mu \mathrm{mho} / \mathrm{cm}$ under normal purification operation, the cell with high conductivity should be removed from in-line operation, the cells should be switched, and day supervision should be notified.

3. If the conductivity is greater than $3.3 \mathrm{umho} / \mathrm{cm}$ while DPSOL 105-303, "Purification Cell Operation with Modified Deionizer", [18] is in progress, the cation deionizer should be taken off-line, operation of the mixed bed deionizer should continue, and Reactor Engineering and day supervision should be notified.

4. If the conductivity remains high for more than 30 minutes, distillation should be isolated.

\section{d. $\mathrm{pH}$ Values Out of Limits:}

The following actions are to be taken per DPSOL 105-PW-730, "pH Abnormal", [15] when the moderator $\mathrm{pH}$ for either the reactor effluent or influent streams is out of limits:

1. Check the PCF and CCR conductivity recorders. If the conductivity of the reactor effluent stream is out of limits, DPSOL 105-PW-702, "High or Low Conductivity from Reactor", [11] should be implemerited. If the conductivity of the reactor influent stream is out of limits, DPSOL 105-PW. 724, "High Conductivity - Moderator to Reactor", [12] should be implemented.

2 For $\mathrm{L}$ and $\mathrm{K}$ areas, if the $\mathrm{pH}$ meter sample is taken from the coolant return tank discharge,distillation should be taken off line.

3. If the conductivity values are within the normal range, the in-line $\mathrm{pH}$ meter valving should be checked. In addition, E\&l should be asked to check and, if necessary, repair or calibrate the $\mathrm{pH}$ meter.

4. When the $\mathrm{pH}$ is returned to the normal range, distillation should be returned on line.

\section{e. High Dissolved Oxvgen:}

When the dissolved oxygen exceeds the high alarm setpoint $(2.0 \mathrm{ppm})$, the following actions are to be taken per DPSOL 105-PW-722, "Dissolved Oxygen Abnormal", [16].

1. Verify that the requirements for DPSOL 105756A, "Reactor Oxygen Control", [10] are being met.

2. Request E\&I to calibrate the analyzer.

3. Notify day management if dissolved oxygen remains high for longer ihan 24 hours.

\section{MANUAL SAMPLNG REQUIREMENTS}

This chapter describes all requirements related to manual sampling for the purpose of moderator quality assessment within the 100-Areas. The sampling locations and frequencies, along with the precautions and requirements for drawing and transportation of samples, are given.

\section{III.1. Sampling Locations and Frequencies}

Table III.1 lists the various sampling points and their locations. A corresponding list of moderator quality samples and their frequency requirements is given in Table III.2. 
TABLE III.1

MANUAL SAMPUNG POINTS \& LOCATIONS

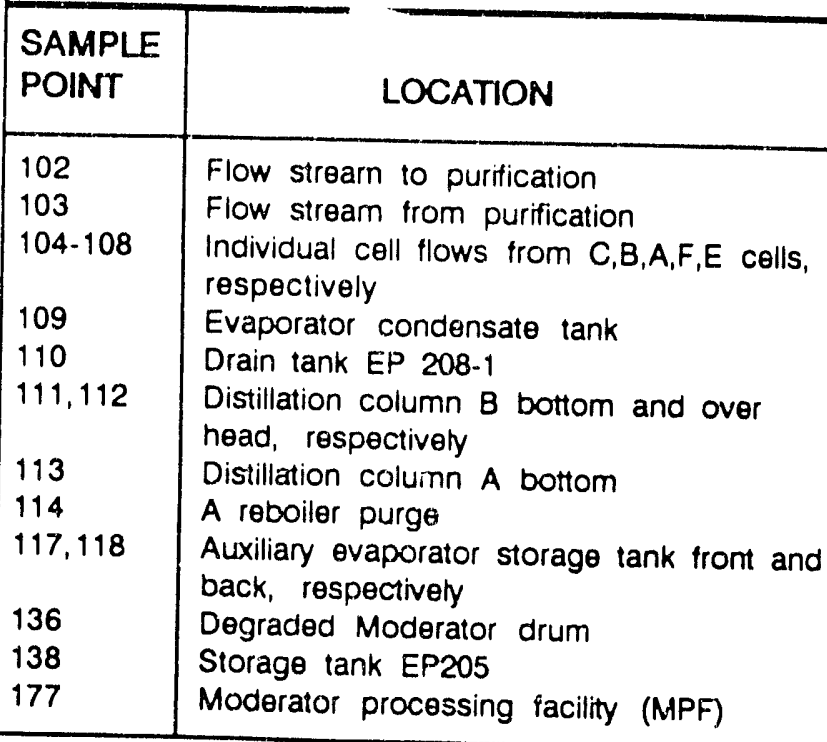

TABLE III.2

\begin{tabular}{|c|c|c|c|}
\hline \multicolumn{4}{|c|}{ REOUIRED SAAPLING FREQLENCIES } \\
\hline $\begin{array}{l}\text { SNAPLE } \\
\text { POIMT } \\
\end{array}$ & SUAPLE & FREQUEMCY & $\operatorname{rim}(1.2)$ \\
\hline \multirow[t]{8}{*}{102} & $\mathrm{H}_{2} \mathrm{O}_{2}$ & imonth & 2nd nondey of the month \\
\hline & $\begin{array}{l}\text { Turoldity, Alusha. } \\
2 \mathrm{hr} \text { Bota-gases }\end{array}$ & 3/menk & $\begin{array}{l}\text { Monday. Uedmestay. and } \\
\text { Priday }\end{array}$ \\
\hline & Conouctivity, on & indoes & onesay \\
\hline & $1003 \cdot, 102-, \mathrm{Cl} \cdot \mathrm{O}_{2} \mathrm{O}$ & Inimex & nondey \\
\hline & 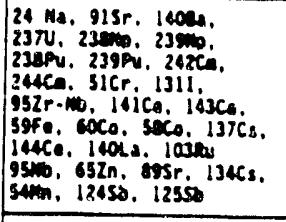 & $1 / \operatorname{men}$ & $\begin{array}{l}\text { Thursday for } P_{1} \\
\text { Twanday for } 1 . \\
\text { fertday for } \mathrm{K}\end{array}$ \\
\hline & 355. 32P & -.. & As momired \\
\hline & Tritive & 2 Monten & 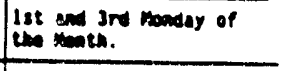 \\
\hline & 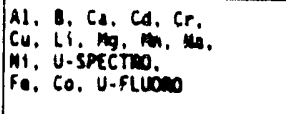 & vaurter & $\begin{array}{l}\text { 1st maseseloy of exch } \\
\text { esarter }\end{array}$ \\
\hline \multirow[t]{3}{*}{103} & $\begin{array}{l}\text { Turtidity, Alpha, } \\
2 \text { hr Cota-genes, }\end{array}$ & $2 / 25006$ & 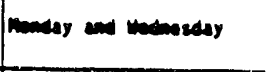 \\
\hline & 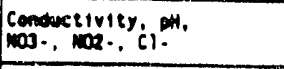 & $1 /$ Meat & menescay \\
\hline & $\mathrm{O}_{2} \mathrm{O}$ & 4/Mosit & 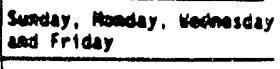 \\
\hline $\begin{array}{l}\text { los } \\
\text { inrough } \\
\text { ias }\end{array}$ & $\begin{array}{l}\text { iurbldity, Aloha. } \\
2 \text { kr Eota-gatsa. } \\
\text { conowetivity }\end{array}$ & 1/2met & now \\
\hline 109 & 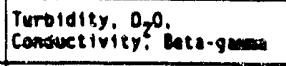 & 1/0ay & Danlly \\
\hline 110 & 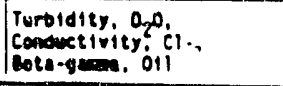 & 2 monen & 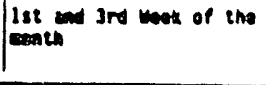 \\
\hline
\end{tabular}

TABLE III.2, CONTD

\begin{tabular}{|c|c|c|c|}
\hline $\begin{array}{l}\text { SAMP!? } \\
\text { POINT }\end{array}$ & suspe $\mathrm{E}$ & EREQUENCY & $\operatorname{rime}(1,2)$ \\
\hline $\begin{array}{l}111 \\
\text { ind } \\
112\end{array}$ & $0_{2} 0$ & $2 / 200 \mathrm{k}$ & Monday and Thursoay \\
\hline \multirow[t]{3}{*}{113} & Turblatey, Bata.qua & INank & Mursday \\
\hline & $\mathrm{O}_{2} \mathrm{O}$ & $2 /$ Nonk & Monday and Thursoay \\
\hline & Conductivity & $2 / \operatorname{month}$ & $\begin{array}{l}\text { 2no and ath vednesody } \\
\text { of esen sonen. }\end{array}$ \\
\hline 114 & $\begin{array}{l}\text { Turblatty, } 0,0 \text {. Condre. } \\
\text { tivity, Boti? }\end{array}$ & 2 Month & $\begin{array}{l}\text { 2nd and ith wodnesaly } \\
\text { of auch eonth. }\end{array}$ \\
\hline 117 & $\begin{array}{l}\text { Turoldity, } 0,0, \text { Aloms. } \\
\text { Bota-gen, } \\
\text { oH, ofl, Ci., }\end{array}$ & oach & \\
\hline 110 & 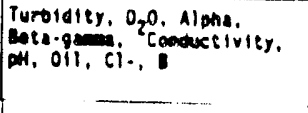 & exch & \\
\hline 136 & 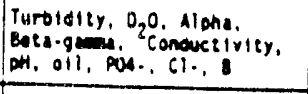 & ouch & \\
\hline 130 & $\begin{array}{l}\text { Turbidity, } 0,0, \text { il. } \\
\text { Conductivity. ofl }\end{array}$ & $\because$ & Wofore deping to res. \\
\hline 177 & 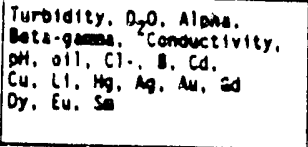 & ouch & \\
\hline
\end{tabular}

- (1) Rescior sbould be operasing for a leas ate dos butore alang any radionuclide

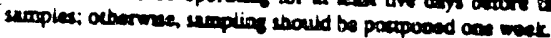

(2) All umples arn to be druos per Table IfI2 a 7:30 A.M. and delivered to T:2.F

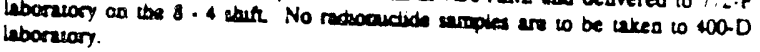

The data given in Table 11.2 is obtained from DPSOL 105-6101A-PLK, "Sample Analysis Schedule and Control-Routine", [19]. Pages 4 through 23 of DPSOL 105-6101A.PLK are printouts from the Sample Analysis Schedule and Control (SAN. SCO) computer program. Only samples pertaining to moderator quality are included in Table III.2. The conditions which must be satisfied before manual sampling can be initiated are summarized in Table 111.3 .

TABLE III.3

\begin{tabular}{|c|c|}
\hline EQUIR & SYSTEM CONDTIONS FOR SAI \\
\hline SAMPLE & REQUIRED SYSTEM STATUS \\
\hline $\begin{array}{l}102,103 \\
102 \mathrm{~B}\end{array}$ & $\begin{array}{l}\text { Purification flow established } \\
\text { Px operating for } 5 \text { days after shutdown }\end{array}$ \\
\hline $102 \mathrm{E}$ & Px operating \\
\hline $104-108$ & 2 or mere cells on -line \\
\hline 102.110 & per DPSOL 105-6101A \\
\hline $111-114$ & Distillation on-line \\
\hline $\begin{array}{l}117-118 \\
136,138\end{array}$ & per DPSOL 105-6101A \\
\hline 177 & MPF operating \\
\hline
\end{tabular}




\subsection{Manual Sampling Procedures}

Manual sampling procedures are described in DPSOL 105-6102-PLK, "Process Water Sampling" [20], DPSOL 105-6103, "Radionuclide Sample. $\mathrm{D}_{2} \mathrm{O}$ from Reactor", [21], arid DPSOL 105-6105PLKC, "Moderator Drum Sampling" [22]. The following practices are emphasized in all manual sampling procedures:

1. Sample bottles are to be kept capped before sampling and should be clean. Dirty bottles are to be rejected.

2. Sample bottles are to be flushed thoroughly with sample before actual filling. After filling, the bottle should be immediately capped. Samples should not be allowed to remain in contact with air for more than 30 seconds.

3. A completely filled out SANSCO sample labsl should accompany all samples.

4. Health protection requirements should be strictly adhered to when pulling samples.

5. All sample bottles are to be filled to the neck. Use the exact size of sample bottle as specified to avoid waste and radiation exposure.

\subsection{Sample Handling Procedures}

Sample hancling procedures are describad in DPSOL 105-6i 22.PLK, "Process Water Sam. pling", [20], DPSOL 100-9005, "Moderator Handling and Shipping", [23], and DPSOL 100-9006, "Liquid and Gas Sampling and Transporting Samples to Laboratory" [24].

These procedures deal primarily with protection of personnel and the environment while handling or transporting samples. Requirements aimed at maintaining the quality oi the samples and/or the accuracy of the analysis are covered in Section III.2.

The fol!owing actions are to be taken when handling or transporting samples:

1. Whenever samples are to be transported on highways SC-125 or SRP-1, form OSR 16-69 must be completed. The sample vehicle must be identified by a "Regulated Service Vehicle" sign (form OSR4-284A). Each reactor area has its own vehicle for use in transporting samples to the laburatory in 772-D or 772-F.

2. Each sample vehicle must have an approved
DT7 drum to hold the samples. The inner fiber lid, the metal drum lid, and the lid retaining ring must be in place and tightened when in transport.

3. Samples are to be removed from the vehicle by Reactor Department personnel and hand delivered in sample carriers to the "Sample Receiving" door in the laboratory.

4. Two hour beta-gamma activity samples are to be delivered to the laboratory within one hour of pulling the sample. All other moderator samples are to be delivered within two hours of pulling them.

5. Samples HB-103 and HB-105 (HB-205 and HB 219 in $P$ area) are to be handled with tongs. Samples with radiation rates greater than $50 \mathrm{mR} /$ $\mathrm{hr}$ are to be handled with tongs and placed inside the lead pig in the regulated area.

6. The $\mathbf{4 0}$ milliliter plastic vials should not be used for liquid samples since the tops have a tendency to leak or come off while in transport.

7. Samples should be placed in plastic bags, folded and taped to prevent spillage. They should be surveyed for radioactivity level and labeled using form OSR 4-38A or equivalent. LCW level tritium samples are to be separated from moderator samples at all tirnes.

\section{III.4. Laboratory Turn-Around Time}

Currently, there are no procedures which specify a required laboratory turn-around time. However, DPSOL 105-6101 A-PLK, "Sample Analysis Schedule and Control Routine", [19], instructs the operators to take samples late on the scheduled shift so that they can be take.n to thie laboratory earty on the following shift. The laboratory turn around time for 100-Area routine moderator sample analysis is approximately 8 hours; this estimate is based on current experience of laboratory personnel.

\section{N. ANALYSIS AND EVALUATION REQUIRE- MENTS}

This chapter describes the analysis, evaluation and reporting requirements for sample analyses results (laboratory data). Laboratory procedures dealing with the conduct of samiple analyses are outside the scope of this report; these procedures are assembled within DPSOP 84, "Analytical Procedures-400 Areas", [25] which is under the cus- 
todianship of the Analytical Laboratories Department.

\section{IV.1. Data Reporting Requirements}

The results of all routine samples analyzed per DPSOL 105-6101A, "Sample Analysis Schedule and Control-Routine", [19] are reported by the Laboratory to purification control room personnel via telephone. They are then recoroed on DPSOL 105-6101C "Sample Analysis Schedule and Control-Data Sheet 1 Sample Schedule", [26] by PCR personnel. The results are also key punched into the SANSCO computer program by the Laboratory. A "Daily Laboratory Analysis Report" containing the results of all routine sample analyses conducted each day is printed by SANSCO; the print is distributed 3 or 4 days after the analyses are conducted. The results of all routine sample analyses run by the Laboratories Department during each month is printed by SANSCO as a "Monthly Summary Laboratory Analysis Report". In addition, once per menthi, DPSOL 105-83. PLKC, "Moderator System Data Collection", [27] is to be performed by PCR personnel and forwarded to the Production Control Supenisor for review. This procedure is essentially a log sheet for 100-Area distillation system data (e.g. D2O purity, flows, boil-up rates, etc.).

\section{IV.2. Response to Out-of-Limits Conditions}

For routine samples taken per the SANSCO daily schedule, any out-of-limits data are to be circled when recorded and reported to supervision.

\section{IV.3. Evaluation and Trending of Data}

Evaluation and control of the error, accuracy; and precision of sarnple analysis data are governed by laboratory DPSOP 81-1, "Laboratory Department Standard Practices-Quality Assurance Procedures", [28]. An informal evaluation of the data is made every time data are to be compared with the corresponding limits.

Evaluation of data taken in DPSOL 105-83-PLKC [27] is performed using DPSOL 105-84-PKLC, "Analyzing 100-Area Moderator System Report", [29].

The Systems Chemistry Group is currently trendIng liquid and gaseous radioactive reieases irom 400-Area process sewers and stacks. No other routine trending of moderator chemistry data is currently performed by Reactor Engineering personnel (SANSCO has a limited capability of trending chemistry data).

\section{REFERENCES}

1. "Moderator Chemistry Control During Shutdown", SRS Reactor Operations Department (ROD) Procedure DPSOL 105-6133-PLK, Revision $O(10 / 12 / 89)$.

2. "Purification Control Room Alarm Settings", SRS ROD Procedure DPSOL 105-75-PLK, Revision $28(6 / 22 / 89)$.

3. "Purification Control Room Data Sheets", SRS FOD Procedure DPSOL 105-82-P, Revision 38 (3/ 22/88).

4. "Calibration and Check out of Conductivity System", SRS Reactor Maintenance Procedure DPSOL 1-80802-RPLKC, Revision 1 (11/63).

5. "In-Line $\mathrm{pH}$ Meters Calibration", SRS Reactor Maintenance Procedure DPSOL 1-81401-PKC, Revision 2 (11/9/87).

6. "Calibration and Maintenance of Dissolved Oxygen Analyzer and Probes", SRS Procedure DPSOL 1-81406, Revision 2 (4/22/88).

7. "Comparing Purification and Center Section Conductivity Recorder Readings", SRS ROD Procedure DPSOL 105-306-PLK, Revision 10 (8/8/88).

8. "Moderator Conductivity Analysis", SRS ROD Procedure DPSOL 105-6120-PLK, Revision 5 (7) 28/88).

9. "Moderator $p D$ Control", SRS ROD Procedure DPSOL 105-382-PL.K, Revision 16 (6/9/88).

10. "Reactor Oxygen Control", SRS ROD Procedure DPSOL 105-756 A-PLKC, Revision 4 (7/15/ 85).

11. "High or Low Conductivity D2O from Reactor", SRS ROD Abnormal Condition Control (ACC) Procedure DPSOL 105-PW-702-PLK, Fevision 3 (8/2/88).

iz. "riigin Concuciivity - Mioúerator to Reactor", SRS ROD ACC Procedure DPSOL 105-PW-724PLKC, Revision 1 (1/27/83). 
13. "Nitric Acid Injection System Operation", SRS ROD Procedure DPSOL 105-1197C-PLKC, Revision 4 (10/88).

14. "Oxygen Addition to Moderator System", SRS ROD Procedure DPSOL 105-754-PLKC, Revision $5(3 / 86)$.

15. "pH Abnormal", SRS ROD ACC Procedure DPSOL 105-730, Revision 1 (1/12/83).

16. "Dissolved Oxygen Abnormal", SRS ROD ACC Procedure DPSOL 105-PW-722, Revision 2 (9/6/ 83).

17. "Lowering Reactor Power to Shutdown Conditions", SRS ROD Procedure DPSOL 105-1205PLK, Revision 50 (1/89).

18. "Purification Cell Operation with Modified Deionizer", SRS ROD Procedure DPSOL 105-303PLKC, Revision 1 (8/84).

19. "Sample Analysis Schedule and Control-Routine", SRS ROD Procedure DPSOL 105-6101APLK, Revision 11 (5/18/89).

20. "Process Water Sampling", SRS ROD Procedure DPSOL 105-6102-PLK, Revision 16 (9/15/89).

21. "Radionuclide Sample $-D_{2} \mathrm{O}$ from Reactor", SRS ROD Procedure DPSOL 105-6103-PLKC, Revision 1 (3/28/84).

22. "Moderator Drum Sampling", SRS ROD Procedure DPSOL 105-6105-PLKC, Revision 5 (3/28/ 84).

23. "Moderator Handling and Shipping", SRS Health Physics (HP) Procedure DPSOL 100-9005, Revision 8 (11/81).

24. "Liquid and Gas Sampling and Transporting Samples to Laboratory", SRS HP Procedure DPSOL 100-9006, Revision 9 (11/81).

25. "Analytical Procedures-400 Areas", SRS ROD Procedure DPSOP 84, Revision 29 (11/89).

26. "Sample Analysis Schedule and Control-Data Sheet 1 Sample Schedule", SRS ROD Procedure DPSOL 105-6101 C.PLK, Revision 3 (3/7/88).

27. "Moderator System Data Collection"; SRS ROD Procedure DPSOL 105-83-PLKC, Revision 7 (2/14/83).
28. "Laboratory Department Standard Practices Quality Assurance Procedures", SRS Laboratory Department Procedure DPSOP 81-1, Revision 6 (6/89).

29. "Analyzing 100-Area Moderator System Report", SRS ROD Procedure DPSOL 105-84-PLKC, Revision 3 (1/27/83).

30. "Charging Moderator to Circulating System", SRS ROD Procedure DPSOL 105-101-LK, Revision $23(7 / 11 / 88)$.

\section{APPENDIX A \\ Moderator Chemistry Requirements During Extended Shutdown Conditions}

As indicated earlier, all moderator chemistry control practices described in Chapters II through IV of the report apply to normal reactor operating conditions, including C\&D operations. Currently, there is no formal moderator chemistry control program for lay-up conditions; activities in that area await development of such a program.

A new procedure, DPSOL 105-6133, "Moderator Chemistry Control During Shutdown", [1] has recently been implemented; this procedure extends moderator control practices to shutdown conditions. The Supplementary requirements for moderator chemistry control during shutdown as defined in DPSOL 105-6133 include:

1. The reactor must be discharged of heat generating assemblies and drained if purification is offline for more than two weeks.

2 If the moderator in any process water system, including the reactor tank and heat exchangers, cannot be circulated and sampled for a period of two weeks. that system should be drained.

3. Distillation and purification flow should be on at all times. 
4. Moderator chemistry control should be maintained as usual per DPSOL 105-6101A [19] in both the reactor tank and the storage tanks. If the conductivity, $\mathrm{pH}$, and chlorides cannot be maintained within limits, the system should be discharged of heat generating assemblies and drained.

5. If the moderator has been drained to the storage tanks, it must be sampled as usual per DPSOL 105-6101A [19] and circulated through purification. If the chlorides, conductivity, and $\mathrm{pH}$ cannot be maintained within limits in the storage tanks, Reactor Engineering must be notified for further action.

The above requirements are to be accomplished through the following practices:

1. Maintain moderator chemistry control as usual by following DPSOLS 105-6101A and 105-6101C.

2. Complete the data sheets of DPSOL 105-6133 [1] to keep an updated status of the process water system (i.e., whether pumps, heat exchangers, etc. contain moderator and/or circulating the moderator).

3. Given the current status of the process water system, a decision is made as to any actions required based on the requirements above (i.e., if the moderator in a certain process water loop has been documented in the data sheets as not having circulated in over two weeks, then a decision is made to drain the system).

In addition to the requirements of DPSOL 105. 6133 [1], reactor effluent conductivity limits are 0.3 to $3.0 \mu \mathrm{mho} / \mathrm{cm}$ for all reactor areas; this requirement is reflected on Temporary Procedure Changes (TPCs) for several procedures.

\section{APPENDIX B}

\section{Roles of the MPF, HAM, and 400-D Area in Moderator Chemistry Control}

As indicated earlier, all moderator chemistry control practices described in Chapters 11 through IV of the report pertain to the reactor process water systems. The roles of the Moderator Processing Facility (MPF), the High Activity Moderator Processing Facility (HAM), and the 400-D Area and their interfaces with the Chemistry Control requirements within the reactor process water systems are briefly described in this Appendix.

The purpose of the MPF and the HAM is to remove impurities from the moderator discharged from the circulating system before shipment to I e 400 area for additional processing in the Hework Unit. This is accomplished via the use of cation and anion exchange resin beds and an evaporator.

The 400 area consists of a DW plant, a Rework Unit, the D-Area Purification Facility (DPF), and the T-Area Purification Facility (TPF). The DW plant is used to concentrate heavy water with low tritium content $(<15 \mathrm{mCi} / \mathrm{ml})$. Feed material usually comes from offsite. The Rework Unit is used to reconcentrate degraded heavy water of $<99.75$ mol\% D2O with tritium content $>15 \mathrm{mCi} / \mathrm{ml}$. Feed material can come from on-plant (reactor areas) or off plant. Specification product contains $>99.75 \mathrm{~mol} \% \mathrm{D}_{2} \mathrm{O}$. The TPF is used to remove Mercury from heavy water received from the laboratory via packed columns.

Any drums of heavy water not meeting DW plant feed specifications need to be treated in the DPF. The DPF is a combination of several separations techniques used to remove oxidizable organic impurities, ions, and dissolved solids with low activity.

All drums meeting 400 area product specifications are shipped to the reactor areas as they are needed. Thus, reactor moderator quality is greatly dependent upon the interface between the reactor areas and the 400 area.

All moderator shipments from the 400 area to the reactor areas are checked to ensure that each drum contains a drum record with sample analysis results. Anaiysis iniormation on ine dirum record is verified to meet certain feed specifications 
before that drum is charged to the circulating system per DPSOL 105-101, "Charging Moderator to Circulating System", [30]. These feed specifications are given in Table B.1.

TABLE B.1.

\section{FEED SPECIFICATIONS FROM 400-AREA} TO THE REACTOR

Purity, mole \%

Conductivity, $\mu \mathrm{mho} / \mathrm{cm}$

$>99.75$

Turbidity, ppm

$<30.00$

Chlorides, ppm

$<20.00$

Boron, ppm

$<0.01$

Mercury, ppm

$<2.00$

Copper, ppm

$<0.01$

$<0.05$

Silver, ppm

$<0.05$

Gold, ppm

$<0.05$

Gadolinium, ppm

$<0.60$

Dysprosium, ppm

$<20.00$

Cadmium, ppm

$<5.00$

Europium, ppm

$<5.00$

Lithium, ppm

$<3.00$

Samarium, ppm

$<2.00$ 


\section{ASSESSMENT OF MODERATOR CHEMISTRY SURVEILLANCE AND ANALYSIS REQUIREMENTS AT SRS}

(Task 8 Report)

\section{INTRODUCTION}

As a part of the SRS Moderator Chemistry Program conducted by the Reactor Engineering Department, current moderator chemistry surveillance and analysis requirements at SRS have been documented (Task 4 Report) [1]. An assessment of those requirements has revealed numerous items of improvement. Recommended enhancements to upgrade the identified items have been developed.

The purpose of this report is to document the identified items of improvement in current moderator chemistry surveillance and analysis requirements at SRS. The recommended actions to enhance these items along with the rationale behind such recommendations, are given.

The report is divided into two main chapters, viz., identified items of improvement and recommendations. The items of improvement identified in Chapter II are grouped into three areas: (1) In-line monitoring requirements, (2) manual sampling requirements, and (3) analysis and evaluation requirements. The organization of Chapter II parallels that of the task 4 report (reference 1) on which this assessment has been based. Chapter III summarizes the recommended enhancements to upgrade the identified items, along with the bases for such recommendations. In order to allow easy follow up and cost-benefit analysis of the recommendations, they have been grouped into three categories: (1) Hardware-related recommendations, (2) procedures-related recommendations, and (3) upgrades in current practices.

It should be noted that the material presented in Chapters II and III pertains to normal reactor operating conditions, including $C \& D$ operations. Recommended improvements relating to requirements for extended shutdown conditions, as defined in the recently adopted DPSOL 105-6133 procedure entitled: "Moderator Chemistry Control During Shutdown", [2] are discussed in Appen$\operatorname{dix} A$.

It should also be noted that this report deals only with moderator control requirements within the reactor process systems. Independent purification facilities such as the Moderator Processing Facility (MPF), the High Activity Moderator Processing Facility (HAM), and the 400-Area are outside the scope of this report; thus, possible improvements to moderator chemistry practices within these facilities will be addressed in a different program.

\section{IDENTIFIED ITEMS OF IMPROVEMENT}

This chapter documents identified items of improvement in current moderator chemistry surveillance and analysis requirements at SRS. It is based on an assessment of requirements as of mid-October, 1989 which have been documented in reference 1 (Task 4 Report). The organization of this chapter parallels that of reference 1 , in order to assure consistency and allow easy comparison between the two reports. Each of the three sections below, namely in-line monitoring requirements, manual sampling requirements, and analysis and evaluation requirements, corresponds to one of the chapters in reference 1.

\section{II.1. In-Line Monitoring Requirements}

This section describes items of improvement related to in-line monitoring requirements of moderator quality parameters within the reactor process water systems. It is divided into four subsections: general requirements, reading and calibration frequencies, response to out-of-service conditions, and response to out-of-limits conditions.

\section{a. General Requirements:}

1. No alarm exists for the conductivity monitors in the Central Control Room (CCR).

\section{No redundancy exists for $\mathrm{pH}$ monitoring.}

3. No in-line monitoring of ionic species (chlorides, sulfates, etc.) is currently taking place.

\section{b. Reading and Calibration Frequencies:}

1. The calibration frequency for in-line conductivity monitors is not stated in the calibration procedure DPSOL 1-80802,"Calibration and Checkout of Conductivity System" [3]. 
2. DPSOL 105-6120, "Moderator Conductivity Arialysis" [4] does not provide for verification of calibration of portable conductivity meter.

3. Data from in-line monitors is not being trended.

c. Response to Out-of-Senvice Conditions:

1. No instructions exist for actions to be taken wherl the in-line conductivity meters are inoperable.

2. No limits exist for the length of time an in-line monitor may be inoperable or for the repairs of inoperable in-line monitors to be completed.

\section{d. Response to Out-of-Limits Conditions:}

1. The instructions for out-of-limits dissolved oxygen per DPSOL 105-PW-722, "Dissolved Oxygen Abnormal", [5] are inadequate. Calibration of the monitor should not be an automatic consequence when dissolved oxygen is out-of-limits.

2 The CCR procedures do not reference DPSOL 105-PW-702, "High or Low Conductivity $\mathrm{D}_{2} \mathrm{O}$ From Reactor" [6].

3. Procedures DPSOL 105-756A," Reactor Oxygen Control" [7], and DPSOL 105-PW-702, "High or Low Conductivity $\mathrm{D}_{2} \mathrm{O}$ from Reactor", [6] are inconsistent in their criteria for when and how much oxygen and acid are to be added when the conductivity of the reactor effluent stream is low.

4. DPSOL 105-PW-702, "High or Low Conductivity $\mathrm{D}_{2} \mathrm{O}$ from Reactor",[6] does not give any criteria for reactor shutdown for out-of-limits conditions, whereas DPSOL 105-756A, "Reactor Oxygen Conirol", [7] does.

\section{II.2 Manual Sampling Requirement}

This section describes items of improvement related to manual sampling requirements for the purpose of moderator quality assessment within the 100-Areas. It is divided into four subsections: sampling locations and frequencies, manual sam. pling procedures, sample handling procedures, and laboratory turn-around time.

\section{a. Sampling Location and Frequencies:}

1. Analysis of moderator for sulfates, silver, gold, mercury, and copper is not required.
2. Analysis of the storage tank contents for nitrates, nitrites, sulfates, $\mathrm{pH}$, etc. is not required.

3. The basis for determining sampling frequencies (and frequency of observing in-line readings) is not documented.

4. Special analysis results cannot be efficiently recorded on the Sample Analysis Schedule and Control (SANSCO) [8] sample schedule.

5. The SANSCO sample schedule computer program contains no provisions for conditions when systems are out-of-senvice. There is no interaction between the user and the program concerning process conditions.

b. Manual Sampling Procedures:

1. The requirement of keeping sample bottles capped and stored properly before sampling is not always adhered to in the field.

\section{c. Sample Handling Procedures:}

1. Current requirements prohibit the use of $40 \mathrm{ml}$ plastic vials for transporting liquid samples. No vials of such size are known to be currently in use. A similar requirement for plastic vials of other sizes does not exist.

\section{d. Laboratory Turn-around Time:}

1. There are no documented guidelines concerning laboratory turn-around time.

\section{II.3. Analysis and Evaluation Requirements}

This section describes items of improvement related to analysis, evaluation, and reporting requirements for sample analyses results (laboratory data). It is divided into three subsections: data reporting requirements, response to out-oflimits conditions, and evaluation and trending of data.

\section{a. Data Reporting Requirements:}

1. No reactor procedures are known to exist which give instructions for inputting analysis results into the SANSCO program so that daily and monthly reports can be generated. If such procedures do exist, they need to be referenced in DPSOL 105-6101A, "Sample Analysis Schedule and Control-Routine", [8].

2 SAAYSCO daihy reports are not timely. They 
are distributed three or four days after the analsis results are obtained.

3. SANSCO Monthly Summary Laboratory Analysis Report provides only one analysis result of a particular parameter per day even if multiple analyses of that parameter are performed. All results need to be reported.

4. Reporting sample results over the phone is inefficient.

\section{b. Response to Out-of-Limits Conditions:}

1. DPSOLs referenced on DPSOL 105-6101A [8] schedule printout are incorrect. They do not contain actions for out-of-limits SANSCO data.

2. No procedures exist which give instructions when parameters such as chlorides, peroxides, nitrates, etc. are out-of-limits.

3. Circling out-of-limits data and reporting to supervision is inadequate. Few documented guidelines exist for supervision to make decisions. Data should be routinely trended to anticipate problems rather than letting them occur.

\section{c. Evaluation and Trending of Data:}

1. Confusion exists concerning the normal and unavoidable discrepancy between manual sample analysis results and data from in-line continuous monitors for $\mathrm{pH}$ and conductivity. There exists no documentation concerning the reason for the discrepancy.

2. No routine trending of moderator chemistry data is taking place. SANSCO is currently not programmed to perform the task.

\section{RECOMMENDED IMPROVEMENTS}

This chapter summarizes the recommended enhancements to upgrade the identified items in Chapter II, along with the rationale for such recommendations. In order to allow easy follow-up and cost-benefit analysis of the recommendations, they have been grouped into three categories, namely, hardware-related recommendations, procedures-related recommendations, and upgrades in current practices.

The listed recommendations within each category are ranked in order of importance; the categories themselves are not prioritized. Clearly, the decision to implement any, or all, of these recommen- dations may need to await estimates of resource requirements and cost-benefit analyses. Development and delivery of appropriate training to operations personnel should follow that decision.

\section{III.I. Harcware-Related Recommendations}

The following hardware-related improvements are recommended. The underlying rationale for each recommendation is also given. The recommendations are listed in order of priority and importance, with "a" being the highest priority.

a Install alarms for conductivity monitors in the Central Control Room (CCR).

Rationale: No alarm exists for the conductivity monitors in the CCR. High conductivity situations can go uncorrected for a lengthy period of time without an alarm.

b. Install back-up in-line $\mathrm{pH}$ meters in both the reactor influent (from purification) and reactor effluent (to purification) streams.

Rationale: Currently, no redundancy exists for $\mathrm{pH}$ monitoring.

c. Install an in-line ion chromatograph and/or ionspecific electrodes to perform continuous analyses of ionic species.

Rationale: No in-line monitoring of ionic species (chlorides, sulfates, etc.) is currently taking place. Continuous in-line monitoring will allow for 'real time' monitoring and will prevent contamination of samples from off-line analyses and manual sampling. Also, personnel exposure will decrease.

d. Modify SANSCO so that in-line readings are recorded automatically and trending of any parameter can be executed on command.

Rationale: SANSCO is not currently programmed to record in-line readings. Routine trending of the data is not being done by any group. Computerized trending of data will make it possible to interpret them quickly and easily.

e. Establish portable conduciivity and $\mathrm{pH}$ monitoring with flow cell probes for both the reactor influent and effluent streams to eliminate the need for taking grab samples and to help eliminate the discrepancy between results of the grab sample analysis and the in-line monitors.

Rationale: Confusion exists concerning the nor- 
mal and unavoidable discrepancy between manual sample analysis results and data from in-line continuous monitors for $\mathrm{pH}$ and conductivity.

ill.2 Procedures-Pelated Recommendations

The following procedures-related improvements are recommended. The underlying rationale for each recommendation is also given. The recommendations are listed in order of priority and importance, with " $a$ " being the highest priority.

a. Establish a calibration frequency for in-line conductivity monitors and document it in DPSOL 1-80802, "Calibration and Checkout of Conductivity Systems"[3].

Rationale: The calibration frequency for in-line conductivity monitors is not stated in the calibration procedure DPSOL 1-80802 [3].

b. Include instructions to consult DPSOL 105$\mathrm{PW}-702$, "High or Low Conductivity $\mathrm{D}_{2} \mathrm{O}$ from Reactor"'[6] in all $\mathrm{CCR}$ procedures which require routine monitoring of conductivity.

Rationale: The CCR procedures do not reference DPSOL 105-PW-702 [6].

c. In DPSOL 105-PW-722, "Dissolved Oxygen Abnormal'"[5], require that the analyzer be calibrated only if requirements of DPSOL 105-756A, "Reactor Oxygen Control" [7], are being met. Include steps requiring more oxygen additions if dissolved oxygen is low, and fewer additions if dissolved oxygen is high.

Rationale: The instructions for out-of-limits dis. solved oxygen per DPSOL 105-PW-722 [5] are inadequate. They do not tell how to specifically correct the situation. There are too many references to other procedures and not enough "stand-alone" instructions. Also, calibration of the monitor should not be an automatic consequence when dissolved oxygen is out-of-limits.

d. Reevaluate the technical bases for oxygen and acid additions to the moderator and determine the correct procedure for such additions. Make necessary changes to DPSOL 105-PW-702, "High or Low Conductivity $\mathrm{D}_{2} \mathrm{O}$ from Reactor",[6] and DPSOL 105-756A, "Heactor Oxygen Control", [7] to make them consistent.

Rationale: Procedures DPSOL 105-756A [7], and DPSOL 105-PW-702 [6], are inconsistent in their criteria for when and how much oxygen and acid are to be added when the conductivity of the reactor effluent is low. Also, DPSOL 105-PW-702 [6] does not give any criteria for reactor shutdown for out-of-limits conditions, whereas DPSOL 105756A [7] does.

e. Identify the procedures to be referenced when applicable parameters are oui-of-limits; revise DPSOL 105-6101A, 'Sample Analysis Schedule and Control-Routine", [8] to list only those procedures.

Rationale: The DPSOLS referenced on DPSOL 105-6101A [8] schedule printout are incorrect. They do not contain actions for out-of-limits SANSCO data.

f. Provide steps in DPSOL 105-6120, "Moderator Conductivity Analysis", [4] for the operator of a portable conductivity monitor to verify that the monitor is not past due on calibration.

Rationale: DPSOL 105-6120 [4] does not provide for verification of calibration of portable conductivity meter. Including such a step would increase the likelihood of accurate data.

g. Revise DPSOL 105-6101A, "Sample Analysis Scheciule and Control-Routine", [8] so that special analysis results can be recorded more efficiently.

Rationale: Special analysis results cannot be efficiently recorded on the SANSCO sample schedule, making it difficult to evaluate and trend such data.

h. Revise DPSOL 105-6102, "Process Water Sampling", [9] so that it is understood which sample vials are acceptable.

Rationale: Current requirements prohibit the use of $40 \mathrm{ml}$ plastic vials for transporting liquid samples. No vials of such size are known to be currently in use. There is no similar requirement for plastic vials of other sizes.

i. Reference should be made within DPSOL 1056101A, "Sample Analysis Schedule and ControlRoutine", [8] to procedures which provide instructions for inputting SANSCO analysis data back into the program.

Rationale: No reactor procedures are known to exist winich give instructions for inputting analysis results into the SANSCO programs so that daily and monthly reports can be generated. If such 
procedures do exist, they need to be referenced in DPSOL 105-6101A [8].

\section{III.3. Upgrades in Current Practices}

The following upgrades in current practices are recommended. The underlying rationale for each recommendation is also given. The recommendations are listed in order of priority and importance, with "a" being the highest priority.

a. Require that portable conductivity monitors be calibrated and used when in-line conductivity monitors fail and cannot be repaired within specified time limits (see b below).

Rationale: No instuctions exist for alternate actions to be taken when the in-line conductivity meters are inoperable.

b. Establish limits sor the length of time an in-line monitor may be inoperable so that repairs would be made in a timely manner. It is recommended that if an in-line monitor is inoperable for a period of time that couses a routine reading to be skipped, portat, se monitoring should be done.

Rationale: There is no time limit for the repairs of inoperable in-line monitors.

c. Develop actions and associated procedures for out-of-limits conditions for chlorides, peroxides, nitrates, and any other relevant parameters for which no procedures currently exist for out-oflimits conditions.

Rationale: No procedures currently exist which give instructions when parameters such as chlorides, peroxides, nitrates, etc. are out-cf-limits.

d. Data should still be circled and reported to supervision if it is out-of-limits. However, specific guidelines for out-of-limits data should be well documented in DPSOL 105-6101A [8] (e.g.,increase sampling frequency, change out deionizers(s), decrease reactor power, shut down reactor, etc.).

Rationale: Circling out-of-limits data and reporting to supervision is inadequate. Few documented guidelines exist for supervision to make decisions. Data should be routinely trended to anticipate problems rather than letting them occur.

e. Restructure the SANSCO computer program so that it is more user interactive. Determine re- quired sarnples and sample frequencies for various process conditions (e.g.,operation, shutdown, startup, extended shutdown, etc.). Incorporate new changes into the program. Alternatively, purchase or develop new software to better perform the required functions currently performed by SANSCO.

Rationale: The SANSCO sample schedule computer program contains no provision for conditions when systems are out-of-service. There is no interaction between the user and the program concerning process conditions.

f. Develop a computer network to report analysis results to all appropriate personnel in a timely manner. Eliminate phone calls as a means of reporting results to PCR and CCR personnel.

Rationale: The SANSCO daily reports are not timely. They are distributed three or four days after the analysis results are obtained. Reporting of sample results over the phone is inefficient.

g. Require that the performance of procedures involving sampling of the moderator for chemistry control purposes be audited regularly.

Rationale: The requirement of keeping sample bottles properly stored and capped before sampling is not always adhered to in the field.

h. Determine acceptable maximum limits for quantities of sulfate, mercury, gold, silver, and copper in the moderator (not makeup), along with sampling frequencies. Document the requirement for sampling these species along with limits and sampling frequencies in appropriate procedures.

Rationale: Analysis of the moderator for sulfates, silver, gold, mercury and copper is not required by any procedure or technical standard (except for makeup $\mathrm{D}_{2} \mathrm{O}$ ) because there is no source for these species. However, this condition should be verified periodically.

i. Determine the parameters which need to be analyzed for the storage tank moderator. Determine acceptable maximum limits for these parameters, along with sampling frequencies. Document the requirement for sampling these species along with limits and sampling frequencies in appropriate procedures.

Rationaie: The analysis of storage tank contents for nitrates, nitrites, sulfates, $\mathrm{pH}$, etc. is not required. Periodic analyses will help verify quality

WSRC-TR-90-42-125 
of storage tank contents until they are pumped back through the deionizers.

j. Perform statistical analyses on moderator chemistry data to determine ideal sampling frequency. This may involve determining the tendency of various parameters to deviate from an average value over a given time period.

Rationale: The basis for determining sampling frequencies (and frequency of observation of inline readings) is not documented. A frequency that will help accomplish the overall objectives of the Moderator Chemistry Program should be developed.

k. Require that, if multiple analyses of a particular parameter are performed in a day, all results must be entered back into the SANSCO computer so that they can be reported.

Rationale: The SANSCO Monthly Summary Laboratory Analysis Report provides only one analysis result of a particular parameter per day even if multiple analyses for that parameter are performed. All analysis results need to be reported.

I. Establish agreement on acceptable laboratory turn-around times and document them appropriately.

Rationale: There are no documented guidelines concerning laboratory turn-around time.

\section{REFERENCES}

1. "Moderator Chemistry Surveillance and Analysis Requirements", OPS-ROD-890246, SRS Report $(12 / 27 / 89)$.

2. "Moderator Chemistry Control During Shutdown", SRS Reactor Operations Department (ROD) Procedure DPSOL 105-6133-PKL, Revision 0 (10/12/89).

3. "Calibration and Checkout of Conductivity System", SRS Reactor Maintenance Procedure DPSOL 1-80802-RPLKC, Revision 1 (11/63).

4. "Moderator Conductivity Analysis", SRS ROD Procedure DPSOL 105-6120-PLK, Revision 5 (7) 28/88).

5. "Dissolved Oxygen Abnormal", SRS ROD Abnormal Condition Control (ACC) Procedure
DPSOL 105-PW-722, Revision 2 (9/6/83).

6. "High or Low Conductivity $\mathrm{D}_{2} \mathrm{O}$ From Reactor", SAS ROD ACC Procedure DPSOL 105-PW. 702-PLK, Revision 3 (8/2/88).

7. "Reactor Oxygen Control", SRS ROD Procedure DPSOL 105-756A-PLKC, Revision 4 (7/15/ 85).

8. "Sample Analysis Schedule and Control-Routine", SRS RDD Procedure DPSOL 105-6101APLK, Revision 11 (5/18/89).

9. "Process Water Sampling", SRS ROD Procedure DPSOL 105-6102-PLK, Revision 16 (9/15/85).

10. "Analyzing 100-Area Moderator System Report", SRS ROD Procedure DPSOL 105-84-PLKC, Revision $3(11 / 27 / 83)$. 


\section{APPENDIX A \\ RECOMMENDED IMPROVEMENTS IN MODERATOR CHEMISTRY REQUIREMENTS DURING SHUTDOWN CONDITIONS}

As indicated earlier, all moderator chemistry control practices and recommendations described in Chapters II and III of this report apply to normal reactor operating conditions, including $C$ \& $D$ operations. A new procedure, DPSOL 105-6133, "Moderator Chemistry Control During Shutdown" [2], has recently been implemented. The identified items of improvement in the supplementary requirements for moderator chemistry control during shutdown are:

1. New reactor effluent conductivity requirements are not docurnented in DPSOL 105-6133 [2]. The procedure also does not document limits for other parameters.

2. No lay-up program exists.

The following actions are recommended:

1 Incorporate new conductivity limits into DPSOL 105-6133 [2]. Determine the limits for other chemistry parameters during shutdown and incorporate them into the procedure.

2. The ultimate long-term solution is to invest the resources necessary to develop a comprehensive lay-up program.
APPENDIX B

\section{ADDTIONAL ITEMS OF IMPROVEMENT WITHIN VARIOUS PROCEDURES}

Most of the procedures dealing with the requirements of moderator chemistry surveillance and analysis practices referenced in this report and in the task 4 report [1] need to be improved. The corrections range from simple typographical errors and human factors inadequacies to confusion regarding practices affecting moderator chemistry. All of the procedures need to be revised. A few of the more important items are listed below.

1. Page 2 on DPSOL 105-6133 [2], General Limitations and Cautions, step 7, does not specify a time limit for out-of-limits chlorides, conductivity, and $\mathrm{pH}$ before it is necessary to discharge the reactor and drain it.

2 There is no definition for an "acid instability condition" documented in DPSOL 105-756A [7].

3. There is no definition for "enrichment ratios" and "enrichment factors" in DPSOL 105-84, "Analyzing 100-Area Moderator System Report",[10]. The procedure does not document whose responsibility it is to perform it or when the results are to be documented.

The following action is recommended:

1. Review all procedures pertaining to moderator chemisty control and make necessary revisions. 


\section{IDENTIFICATION OF OPERATING PRACTICES WITH POTENTIALY ADVERSE IMPACT ON MODERATOR CHEMISTRY}

\author{
(Task 5 Report)
}

\section{INTRODUCTION}

The purpose of this repori is to document potentially adverse chemistry impacts which may directly or indirectly result from normal SRS reactor operating practices. Actions taken to minimize adverse impacts on moderator chemistry include: quality control during purchasing, in-line instrumentation and alarms, operating practices, and surveillance. Additional actions to further minimize adverse impacts on moderator chemistry, along with the rationale behind each recommendation, are given.

This report summarizes chemistry impacts from normal operating practices, along with recommendations for minimizing these impacts. The impacts are grouped into six main areas depending on the operating mode of the reactors: (1) Chemistry Impacts During Operation, (2) Chemis. try Impacts During Startups, (3) Chemistry Impacts During Shutdowns, (4) Chemistry Impacts During Charge and Discharge, (5) Chemistry Impacts During Outages, (6) Chemistry Impacts After Activation of Emergency Systems.

ins indicated in reference [1], the objective of moderator chemistry control is to ensure the safe and continued operation of the SRS reactors through: (1) minimizing corrosion of the stainless steel and aluminum reactor components, (2) maximizing the reactor productivity, (3) minimizing radioactive releases to the environment, (4) minimizing radiation exposure of personnel, and (5) assuring the effectiveness of the Supplementary Safety System. This is accomplished by: (1) minimizing the addition of any chemical or material to the process water system, (2) removing any undesirable chemical or material that is inhereni or generated in the process water system, and (3) maintaining rigorous chemistry and material quality control to minimize the impact of the presence of chemicals or materials in the process water system. With these guidelines in mind, the various operating practices at SRS have been assessed to identify practices that may adversely impact moderator chemistry and to recommend corrective actions for such practices.

\section{CHEMISTRY IMPACTS DURING POWER OP. ERATION}

This chapter documents the chemistry impacts associated with current operational practices of the SRS reactors during power operations. Nine issues are discussed: (1) Aluminum Cladding Corrosion, (2) Stainless Steel Corrosion, (3) Nitric Acid Addition, (4) Moderator Addition, (5) Dxygen Addition (6) Deionizer Breakthrough, (7) Light Water In-leakage, (8) Distillation Upsets, and (9) Fuel Failure/Target Failure.

\section{Aluminum Cladding Corrosion}

SRS fuel and target assemblies are aluminum clad. Cladding corrosion is an important consideration in moderator chemistry control. Aluminum coirosion is controlled by nitric acid and oxygen addition which maintains $\mathrm{pH}$ and assuresins an oxidizing medium is maintained. Aluminum corrosion is minimized by maintaining the moderator $\mathrm{pH}$ between 4.6 and 4.8 (the measured $\mathrm{pH}$ of 4.6 to 4.8 actually corresponds to the actual acidity PD of 5.0 to 5.2) and the dissolved oxygen concentration at approximately 1 ppri. [2]

\section{Stainless Steel Corrosion}

SRS reactor tanks, process water heat exchangers, process water piping, and other process water components are constructed primarily of 304 and 304L stainless steel. The same chemistry control is used to minimize aluminum and stainless steel corrosion. Stainless steel corrosion is minimized by controls on chloride and sulfate concentrations and maintaining the minimum dissolved oxygen necessary for aluminum corrosion control.

\section{Nitric Acid Addition}

Nitric acid addition is used to control $\mathrm{pH}$ between 4.6 and 4.8 to minimize aluminum and stainless steel corrosion. Excess nitric acid addition would lower $\mathrm{pH}$, raise the conductivity of the moderator, and increase the corrosion rate of the aluminum components. On-line conductivity and $\mathrm{pH}$ alarris would alert operations to the over-addition $\mathrm{Cl} \mathrm{ni}$. tric acid. The nitric acid would be removed by the deionizers. Increasing purification flow and put- 
ting multiple cells on-line would increase rate of the nitric acid removal. $[3,4,5]$

Reagent grade nitric acid and Product Rework Unit (PRU) Specification moderator are used to minimize the impurities added to the moderator system through nitric acid addition.

\section{Moderator Addition}

Moderator addition is used to replace moderator losses from the reactor system. Moderator addition is used to replace or make-up any moderator removed from the system (such as distillation drawoff or 208-1 Tank draining) or other losses (stack losses, spills). All make-up moderator must meet the specifications of Reference [4] (DPSOL 105-101, Charging Moderator to Circulating System). In addition to meeting the chemical specifications, the moderator is purified by circulation through the on-line deionizers before being added to the process water system.

\section{Oxygen Addition}

A minimal amount of dissolved oxygen is necessary to keep the nitrate of the system from decomposing to ammonia. Nitric acid is used to keep the general corrosion of aluminum and turbidity generation under control. The dissolved oxygen concentration is maintained at 0.5 to 1.5 ppm. Power reactors, which operate at much higher temperatures find that high dissolved oxygen can promote Intergranular Stress Corrosion Cracking (IGSCC), but SRL's Reactor Materials Program has found no oxygen effect in the low range of oxygen and the lower temperatures of SRS reactors. The dissolved oxygen concentration is monitored in-line. An alarm in the purification coiltrol room warns of a high dissolved oxyaen concentration. Oxygen is added to moderator during startup to maximize the oxygen addi. tion rate and to blanket gas during routine opera. tions. Oxygen addition would be stopped and the blanket gas purged to lower the dissolved oxygen concentration if the operating limit is ex:ceeded. [6]

\section{Deionizer Breakthrough}

Deionizer breakthrough occurs when the ion exchange resin becomes exhausted, allowing ions previously removed from the process water to be released back into the process water system. For example, chloride ions held by the ion exchange resin will be exchanged for the nitrate ion, increasing the chloride ion concentration in the process water system. Chloride concentration is limited to $30 \mathrm{ppb}$ to minimize corrosion in the reactor system. The deionizers are replaced before breakthrough to prevent high ion concentration based on a deionizer effluent conductivity limit of $0.3 \mu \mathrm{mhos} / \mathrm{cm}$. [7]

New deionizer resin is a source of ionic impurities such as chlorides and other ions which decrease the useful life of the resin and decrease the time to breakthrough. The ionic impurities in the resin are minimized through the purchase of high purity anion and cation resin as documented in Essential Material Specifications 63 and 64 (Reference [8]). Utilizing mixed resins will eliminate virtually all ions prior to exhaustion of resin. Mixed resins are self correcting, that is if the cation resin breaks down to sulfate ions, the anion resin takes them out; if the anion resin gives off amines, the cation resin takes them out. In addition, each drum of resin is tested on site to verify that it meets specifications prior to use in a deionizer as required by [9]).

Deionized light water is used to form a slurry with the resin and pump the resin into the deionizer. The light water is then displaced with heavy water (deuterization). Ions from either of these sources will tend to use up resin sites and lead to early exhaustion of a deionizer. This is minimized by testing all deionized light water and heavy water to verify it meets specifications for producing deionizers [10].

\section{Light Water In-leakage}

The presence of light water in the moderator reduces production by absorbing neutrons without producing any useful product. Light water is the most abundant neutron absorber in the moderator. Light water is removed by purifying a 4.5 gallon per minute stream using fractional distillation. The 100 Area distillation columns were designed to maintain moderator purity at or above $99.75 \mathrm{~mol} \% \mathrm{D}_{2} \mathrm{O}$ by removing approximately 100 pounds of light water per month through the drawoff of approximately $300 \mathrm{lbs}$ per day of lower isotopic purity moderator from the column distillate. [11]

Sources of light water during operation include vacuum leakage in the distillation columns, light water added as part of makeup moderator, exposure to air in the actuator forest, exposure to air in the vacuum breakers, and contact with water vapor in the blanket gas system. [12] 
Distillation Upsets

The distillation columns concentrate ions and turbidity in the $A$ Reboiler in addition to removing light water from the moderator. The ions and turbidity are removed from the moderator through the regular purging of 50 gallons per day of the A-reboiler moderator to the system evaporator and pumping all moderator through the purification cells prior to being pumped back to the reactor system. Distillation upsets may transfer the concentrated ions and turbidity directly to the reactor system.

During distillation upsets, distillation is isolated from the rest of the process water system to minimize increasing the ionic concentration of the moderatoi. The conductivity of the moderator exiting purification is also monitored to verify that it is less than $0.3 \mu \mathrm{mho} / \mathrm{cm}$. If the moderator conductivity of the stream exiting purification is greater than $0.3 \mu \mathrm{mho} / \mathrm{cm}$ for 30 minutes, distillation is manually isolated from the process water system. [13]

\section{Fuel Failure/Target Failure}

Fuel and target failures release large amounts of radioactivity to the moderator. This radioactivity is a combination of particulate and ionic material. The elevated radioactivity levels cause higher radiation exposure to personnel and higher potential environmental releases. Many monitoring systems such as the fuel failure gas chromatograph, moderator radioactivity sampling, and assembly flow rates are used to detect a fuel or target failure. Once the failed assembly is detected, it is discharged from the reactor. The radioactivity is removed through the deionizers, filters, system evaporator, deposition on aluminum assemblies, and radioactive decay. [2]

\section{CHEMISTRY IMPACTS DURING STARTUPS}

This chapter documents the chemistry impacts associated with current operational practices of the SRS reactors during reactor startups. Three issues are discussed: (1) Aluminum Corrosion , (2) Radiolysis of Moderator, (3) Temperature Impacts of Power Ascension.

\section{Aluminum Corrosion}

The aluminum corrosion rate is highest at the start of a reactor cycle with a fresh fuel load.
Aluminum corrosion is initially rapid and decreases with time. The blanket gas system recombines the deuterium gas and oxygen to reform $\mathrm{D}_{2} \mathrm{O}$. Oxygen must be added to the moderator through the blanket gas or by direct addition to the moderator to maintain an oxidizing medium for the nitric acid. Failure to maintain an adequate concentration of oxygen in the moderator allows a stepwise reduction of nitrate to ammonia as simplified below:

$\mathrm{DNO}_{3} \ldots>\mathrm{NO}_{2} \ldots \mathrm{NO} \ldots \mathrm{ND}_{4}$

The Aluminum corrosion in water is described below:

$2 \mathrm{Al}(\mathrm{s})+6 \mathrm{D}_{2} \mathrm{O}(\mathrm{l})-->2 \mathrm{Al}(\mathrm{OD})_{3}(\mathrm{~s})+3 \mathrm{D}_{2}(\mathrm{~g})$

This reaction produces deuterium gas which presents a potential flammability hazard and aluminum oxide which may contribute to the moderator turbidity.

Aluminum corrosion is controlled by maintaining the moderator $\mathrm{pH}$ between 4.6 and 4.8. Aluminum corrosion is controlled by nitric acid addition to maintain $\mathrm{pH}$, and oxygen addition to maintain an oxidizing medium. [2]

Radiolysis of Moderator

The effect of ionizing radiations on the moderator is the breakup of $D_{2} O$ into $D$ and $O D$ radicals. Free radicals are highly reactive; they react with other constituents in the moderator and also recombine in a back reaction to form the primary products $D_{2}$ and $D_{2} O_{2}$. $O_{2}$ comes from decomposition of $\mathrm{D}_{2} \mathrm{O}_{2}$. One reason for maintaining low concentrations of ionic impurities is to promote the back reaction and minimize radiolytic decomposition of the moderator. $\mathrm{D}_{2}$ and $\mathrm{O}_{2}$ are removed by the blanket gas system's catalytic recombiners. The $\mathrm{D}_{2} \mathrm{O}_{2}$, in combination with the chloride ion, have been shown to accelerate corrosion of stainless steel. The $\mathrm{D}_{2} \mathrm{O}_{2}$ is slowly removed by the deionizers and decomposition of the $\mathrm{D}_{2} \mathrm{O}_{2}$. [2]

\section{Temperature Impacts of Power Ascension}

The strongest impact of power ascension and power operations is the acceleration of corrosion at higher temperatures. Corrosion is minimized by gradual power ascension which minimizes heat induced stress, together with the relatively low operating temperatures of SAS reactors relative to power reactors. [14] 
Thermal shock to the aluminum and stainless steel components can also release ioris that had been previously removed from the bulk moderator by absorbtion of chloride ions by alumina. Chloride ions absorbed in the oxide film of reactor components may be released to the moderator causing a localized increase in chloride concentration, particularly at the beginning of a charge.

\section{N. CHEMISTRY IMPACTS DURING SHUT DOWNS}

This chapter documents the chemistry impacts associated with current operational practices of the SRS reactors during reactor shutdowns. The major impact during fast shutdowns (SCRAMs) and normal shutdowns is directly related to the rapid temperature decrease which causes thermal stresses to the stainless steel and aluminum components. The rapid temperature decrease after a SCRAM may cause an increase in turbidity resulting from flaking of the alumina oxide film. This impact is minimized by maintaining continuous deionization to control chemistry. The safety concerns requiring reactor shut down outweigh any potential impacts on the moderator chemistry.

\section{CHEMISTRY IMPACTS DURING CHARGE AND DISCHARGE}

This chapter documents the chemistry impacts associated with current operational practices of the SRS reactors during charge and discharge operations. Two issues are discussed: (1) Air Exposure, and (2) Impurities Introduced During Charging Assemblies.

\section{Air Exposure}

The reactor tank is vented to air during charge and discharge operations. The moderator $\mathrm{D}_{2} \mathrm{O}$ purity degrades as a result of light water exchange and condensation of light water in the air space above the reactor tank. Chemical impurities including increased chloride levels result from air exposure and condensation. Chemical degradation is minimized by maintaining purification on-line while moderator is in the reactor system. Moderator $\mathrm{D}_{2} \mathrm{O}$ degradation is minimized by minimizing the time the tank is vented to air. [11]
Impurities Introduced During Charging Assemblies

Impurities may be introduced during charging of new assemblies. Impurities are minimized by steam cleaning all assemblies before they are charged. Chemical degradation is minimized by maintaining purification on-line during charge and dische"ge operations.

\section{CHEMISTRY IMPACTS DURING OUTAGES}

This chapter documents the chemistry impacts associated with current operational practices of the SRS reactors during outages. Four issues are discussed: (1) Air Exposure, (2) Incomplete Drainage of System, (3) Construction Activities, and (4) Minimum Moderator Mixing.

\section{Air Exposure}

The reactor and storage tanks are vented to air through the blanket gas system (5 psig helium blanket is off-line) during outages. The moderator $\mathrm{D}_{2} \mathrm{O}$ purity degrades as the result of light water exchange and condensation of light water in the air space above the reactor and storage tanks. Chemical impurities including increased chloride levels result from air exposure and condensation. Chemical degradation can be minimized by maintaining purification on-line while moderator is in the reactor system. Moderator $\mathrm{V}_{2} \mathrm{O}$ degradation is minimized by minimizing the time the tanks are vented to air. [11]

Incomplete Drainage of Siystem

Process water heat exchanger design does not allow complete moderator draining. Approximately 200 gallons of mciderator are left in each of the twelve heat exchangers after draining the process water system. There are no methods to circulate the residual moderator in the heat exchanger. The air/moderator interface allows degradation of the moderator and a point for corrosion of the stainless steel. Concentration gradients of ionic impurities such as chlorides may also enhance corrosion. Potential damage to the process water heat exchangers is minimized by having high purity moderator before draining the process water system and minimizing the time the heat exchangers are drained. The heat exchangers were designed to be leplaced as needed. 


\section{Construction Activities}

Construction activities during outages can introduce impurities to the moderator through exposure of the process water system to air, impurities on surface of new piping, etc. Degradation is minimized by maintaining tight quality control of materials and work during construction activities.

\section{Minimum Moderator Mixing}

Low flow and no flow conditions are common during outages. Low or no flow conditions reduce mixing within the process water system. Concentration gradients of ionic impurities may exist which could cause localized corrosion. Mixing problems are minimized during operations sy maintaining purification flow as much as possible. Operation of three main circulating pumps is maintained where practical.

\section{CHEMISTRY IMPACTS AFTER ACTIVATION OF EMERGENCY SYSTEMS}

This chapter documents the chemistry impacts associated with current operational practices of the SRS reactors after activation of chemical based safety systems. Three issues are discussed: (1) Supplementary Safety Svstem Operation, (2) Emergency Cooling System Operation, and (3) Moderator Recovery System Operation.

\section{Supplementary Safety System Operation}

Activation of the Supplementary Safety System (SSS) injects 250 gallons of HEAVY water based gadolinium nitrate solution to the process water system. The purpose of the SSS is to act as an independent shutdown system that can be automatically or manually activated. The gadolinium nitrate must be removed prior to reactor operation using a special mixed bed deionizer containing 0.87 equivalents anion resin: 1.0 equivalent of cation resin. It requires approximately 84 hours of cleanup to remove the gadolinium. Other impurities in the gadolinium nitrate salt are controlled by purchasing saft that meets Essential Material Specification 148 [8]. Impurities introduced in the ink production are controlled by using PRU specification moderator and clean, stainless steel drums.

The long term impact of SSS activation is the addition of the light water impurity from the gadolinium nitrate salt. The safety importance of reactor shutdown during potential accident condi- tions requiring SSS activation would far outweigh any concerns regarding chemical degradation of the moderator. [15]

\section{Emergency Cooling System Operation}

Activation of the Emergency Cooling System (ECS) injects about 23,000 gallons of borated $\mathrm{H}_{2} \mathrm{O}$ (2\% Polybor ${ }^{T M}$ or Solubor ${ }^{T M}$ solution) followed by up to $14,000 \mathrm{gpm}$ of $\mathrm{H}_{2} \mathrm{O}$ into the reactor. In addition, approximately 39,000 gallons of filtered water is available and can be supplied at 500-750 gpm. The water injected into the reactor is initially fittered river water followed by raw river water. The importance of core cooling in such an event would far outweigh any concerns regarding chemical degradation of the moderator. [15]

TMTrademark of U.S. Borax Company

\section{Moderator Recovery System Operation}

Activation of the Moderator Recovery System (MRS) recirculates up to $1000 \mathrm{gpm}$ to make-up for a small process water leak. The system eliminates the need for actuation of the ECS for leaks of less than $1000 \mathrm{gpm}$. Moderator is recirculated from the sumps back to the reactor tank to maintain a constant moderator level. A screen is installed to remove debris but small amounts of oil may be pumped to the reactor. Chemical degradation of the water is expected because of contact with the floor, sumps, equipment, and air. The importance of core cooling in such an event would far outweigh the consequenses of any chemical degradation of the moderator. [16]

\section{RECOMMENDATIONS}

This report summarizes the potentially adverse impacts of SRS operating practices on moderator chemistry identified earlier. Recommended changes that could be made to minimize such adverse impacts to moderator chemistry, along with the rationale for such recommendations, are also given.

Recommendations have been identified in areas where improvements may enliance the moderator chemistry program in the SRS reactors. The recommendations are grouped by the operational state of the reactor. It should he noted that there are no recommendations concerning the following three states: (1) Chemistry Impacts During Startups, (2) Chemistry Impacts During Shutdowns, and (3) Chemistry Impacts During Charge 
and Discharge. Many of the recommendations will impact all of the reactor states but will primarily improve the moderator chemistry state under which they are listed.

It should be noted that the recommendations listed in this section are not arranged in order of priority. The decision to implement any of these recommendations should await a detailed costbenefit assessment of all recommendations made in this report.

The following nine tasks are recornmended:

\section{RECOMMENDED IMPROVEMENTS DURING POWER OPERATION}

1. Improve the program for ensuring that all materials in contact with the process water system (gaskets, O-Rings, filters, sealants, etc.) are examined and tested to determine that the highest quality (compatible with system, non-leachable, radiation resistant, and heat resistant) components are specified for use in the process water system. All new materials which are recommended for use in the process water system should be tested to assure their suitability in the SRS reactors.

Rationale: Impurities introduced by materials in contact with the process water system are transferred directly to the process water system. They will eventually be removed by the filters, deionizers, distillation, and the system evaporator but may cause localized corrosion. All new materials should be tested to verify that they will not degrade the moderator chemistry prior to approval for use in the SRS reactors.

2 Current specifications for reagent grade nitric acid should be reconsidered to determine if the purity specifications are adequate to minimize addition of impurities to the reactor system.

Rationale: Nitric acid is added directly to the moderator through systems 1,6 or 5 . Nitrates (Nitric acid) have a higher selectivity than chloride, Nitric acid is removed preferentially to chloride. Since only a side stream is deionized, the ionic impurities injected into the moderator may remain in the system for days before removal by the deionizers.

3. Current specirications for make-up neavy water should be studied to determine if the purity specifications are adequate to minimize addition of impurities to the reactor system.
Rationale: Moderator is added to the process water system through the deionizers. Approximately one drum of moderator is added per day to make-up for losses and drumming off the Distillation B Column Overhead drawoff. The current moderator specifications were developed based on the capabilities of the current Rework Unit purification equipment and the capabilities of the $772 D$ laboratory. Tighter specifications on the make-up moderator would extend the life of the deionizers. Also, for moderator fed directly to the moderator (Nitric acid addition), higher purity moderator would minimize impurities added to the process water system.

4. The essential material specification for deionizer resin should be reviewed.

Rationale: New deionizer resin is a source of ionic impurities added to the process water system in addition to removing ionic impurities from the process water system. Higher purity resin would introduce less impurities to the process water systern and have a longer service life. Consideration should be made to utilize nuclear grade resin.

\section{RECOMMENDED IMPROVEMENTS DURING OUT- AGES}

5. The possibility of maintaining low pressure helium blanket on-line during outages should be examined.

Rationale: Maintaining the blanket gas system online at all times would minimize the isotopic degradation of the moderator through contact with air. It would also minimize ionic degradation because of condensation of light water vapor in the air.

6. The possibility of modifying the process water heat exchangers to allow complete draining of the process water system should be examined.

Rationale: The safest state for a drained system is to be completely drained and dry. SRS heat exchangers can not be completely drained which leaves approximately 200 gallons (20\% full) of moderator in each heat exchanger.

7. All construction practices should be reviewed in order io deiermine itie exienit io winicií thiey may impact moderator chemistry. Steps should be taken to minimize air exposure of the process water system, utilize the highest quality materials 
(piping, gaskets, sealants, etc.), and minimize inadvertent addition of non-approved materials through strict material control.

Rationale: Construction activities have a high likelihood of introducing moderator impurities. Experience at SRS and commercial nuclear plants confirms that the process water is frequently degraded as a result of construction activities and it is generally impossible to prevent with strict quality assurance and material control.

8. The need to operate three main circulating Pumps at all times the process water system is not drained should be evaluated.

Rationale: Adequate flow is necessary to ensure that concentration gradients do not exist in the process water system which could cause localized corrosion. Operating practices should maintain adequate circulation in all six systems and all twelve heat exchangers.

\section{RECOMMENDED IMPROVEMENTS ASSOCLATED WTIH ACTIVATION OF EMERGENCY SYSTEMS}

9. Heavy water based Supplemeritary Safety System ink should be used to eliminate the deliberate addition of light water to the moderator.

Rationale: Light water based ink would degrade the moderator by approximately $0.2 \mathrm{~mol} \% \mathrm{D}_{2} \mathrm{O}$ per addition. Light water should not be deliberately added to the reactor system since it will take at least one year of efficient distillation operation to return the isotopic purity to its pre-injection concentration. Since production is a function of isotopic purity, intentionally adding light water is intentionally lowering production.

\section{REFERENCES}

1 ."Moderator Chemistry Control Guidelines (Task 1 Report)", A. Gibbs, October 23, 1989.

2. "Reactor Chemistry \& Radioactivity Manual", F. B. Longtin, RTR-1806, August 9, 1978.

3. "Moderator $p D$ Control", SRS ROD Procedure DPSOL 105-382-PLK, Revision 16 (6/09/88).

4. "Charging Moderator to Circulating System", SRS ROD Procedure DPSOL 105-101-LK, Revision $26(2 / 07 / 90)$.
5. "Nitric Acid Injection System Operation", SRS ROD Procedure DPSOL 105-1197C-PLK, Revision $5(01 / 09 / 90)$.

6. "Reactor Oxygen Control", SRS ROD Procedure DPSOL 105-755A-PLK, Revision 4 (07/15/ 89).

7. "Radiolysis of Ion Exchange Resins Used in the Purification Systems of Savannah River Reactors", E. W. Baumann, DP-977, September 28, 1965.

8. "Essential Material Specifications", DPSOP 116, Revision 76, July, 1988.

9. "Sampling Deionizer Resin", SRS ROD Procedure DPSOL 105-151-K, Revision 1 (03/15/85).

10 "Resin Bed Preparation", SAS ROD Procedure DPSOL 105-152-K, Revision 9 (01/19/90).

11."Distillation Handbook - 100 Areas", E. C. Bertsche, DPSPU 57-11-29, July 9, 1957.

12." Moderator Conservation - 1967 through 1970", C. T. Axelberg, B. S. Spangler, DPSPU 71-11-10, September 1971.

13."High Conductivity - Moderator to Reactor", SRS ROD Procedure DPSOL 105-PW-724-PLK, Revision 1 (01/01/83).

14."Assessment of Susceptibility of Type 304 Stainless Steel to Intergranular Stress Corrosion Cracking in Simulated Savannah River Reactor Environments (U)", R. S. Ondrejcin, G. R. Caskey, Jr., WSRC-RP-89-1230, December 1989.

15. "Savannah River Reactor System Descriptions", B. G. Beier, T. C. Gorrell, December 1982.

16. "Continuing Training Module - Moderator Recovery System". 
IMPLEMENTATION PLAN FOR IDENTIFIED ITEMS OF IMPROVEMENT IN THE MODERATOR CHEMISTRY PROGRAM AT SRS

(Task 9 Report)

\section{INTRODUCTION}

Over the past year, the Systems Chemistry Group of the Reactor Engineering Department has undertaken a comprehensive study of moderator chemistry control at SRS. The objectives of the study, as outlined in its mission statement and action plan [1], are:

1. To document, and provide the underlying technical bases for the methods, systems, procedures, requirements, and administrative controls currently used at SRS to maintain, control, monitor, analyze, and record moderator quality during all phases of plant operation and lay-up.

2. To examine the adequacy of such methods, systems, procedures, requirements, and administrative controls vis-a'-vis heavy water chemistry state-of-the-art, as well as applicable commercial industry practice and guidelines (e.g. INPO good practices).

3. To develop a timely and comprehensive implementation plan for identified items of improvement in the current methods, systems, procedures, requirements, and administrative controls related to moderator chemistry.

4. To implement the plan upon SRS management approval.

The first two objectives have been accomplished. The plan presented in this report accomplishes the third objective. The technical bases and status of various methods, systems, procedures, instrumentation, and surveillance requirements, as of mid-October 1989, have been documented $[2,3,4,5]$. A specific reference date is necessary when documenting the status of various aspects of moderator chemistry sir.ce many improvements are in progress. Additional reports detailing possible areas of improvement or needs for more detailed study in various aspects of moderator chemistry control, along with the rationale for such recommendations, have been issued $[6,7$, 8, 9]. Sixty-nine individual items of possible im- provement have been identified in these four reports. Most of these items are aimed at improving surveillance and communication of moderator conditions for faster response to potential problems. None of the items, however, were judged to have a significant immediate effect on the safety of reactor operations.

The purpose of this report is to provide a prioritized ranking of the recommended items of improvement, along with a status summary of any actions, which may have already been taken and an implementation plan for the remaining tasks. The plan consists of three components:

(1) to continue implementation of tasks already initiated by Systems Chemistry,

(2) to initiate action on those remaining tasks which can be completed with available resources within Systems Chemistry (a detailed time table for implementation of these items is given in this report), and

(3) to submit the remaining items to the Reactor Safety Improvement Program (RSIP) for prioritization and resource allocation. (A. timetable for submittal of these items for RSIP consideration is also given). RSIP will determine the individual item priorities based on the overall reactor needs and their place in the integrated plant safety assessment.

The remainder of this report is organized as follows. Chapter 11 provides a prioritized ranking of the nine task categories and the rationale behind such rankings. Details of the implementation plan are given in Chapter III. Appendix $A$ lists all the individual items of improvement and the task reports in which they were originally recommended. Appendix $B$ lists the nine task categories and the individual items of improvement which they encompass.

\section{RECOMMENDED IMPROVEMENTS}

As indicated earlier, assessments have been made of the adequacy of various aspects of the SRS moderator chemistry program, as compared with state of the art and commercial industry practices and guidelines. Sity-nine items of improvement have been identified and documented in references 6 though 9. A complete list of these recommendations is given in Appendix A. The underlying bases and rationale for each recommendation may be found in the original task re- 
ports. Many of these recommendations are overlapping in nature (Appendix B). They have, therefore, been grouped into nine task categories as shown in Section 11.1 below.

The nine task categories have generally been arrainged in order of priority with the highest priority given to items judged to offer the greatest improvement for the least expenditure of resources. None of the items identified has a significant immediate effect on the safety of reactor operation. Hence, safety considerations have had no effect on the prioritization process; instead, prioritization has been accomplished by consensus of the task team as to which items will provide the most significant improvements in moderator chemistry control in a timely manner using the resources currently available.

A generally prioritized listing of the nine task categories, along with the rationale for their rankings is given below.

\subsection{Prioritized Rankings of Improvements}

\section{Recommendation:}

Improve the scheduling, surveillance, and reporting of analyses affecting moderator chemistry.

a. Perform trending analyses of chemistry control parameters.

b. Institute a computerized system to improve commurications and provide data for analysis of potential problems in moderator chemistry on a nearly real-time basis.

\section{Rationale:}

The most frequently mentioned single item in the recommendations given in the various task reports $[6,7,8,9]$ (Appendix A) was the need to revise the SANSCO Program given in DPSOL 105-6101A, "Sample Analysis Schedule and Control Routine", [10]. The program was developed in the early-1970's for use on the mainframe computer. It provides no flexibility to allow for variables such as operating conditions, need for multiple samples, or unavailability of some analytical equipment. In addition, reporting of data from SANSCO to the cognizant engineers is delayed because of the need to use the mainframe computer. In-line data, which represent the most significant factor in trending of moderator conditions, are never input into the program in any manner.

Due to the above limitations, along with others outlined in the various task reports, the task team has concluded that improvement of SANSCO should be given the highest priority, as it would provide the greatest benefit to all organizations involved with moderator chemistry control at SRS; Reactor Operations, Reactor Engineering, Analytical Laboratories, SRL and Quality.

\section{Recommendation:}

a. Modify chemistry procedures to correct identified errors, remove ambiguities, and include information from external sources on reactor chemistry.

b. Establish a chemicals/materials control program for reactor areas.

Rationale:

The most frequently mentioned general item in the recommendations given in the various task reports $[6,7,8,9]$ has been the need to modify chemistry procedures (Appendix A). A total of twenty-one (21) individual items of possible improvement dealing with errors and ambiguities in the reactor chemistry procedures have been identified (Appendix B, Task Category 2-a). Most of these errors and ambiguities have been addressed using temporary procedure changes. It is important, however, to revise or rewrite the original procedures to make them factually correct and easy to use.

Procedure revision and/or preparation is an ongoing task for Systems Chemistry. It has been accorded a high priority because of its significant impact and comparatively modest resource requirements.

DPSOL 105-1845, "Chemicals and Non-Radioactive Hazardous Materials Control", [11] contains improper and ambiguous guidelines for the approval of new chemicals, and there exists little means of control over proper chemical usage. Improvernents in these areas would greatly reduce the likelihood of chemical (impurity) intrusions and unexpected moderator chemistry and process system degradation.

\section{Recommendation:}

Establish the responsibilities of various organizations with regard to moderator chemistry and the intertaces between them. 
Rationale:

All prior assessments of the SRS moderator chemistry program have had difficulty understanding the relationships between the many different departments involved in various aspects of moderator chemistry control. While definition of the relationships between the various organizations will not improve moderator chemistry per se, it will clarify the way in which business is done and the responsibilities of each organization, and, in turn, reduce the likelihood of errors and misunderstanding of responsibilities.

\section{Recommendation:}

Revise the Technical Specification for the upper limit on moderator $\mathrm{pH}$ from 8.0 to 7.2 to insure gadolinium solubility following actuation of the Supplementary Safety System (SSS).

\section{Rationale:}

The change in maximum $\mathrm{pH}$ is not essential for reactor safety or material protection. If the SSS is actuated, sufficient gadolinium nitrate will circulate in the system even at a $\mathrm{pH}$ of 8.0 to maintain the safety of the reactor. However, lowering the pH upper limit to 7.2 will reduce the probability of gadolinium precipitation on reactor surfaces by a factor of approximately 1000. This will provide more consistent conditions for prediction of reactor physics during restart of the reactor.

\section{Recommendation:}

Provide alarms in the Central Control Poom (CCR) for moderator conductivity.

\section{Rationale:}

Installation of conductivity alarms in the CCR will provide additional protection from adverse chemistry conditions and has been identified as an improvement item. Alarm installation can be delayed until after restart without significant impact on operation. It is awaiting funding for fiscal year 1991 (Project Problem No. 13-01174).

\section{Recommendation:}

Modify in-line and at-line moderator chemistry instrumentation to assure redundancy and accuracy.

\section{Rationale:}

Modification of reactor chemistry instrumentation to provide redundant in-line instrumentation, better sampling systems, better portable instrumentation, etc. will provide greater reliability for the surveillances needed to monitor the condition of the reactor moderator system. Some of these modifications, however, may involve considerable resources; hence, a relatively lower priority has been assigned to this recommendation. These items will be submitted to RSIP for funding competition. Projects will be initiated as resources become available.

\section{Recommendation:}

Improve Analytical Laboratory analyses of reactor chemistry parameters:

a. Report real numbers for chloride and sulfate concentrations.

b. Implement analysis of total organic carbon/ total carbon.

\section{Rationale:}

Improvement of Analytical Laboratories analysis capabilities requires resources from another department to be made available. It has, therefore, been assigned a relatively low priority. However, with encouragement and information transfer from the Systems Chemistry Group, progress is being made on these items. These modifications will result in better surveillance of conditions relating to reactor vessel intergranular stress corrosion and depletion of deionizer resin beds (and $\mathrm{CO}_{2}$ / ${ }^{14} \mathrm{C}$ evolution).

\section{Recommendation:}

Prepare new procedures and/or establish new programs for the following:

a. Storage tank analytical parameters.

b. Lay-up program.

c. A helium blanket gas for storage tanks.

Rationale:

Preparation of new procedures and establishment of new programs for storage tank analytical parameters, lay-up, and a helium blanket gas for storage tanks has been judged to require significant 
resources which are not readily available at this time; they have, therefore, been assigned a relatively low priority.

\section{Recommendation:}

Install new in-line equipment for moderator chemistry surveillance and moderator quality improvement.

a. Change the filter assembly design.

b. Provide cation concentration instrumentation.

c. Automate the acid addition system.

d. Re-use the moderator deionizer vessels.

\section{Rationale:}

Installation of new in-line equipment and systems can significantly reduce operator exposure in drawing samples and increase information flow. Significant resources, however, are required for design, pre-testing, project implementation, installation, and procedures writing. Such resources are not available at this time. It is the consensus of the task team that addition of new equipment for moderator chemistry control at SRS should not be done without detailed testing in order to demonstrate to Reactor Operations that the equipment will be beneficial, operable, reliable, and cost effective.

A summary of the above nine task categories is given in Table 1.
TABLE 1

PRIORTIZED TTEMS OF IMPROVEMENT FOR THE SAS MODERATOR CHEMISTRY PROGRAM AS OF MID-OCTOBER 1989

\begin{tabular}{l|l}
\hline Task & Recommendation
\end{tabular}

1. Improve the scheduling, surveillance, and reporting of analyses affecting moderator chemistry.

a. Perform trending analyses of chemistry control parameters.

b. Institute a computerized system to improve communications and provide data for analysis of potential problems in moderator chemistry on a nearly real-time basis.

2.a. Modify chemistry procedures to correct identified errors, remove ambiguities, and include information from external guidelines.

b. Establish a chemicals/materials control program for reactor areas.

3. Establish the responsibilities of various organizations with regard to moderator chemistry and the interfaces between them.

4. Revise the Technical Specification for the upper limit on moderator $\mathrm{pH}$ from $\mathbf{8 . 0}$ to 7.2 to insure gadolinium solubility following actuation of the Supplementary Safety System (SSS).

5. Provide alarms in the CCR for moderator conductivity.

6. Modify in-line and at-line moderator chemistry instrumentation to assure redundancy and accuracy.

7. Improve Analytical Laboratory analysis of reactor chemistry parameters.

a Report real numbers for chioride and sulfate concentrations.

b. Implement analysis of total organic carbon/total carbon.

8. Prepare new procedures and/or establish new programs for the following:

a. Storage tank analytical parameters.

b. Lay-up program.

c. Provide a helium blanket for storage tanks.

9. Install new in-line equipment for moderator chemistry surveillance and moderator quality improvement.

a. Change the deionizer fitter assembly design.

b. Provide cation concentration instrumentation.

c. Automate the acid addition system.

d. Ae-use the moderator deionizer vessels. 


\section{IMPLEMENTATION PLAN}

Action has been taken on several of the recommendations since their benefits were clearly evident. The status of various tasks within the nine categories is summarized in Table 2. This section outlines the elements and schedule of an implementation plan for all tasks. The plan consists of three components:

(1) Continued implementation of tasks already initiated by Systems Chemistry,

(2) Initiation of action on those remaining tasks which can be completed with available resources within Systems Chemistry, and

(3) Submittal of the remaining iterns to the Reactor Safety Improvement Program (RSIP) for prioritization and resource allocation.

\section{TABLE 2}

\begin{tabular}{|l|c|}
\hline \multicolumn{2}{|c|}{ STATUS OF RECOMMENDED IMPROVEMENTS } \\
(AS OF JULY 1990)
\end{tabular}

1. a. DPSOL 105-6101A-PLK, "Sample Analysis Schedule and Control Routine", restricted by old software design, has been revised within its limitations. Manual trending of important moderator chemistry parameters has been initiated (since June 1990). Since early 1990, the Analytical Laboratories have reported analytical $r e-$ sults to the areas by FAX.

b. Implementation of a computerized Chemistry Monitoring Program has been iritiated. Basic data for implementation of this task have been provided to the Core Methods Section of Reactor Engineering and SRL. A projected completion date for this program has not been received.

2. a. Modification of Chemistry procedures is an ongoing task for the Systems Chemistry Group of Reactor Engineering.

b. Development of an improved chemicals/materials control program is in progress. A procedure revision request for DPSOL 105-1845 [11] will be issued by December 1990. Recommendations for an improved program are projected to be issued by January 1991 (via RTM).
3. A draft of a proposed corporate level moderator chemistry policy and definition of relationships and responsibilities of various SRS departments involved in reactor chemistry has been submitted to the Reactor Engineering Manager.

4. This item has been completed. Technical Specifications (in draft form) now contain this revision.

5. Project Problem No. 13-01174 (CE FY 91) has been identified to provide a CCA alarm.

6. Requests by the Chemistry Group for improved oxygen analyzers have been completed and accepted. Other improvements in equipment such as portable $\mathrm{pH}$ and conductivity meters with flow cells have not yet been completed. This task is on-going. Completion dates cannot be set until after reactor restart since design, project preparation, and cognizant engineering time is required for many of the changes.

7. a. Analytical Laboratories will begin reporting real numbers for chloride and sulfate to $1 \mathrm{ppb}$ and $5 \mathrm{ppb}$, respectively, after completion of their test documentation. (completed July 1990).

b. Analysis of carbon by Analytical Laboratories (AL) will require, at a minimum, a $\$ 20,000$ instrument along with laboratory space. An estimate of project cost is being prepared by $A L$ A schedule and a budget will be submitted for RRD consideration by January 1991.

8. a. Initial analytical parameters for the storage tanks have been specified and incorporated into operating procedures. Further studies will be made to verify and ensure complete coverage of conditions.

b. A procedure has been implemented for the moderator lay-up program. Funther studies will be made to verity and ensure program completeness.

c. No action has been laken on this item due to lack of resources.

9. No action has been taken on this item due to lack of resources.

* Corresponds to those listed in Table 1.

Table 3 provides a time table for implernentation and completion of tasks within components (1) and (2) above, and submittal of tasks within component (3) for RSIP consideration. The time estimates are based on an assessment of available resources coupled with the priorities assigned to tine various tasik categories. Â summañ of 
planned actions for each of the sixty-nine individual items of improvement is given in Appendix C.

In order to document the status and progress made to date, a comprehensive report which includes all prior reports issued under this program (nine task reports) will be published by December 15,1990 . In addition, annual status reports summarizing progress made on implementation of the various tasks within this plan will be issued by Systems Chemistry. The first progress report will be issued by March 15, 1991.

\section{TABLE 3}

\begin{tabular}{|c|c|}
\hline \multicolumn{2}{|c|}{ TIME TABLE FOR IMPLEMENTATION } \\
OF VARIOUS TASKS
\end{tabular}

\section{N. REFERENCES}

1. "Moderator Chemistry Program - Mission Statement and Action Plan", L.V. DeWitt and S.I. Abdel-Khalik, OPS-ROD-890236, SRS Report (12/ 7/89).

2. "SRS Moderator Chemistry Control Objectives", A. Gibbs, OPS-ROD-890241, SRS Report $(12 / 11 / 89)$.
3. "Methods, Systems, and Procedures for Moderator Chemistry Control at SRS", R.L. Fanning, S.R. Bohrer, and S.I. Abdel-Khalik, OPS-RES-900141, SRS Report $(5 / 18 / 90)$.

4. "Technical Bases for Current Reactor Chemisty Technical Specification Requirements at SRS", A. Gibbs and S.I. Abdel-Khalik, OPS-ROD-900081, SAS Report (3/15/90).

5. "Moderator Chemistry Surveillance and Analysis Requirements", S.R. Bohrer and S.I. AbdelKhalik, OPS-ROD-890246, SRS Report (12/27/89).

6. "Identification of Operating Practices with Potentially Adverse Impact on Moderator Chemistry", D.P. Lambert and S.I. Abdel-Khalik, OPSRES-900216, SRS Report (7/23/90).

7. "Assessment of Methods, Systems, and Procedures for Moderator Chemistry Control at SRS", R.L. Fanning, S.R. Bohrer, and S.I. Abdel-Khalik, OPS-RES-900372, SRS Report (8/10/90).

8. "Assessment of Technical Bases for Reactor Chemistry Control at SRS", A. Gibbs and S.I. Abdel-Khalik, OPS-ROD-90082, SRS Report (4/23/ 90).

9. "Assessment of Moderator Chemistry Surveillance and Analysis Requirements at SRS", S.R. Bohrer and S.I. Abdel-Khalik, OPS-ROD- 900073, SRS Report (2/21/90).

10. "Sample Analysis Schedule and Control Routine", SRS ROD Procedure DPSOL 105-6101 APLK, Revision 11 (5/18/89).

11. "Chemicals and Non-Radioactive Hazardous Materials Control", SRS ROD Procedure DPSOL 105-1845-PLK, Revision 13 (5/10/90). 


\section{APPENDIX A}

\section{List of Recommended thems of Improvement}

The following is a list of the sixty-nine individual items of improvement recommended in the various task reports. The recommendations are divided according to the task report in which they were originally recommended.

\section{TASK 5 REPORT [6]:}

1 Improve the materials control prograrn for items in contact with process water system.

2 Restudy reagent grade nitric acid specifications for impurity addition potential to process water system.

3. Restudy moderator make-up spocification for impurity addition potential to process water system.

4. Review essential material specification for deionizer resin for impurity addition potential to process water system.

5. Examine possibility of maintaining helium blanket during outages.

6. Examine possibility of modifying process water heat exchangers to allow complete draining.

7. Review construction practices to minimize exposure of the process water system to contaminamts.

8. Evaluate need to operate a minimum of three main circulating pumps at all times when the process water system is full.

9. Eliminate use of light water to make up Supplementary Safety System ink to avoid isotopic dilution of process water.

TASK 6 REPORT [7]:

10. Replace the filter assemblies used in the Purification System pre-fitter and after-filters.

11. Automate the acid addition system.

12. Replace existing conductivity instrumentation with state of the art equipment.

13. Reconfigure the stream flow and samplers used for the $\mathrm{pH}$ meters.

14. Replace the dissolved oxygen instrument.

15. Install cation conductivity apparatus in-line.
16. Install in-line, ion-specific instrumentation for chloride.

17. Test and install ion chromatography equipment after their reliability is improved and proven.

18. Modify sampling lines and acquire proper portable instrumentation with flow-through cells for surveillance of conductivity and $\mathrm{pH}$ of the moderator.

19. Modity the method in which limits on undesirable species found in chemical materials are calculated. Document and incorporate into DPSOL 105-1845.

20. Revise DPSOL 105-1845.

21. Revise DPSOP 116 so the mole percent and weight percent are specified.

22. Revise DPSOP 116 so the percentages specified for different species are unambiguous.

23. Revise DPSOL 105-382 to explain the relationship between $\mathrm{pH}$ and conductivity.

24. Revise the ACC DPSOL's for $\mathrm{pH}$ and conductivity responses for clarity.

25. Perform a study to determine how control can be exercised over the way chemicals are obtained and used in the field.

26. Determine the feasibility of regenerating puritication deionizers or reusing deionizer vessels.

27. Determine the feasibility of controlling $\mathrm{pH}$ and conductivity using cation and anion resin beds instead of acid addition.

28. Determine the feasibility of establishing helium blankets on the moderator storage tanks currently vented to atmosphere.

29. Develop a formal reactor chemistry policy to define goals and responsibilities for maintaining moderator quality.

30. Restructure the SANSCO computer program so that it is more user interactive.

31. Develop a computer network to repon analysis results to all appropriate personnel in a timely manner.

32. Implement a trending program to track key chemistry parameters.

33. Establish a comprehensive lay-up program which incorporates pre-shutdown planning and needed interfaces.

TASK 7 REPORT [8]: 
34. Lower the maximum pH limit for the moderator from 8.0 to 7.2

35. Report actual analytical values for chloride and sulfate, rather than "less than" numbers.

36. Analyze process water streams for total organic carbon.

37. Install redundant in-line instrumentation, and/or modify sampling lines, and acquire proper portable instrumentation with flow-through cells for surveillarice of the moderator.

38. Install in-line cation conductivity apparatus.

39. Install in-line, ion-specific, instrumentation for chloride.

40. Test and install ion chromatography equipment after reliability is improved and proven.

\section{TASK 8 REPORT [9]:}

41. Install alarms for conductivity monitors in the Central Control Room (CCR).

42. Install back-up in-line $\mathrm{pH}$ meters in both the reactor influent

and reactor effluent streams.

43. Instali an in-line ion chromatograph and/or ion-specific

electrodes to perform continuous analyses of ionic species.

44. Modity SANSCO so that in-line readings are recorded automatically and trending of any parameter can be executed on

command.

45. Establish portable conductivity and $\mathrm{pH}$ monitoring with fiow cell probes for both the reactor influent and effluent streams to eliminate the need for samples and subsequent discrepancies between sample results and in-line monitor results.

46. Establish a calibration frequency for in-line conductivity monitors and document it in DPSOL 1-80802.

47. Include instruction to consult DPSOL 105-PW-702 in all CCA procedures which require routine monitoring of conductivity.

48. In DPSOL 105-PW-722, require that the oxygen analyzer be calibrated only if requirements of DPSOL 105$756 \mathrm{~A}$ are being met. Include steps requiring more oxygen additions if dissolved oxygen is low and fewer additions if dissolved oxygen is high.

49. Reevaluate the technical bases for oxygen and acid additions to the moderator and determine the correct procedure for such additions. Make necessary changes to DPSOLs 105-PW-702, and 105-756A to make them consistent.

50. Identify the procedures to be referenced when applicable parameters are out-of-limits; revise DPSOL 105-6101A (SANSCO) to list only those procedures

51. Provide steps in DPSOL $105-6120$ for the operator of a portable conductivity monitor to verify that the monitor is not past due on calibration.

52. Rovise DPSOL 105-6101A (SANSCO) so that special sample analysis results can be recorded more efficiently

53. Revise DPSOL $105-6102$ so that it is clear which sample vials are acceptable.

54. Reference should be made within DPSOL 105-6101A (SANSCO) to piocedures which provide instructions for inputting SANSCO analysis data back into the program.

55. Require that portable conductivity monitors be calibrated and used when in-line conductivity monitors fail and cannot be repaired within specified time limits.

56. Establish limits for the length of time an in-line monitor may be inoperable so that repairs will be made in a timely manner.

57. Develop actions and associated procedures for outof-limits conditions for chlorides, peroxides, nitrates, and any other relevant parameters for which no procedures currently exist.

58. Specific guidelines for out-of-limits data should be well documented in DPSOL 105-6101A (SANSCO).

59. Restructure the SANSCO computer program so that it is more user interactive. Atternatively, purchase or develop new software to better perform the required functions currently performed by SANSCO.

60. Develop a computer network to report analysis results to all appropriate personnel in a timely manner.

61. Require that the performance of procedures involving sampling of the moderator for chemistry control purposes be audited regularly.

62. Determine acceptable maximum limits for quantities of sulfate, mercury, gold, sitver, and copper in the moderator, along with sampling frequencies. Document the requirement for sampling these species along with limits and sampling frequencies in appropriate procedures.

63. Determine the parameters which need to be analyzed for the storage tank moderator. Docurnent the requirements for sampling these species along with limits and sampling frequencies in appropriate proce- 
dures.

64. Perform statistical analyses on moderator chemistry data to determine ideal sampling frequency.

65. Require that multiple arialyses of particular samples pulled on the same day all be reported and entered into SANSCO.

66. Establish agreement on acceptable laboratory turnaround times and document them appropriately.

67. Incorporate expanded shutdown conductivity limits into DPSOL 105-6133. Determine the limits for other chemistry parameters during shut-down and incorporate into this procedure.

68. Develop a comprehensive lay-up program.

69. Review all procedures pertaining to moderator chemistry control and make necessary revisions.

\section{APPENDIX B \\ List of Task Categories}

As indicated earlier, many of the sixty-nine items of improvement listed in Appendix $A$ are overlapping in nature. They have, therefore, been grouped into nine (9) task categories. The following is a list of the nine task categories and the inclividual items of improvement encompassed within each of them. A prioritized list of the nine task categories is given in Table 1.

Table 1

\begin{tabular}{|c|c|}
\hline $\begin{array}{l}\text { TASK } \\
\text { CATEGORY }\end{array}$ & \multirow{2}{*}{$\frac{\begin{array}{l}\text { ENCOMPASSED TTEMS OF } \\
\text { IMPROVEMENT }\end{array}}{245552545865}$} \\
\hline 1.a. & \\
\hline 1.b. & $\begin{array}{lllll}30 & 31 & 59 & 60 & 64\end{array}$ \\
\hline 2.a. & $\begin{array}{llllllllllllll}2 & 3 & 4 & 9 & 21 & 22 & 23 & 24 & 46 & 47 & 48 & 49 & 51 \\
53 & 55 & 56 & 57 & 61 & 62 & 67 & 69\end{array}$ \\
\hline 2.b. & $\begin{array}{lllll}1 & 7 & 19 & 20 & 25\end{array}$ \\
\hline 3. & 2966 \\
\hline 4. & 34 \\
\hline 5. & 41 \\
\hline 6. & $\begin{array}{llllllllll}12 & 13 & 14 & 15 & 16 & 17 & 18 & 37 & 42 & 45\end{array}$ \\
\hline 7.a. & 35 \\
\hline 7.b. & 36 \\
\hline 8.a. & 63 \\
\hline 8.b. & 683368 \\
\hline 8.c. & 528 \\
\hline 9.8 & 10 \\
\hline 9.6 & $38 \quad 39 \quad 40 \quad 43$ \\
\hline $9 . c$ & 1127 \\
\hline $9 . d$ & 26 \\
\hline \multicolumn{2}{|c|}{$\begin{array}{l}\text { Task Category numbers correspond to those in Table } \\
\text { 1. Numbers for items of improvement correspond to } \\
\text { those used in Appendix A. }\end{array}$} \\
\hline
\end{tabular}




\section{APPENDIX C}

\section{Planned Actions for Individual \\ Items of Improvement}

1. Programmic RTM to be issued $1 / 91$.

2. Complete study, document study, and issue RTM.

3. Complete study, document study, and issue RTP or RTM.

4. RTM-5039 is circulating for approval and will be issued by $10 / 90$.

5. Submit to RSIP for study.

6. RTM-5056 is circulating for approval and will be issued by $10 / 90$.

7. Programmic RTM to be issued by $1 / 91$.

8. Included into DPSOL 6133; RTR will be issued.

9. Included into DPSOL 1092.

10. Complete study on feasibility and submit to RSIP.

11. Complete study on feasibility and submit to RSIP.

12. Compiete study, document, and issue RTM by $2 / 91$.

13. Cornplete study on feasibility, and submit to RSIP.

14. REA-2592-3 has been issued for replacement.

15. Submit to RSIP.

16. Submit to RSIP.

17. Submit to RSIP.

18. Submit to RSIP.

19. Issue RTP by $11 / 90$.

20. Issue RTP by $11 / 90$.

21. Issue revision to Essential Materials DPSOP.

22. Issue revision to Essential Materials DPSOP.

23. Programmic RTM to be issued by $11 / 90$.

24. Programmic RTNi to be issued by $11 / 90$.

25. Programmic RTM to be issued by $1 / 91$.

26. Submit to RSIP for study.

27. Submit to RSIP for study.

28. Submit to RSIP for study.

29. Find appropriate document and incorporate at WSRC level.

30. Chemistry Monitoring System Task Team.

31. Chemistry Monitoring System Task Team.

32. Implemented 6/12/90, OPS-RES-900218.

33. Submit to RSIP for study.

34. Incorporate into Tech Specs; DOE approval expected 12/90. 35. Initiated July 1990.

36. Decision will be based on Lab estimate (due 1/91)

37. Submit to RSIP

38. Submit to RSIP.

39. Submit to RSIP.

40. Submit to RSIP.

41. REA issued; Project Problem No 13-01174 has been assigned. 42. Submit to RSIP.

43. Submit to RSIP.

44. Chemistry Monitoring System Task Team.

45. Complete study, document, and issue RTM.

46. Issue RTP.

47. Issue RTP's.

48. Issue ATP.

49. Complete study, document, and issue RTM or RTP.

50. Issue RTP

51. Issue RTP

52. Chemistry Monitoring System Task Team.

53. Issue RTP.

54. Chemistry Monitoring System Task Team.

55. Issue RTP

56. Complete study, document, and issue RTM or RTP.

57. Complete study, document, and issue RTM by $12 / 90$

58. Chemistry Monitoring System Task Team.

59. Chemistry Monitoring System Task Team.

60. Chemistry Monitoring System Task Team.

61. Issue guidance letter.

62. Complete study document and issue RTP or RTM.

63. Submit to RSIP.

64. Complete study and input to Chemistry Monitoring System Task Team.

65. Issue memo to Analytical Labs.

66. Issue memo to Analytical Labs.

67. Issue RTP.

68. Submit to RSIP.

69. Issue RTP's. 


\section{APPENDIX}

EXTERNAL REVIEW OF SRS REACTOR CHEMISTRY

COMMISSIONED BY SRS REACTOR CORROSION MITIGATION COMMITTEE AND SRS REPONSE 
SG-90-07-004

NSD-MWR-0274

Westinghouse Proprietary Class 2

SAVANNAH RIVER SITE

CHEMISTRY OPERATIONS WALKTHROUGH EVALUATION

FINAL REPORT

J. L. BARKJCH

WESTINGHOUSE ELECTRIC CORPORATION

NSD/STT - STEAM GENERATOR TECHNOLOGY AND ENGINEERING

August, 1990

This document contains information proprietary to Westinghouse Electric Corporation; it is submitted in confidence and is to be used solely for the purpose for which it is furnished. This document and such information is not to be reproduced, transmitted, disclosed or used otherwise in whole or in part without the written authorization of Westinghouse Electric Corporation, Nuclear Service Division Service Technology and Training.

\section{TABLE OF CONTENTS}

\begin{tabular}{ll} 
Section & \multicolumn{1}{c}{ Title } \\
1.0 & Introduction \\
2.0 & Summary of Observations \\
2.1 & Organization \\
2.2 & Communications \\
2.3 & Chemistry Control Operations \\
2.3 .1 & Aucdsiator Chomisiry Contro! Oparations \\
2.3 .2 & Purification \\
2.3 .3 & Heavy Water Distillation Facility \\
2.4 & Analytical Laboratory \\
2.5 & Research Activities \\
3.0 & Conclusions and Recommendations
\end{tabular}




\section{SAVANNAH RIVER STIE \\ CHEMISTRY EVALUATION AND WALKTHROUGH FINAL REPORT}

\subsection{Introduction}

A review of Savannah River Site chemistry operations was performed on May 1 to 3,1990, to evaluate past operating practices, operational enhancements implemented, and plans for future chemistry operations optimization. The purpose of this evaluation is to compare chemistry operations techniques at the Savannah River Site with those of commercial nuclear power plants, to assess current operational enhancernents, and to provide information for additional operations optimization. Although the design and operating characteristics of power and production reactors are quite different, parallels can be drawn for their respective opere"ng philosophy with respect to chemistry and corrosion control.

This evaluation reviewed the organization of parties responsible for moderator chemistry and corrosion control, communication channels between these parties, moderator chemistry and purification control operations, heavy water reprocessing, laboratory operations, and research activities. Discussion sections on these topics are presented below.

\subsection{Summary of Observations}

\subsection{Organization}

The organization of groups impacting moderator chemistry control operations at Savannah River is complex. Several groups were identified as having some direct or indirect input to reactor chemistry operations.

The Reactor Operations group is responsible for the day to day operation of the production reactors. This group is responsible for operation of purification loops and heavy water rework, recording of chemistry monitor output, and obtaining grab samples for analysis by the Analytical Laboratory. Providing diect support to Reactor Operations is the Equipment and Instrument Maintenance group which calibrates and repairs monitoring instrumentation. Health Protection (Health Physics) also may be considered to be under Reactor Operations.

The Analytical Laboratory is a entity separate from any of the other groups although they provide direct support to the Reactor Operations and other interested groups by performing routine and special analyses of the reactor loop, heavy water rework facility, and other system samples.

Reactor Training and Procedures is another separate group which supports the Reactor Operations group by providing specific training in reactor operations. This group also writes formal procedures for reactor operations using input from the other groups.

Reactor Engineering provides support to Reactor Operations by interfacing with other departments and obtaining technology from other sources to improve reactor operations.

Savannah River Laboraton is a technical research organization which investigates long range development of production reactor technology. Aspects of operations related to chemistry and corrosion include development and upgrade of reactor chemistry criteria, corrosion evaluations, and corrosion testing.

\subsection{Communications}

The organizaiions responsible for moderator chemistry and system corrosion control had operated in the past with communication limited to that considered necessary to address particular operational concerns. In 1988, the Reactor Corrosion Mitigation Committee was formed at the Savannah River Site. Pepiesentatives from Savannah River Laboratory, the Analytical Laboratory, Reactor Engineering, and Reacior Operations began to meet regularly to optimize moderator chemistry operations and minimize reactor systems corrosion. In addition, a Moderator Chemistry Program was prepared by Reactor Engineering to address operational concerns and to identify areas where immediale action could be taken.

The primary objectives of the Moderator Chemistry Program are to document and provide technical bases for curremt moderator chemistry operations activities, to examine the adequacy of these activities, to develop an implementation plan for identified improvements, and to implement the plan w, zon approval. Summary reports have been prepared examining current moderator chemistry contril operations, technical bases for current moderator chemistry requirements, requirements for moderator systems chemistry sur:dillance and analysis, operating prac- 
tices adversely impacting moderator chemistry, adequacy of current control techniques, adequacy of current Technical Specifications, and current surveillance and analysis requirements. These reports will be used to determine optimized methods for control of moderator chemistry operations.

Communications with regulatory and other entities outside the production reactor field have also been initiated to expand the knowledge base for systems chemistry and corrosion control. INPO was contacted regarding performance of a chemistry control audit. The Vogtle PWR power station was toured to provide power industry experience in PWR operating chernistry control. EPRI guidelines for PWR primary water chemistry comtrol have been examined and used as a framework for a similarly structured set of guidelines for the Savannah River reactors.

\subsection{Chemistry Control Operations}

\subsubsection{Moderator Chemistry Control Operations}

Although system materials, operating characteristics, and chemistry control criteria for the Savannah River production reactors are different from PWR power reactors, some similarities on chemistry control philosophy are evident. $\mathrm{pH}$ control ( $\mathrm{PD}$ control for heavy water) is of prime consideration for materials corrosion and water clarity control. Elimination of impurities in the coolamt (moderator) is also an important consideration from the aspect of materials degradation control. Moderator chemistry control guidelines for the Savannah River Site are listed in Table 1, below:

Table 1. Routinely Measured Moderator Chemistry Control Guidelines (excluding radioactivity measurements)

$\begin{array}{ll}\text { Parameter } & \text { Range } \\ & \\ \mathrm{H}_{2} \mathrm{O}_{2} & 0 \text { to } 1 \mathrm{ppm} \\ \text { Turbidity } & 0 \text { to } 0.5 \mathrm{ppm} \\ \text { Conductivity } & 1.9 \text { to } 3.0 \mu \mathrm{S} / \mathrm{cm} \\ \mathrm{pH} & 4.6 \text { to } 4.8 \\ \mathrm{NO}_{3}^{-} & 500 \text { to } 630 \mathrm{ppb} \\ \mathrm{NO}_{2}^{-} & 0 \text { to } 30 \mathrm{ppb} \\ \mathrm{Cl}^{-} & 0 \text { to } 30 \mathrm{ppb} \\ \mathrm{D}_{2} \mathrm{O} & 99 \text { to } 100 \mathrm{~mol} \%\end{array}$

Analysis Freguency

Once per month

$3 x$ per week

Once per week

Once per week

Once per week

Once per week

Once per week

Once per week

With these similarities in mind, a walkthrough evaluation of the $K$ area reactor chemistry control operations was performed. Facilities toured included the sampling room, demineralizer preparation area, purification system, blanket gas system, and the monitoring and control room. The tour, guided by the $\mathrm{K}$ area moderator chemistry control foreman, was very informative and provided valuable insight into reactor moderator chemistry control operations. Modeiator chemistry control operations, including sampling and corrective action are performed according to DPSOL-105-6101A and 6101C, standard operating logs for sample analysis and control (SANSCO).

The sampling room contains the sampling sink, $\mathrm{pH}$ and dissolved oxygen analyzers, acid mixing and addition systems, moderator drains and makeup lines, oil separator, rinse tank collection, and fuel failure monitor. Samples are available from the reactor (inlet to the purification system), the purfication flow back to the reactor, the coolant drain tank, drain tank effluem, purification cell effluents, and purification distillation column bottoms and distillate. The sampling sink is shielded to minimize radiation exposure. Sampling lines are flushed for 3 to 4 minutes in accordance with the recommended procedure (DPSOL-105-6102). Grab samples are sent to the Analytical Laboraiory for analysis. Blanket gas samples are taken by purging a sample bomb for about 5 minutes before sealing the sample bomb for analysis. $\mathrm{pD}$ is measured with a Beckman $940 \mathrm{~B} \mathrm{pH}$ analyzer. The $\mathrm{pH}$ analyzer is calibrated twice per month using two $\mathrm{pH}$ butfer solutions.

Nitric acid can be added to loops 1,5 , or 6 for $\mathrm{pD}$ control. Approximately 6 to 12 liters of $0.1 \mathrm{~N}$ nitric acid are addəd daily to maintain $\mathrm{pH}$ within the 4.6 to 4.8 range (pD 5.0 to 5.2). Degraded moderator can be collected from various drain tanks and rinse tanks for reprocessing. High purity reworked moderator is added to the coolant return tank as necessary.

In the purification control room, numerous monitors display moderator system conditions. Alarms are available for key operating parameters so inat action can be taken quickiy sinouid sysiem parameigrs move io oil normai conditions. The purification operator is responsible for tracking and monitoring conditions and taking corrective action through operation of manual controls. Automatic safety controls are available for critical parameters such as system overpressure control. Use of the automatic safety control system can result in reactor shutdown so it is only 
used in the case of emergency. Necessary operator actions may include acid addition, oxygen addition or control, and system pressure control. In the $\mathrm{K}$ area, additional responsibilities include demineralizer vessel makeup, deuterization and de-deuterization, as well as operation of the high activity moderator (HAM) recycle evaporator. These activities are performed at $K$ area for all three reactor areas ( $K, L$, and $P$ ). During normal operations of the three reactors at Savannah River, additional personnel dedicated to performance of demineralizer preparation and other activities common to the three reactors would be necessary to avoid a backlog or to maintain adequate chemistry control at $\mathrm{K}$ area.

The blanket gas system at $\mathrm{K}$ area has two redundant systems for controlling the reactor gas overpressure. Oxygen is added to the gas blanket to prevent reducing conditions from developing in the moderator. The " $A$ " system at $K$ area has proven to be more reliable in maintaining the gas blanket while the " $B$ " system is generally not in service due to concerns that allow it to operate for only a short period of time. The " $B$ " system is therefore used only as a backup to the " $A$ " system should the " $A$ " system require maintenance. It is recommended that efforts continue to troubleshoot the " $B$ " gas blanket system at $K$ area so that it can be used as a full time reliable backup to the " $A$ " system.

The shield water system is a closed loop recirculating system that provides thermal and radiation shielding around the reacior vessel. The top and bottom shield tanks contain Raschig rings for improved shielding and heat transfer characteristics. The shield water is demineralized light water without chemical treatment. The shield water conductivity is maintained in the 0 to $20 \mu \mathrm{s} / \mathrm{cm}$ range. Chloride concentration is determined twice monthly and is maintained in the range of 0 to $0.5 \mathrm{ppm}$. The shield water system operating maximum temperature is in the range of 70 to $75^{\circ} \mathrm{F}$ so that little corrosion is anticipated despite the lack of appreciable chemistry control. Investigations into chemistry control options for the shiold water system indicate that improved deionization or temperature reduction would minimize the potential for IGSCC in the shield tank system. It is suggested that a small continuous flow nonregenerable mixed bed demineralizer be installed on the shield water loop for this purpose.

\subsubsection{Purification}

Purification cell demineralizers within the reactor system are used to remove trace quantities of contailinants. Since the reactor system purification cell demineralizers are within the system moderator loop, they have a very high potential for influencing moderator contaminant concentrations should they be improperly made up, installed, or operated.

Purification cell demineralizers for all three reactors at Savannah River are prepared in the demineralizer deuterization facility at $\mathrm{K}$ area. 25 cubic feet of anion exchange resin (Amberlite IRA-400C) and 5 cubic feet of cation resin (Amberlite IR-120) are charged into the demineralizer vessel in a demineralized water slurry prior to deuterization. This ratio was reported to represent a 2.5 to 1 anion to cation lonic equivalent ratio due to the ionic capacity of the resin beads. Five 55 gallon drums of heavy water are passed upflow through the demineralizer at 0.5 gpm. After displacement of the light water with heavy water, a sample is taken from the demineralizer effluent and the demineralizer is sealed. A second sample is taken after the demineralizer is held in static conditions for 8 hours. If the $\mathrm{D}_{2} \mathrm{O}$ content of the sanples is within 0.35 mol percent of the heavy water used for deuterization, the demineralizers are deemed ready for service. If the $\mathrm{D}_{2} \mathrm{O}$ content in the samples is low, addition of heavy water is continued until the acceptance criterion is met.

Fresh demineralizers are recirculated prior to placing them in service so that potential chemical contamination is limited. Demineralizer effluent is monitored for compliance with the conductivity guideline $(<0.3 \mu \mathrm{S} / \mathrm{cm})$ prior to placing the demineralizer in service.

Demineralizers are exhausted when effluent conductivity increases to greater than $0.3 \mathrm{uS} / \mathrm{cm}$. Typically reported demineralizer effluent conductivity values are in the range of 0.03 to $0.05 \mu \mathrm{S} / \mathrm{cm}$ (theoretical pure $\mathrm{D}_{2} \mathrm{O}$ conductivity is $0.016 \mu \mathrm{S} / \mathrm{cm}$ at $25^{\circ} \mathrm{C}$ ). About 7.5 to 10 million gallons of moderator are purified by the demineralizer before exhaustion. Upon exhaustion, the demineralizer is removed from service for processing. Heavy water present in the demineralizer is reclaimed by displacement with light water until $\mathrm{D}_{2} \mathrm{O}$ content is less than $1.25 \%$. The exhausted demineralizer is then drained, sealed, and buried in the radioactive waste repository.

The purification cell also contains demineralizer prefilters and after fitiers. The fittration medium used to date has been asbestos. The use of asbestos can introduce unwanted contaminant species to the moderator system such as silica, calcium, magnesium, sluminum, ch!nride, and sulfate, as wo!! as ashastos fibars Altemate filtration media have been considered as replacement for the asbestos, including stainless steel mesh. Due to the high radioactivity levels encountered in the purification loop, a relatively simple fitter design is necessary. 
Consideration of the function of the demineralizer filters is important in determination of optimum filtration design. Prefilters designed to trap corrosion products should be of sufficiently small mesh to trap particles and prevent them from reducing demineralizer capacity and efficiency. The after fitter design can address the function of trapping resin bead leakage or resin fine leakage. Since the demineralizers in use at Savannah River reactors are once through demineralizers with no extreme physical atirition mechanisms for resin degradation, resin fine leakage should be minimal. A good pre-service rinse prior to deuterization should remove most resin fines associated with the new resir. In addition, improved resin purchase specifications can be used to obtain fewer resin fines and a more uniform resin bead size distribution from the manufacturer. With the application of these preventive measures, conventional resin trap fitters can be used for control of resin bead leakage. High resin quality control standards can also limit resin radiation degradation.

The purification system also has a distillation loop that is used for lighi water and turbidity removal. This system is designed to remove up to 1200 pounds of light water per year. Distillation column effluent returns to the demineralizer inlet to allow additional removal of ionic contaminants. Use of pD chemistry control has limited turbidity development in the reactor systems. The distillation system is currently configured to run continuously, primarily to remove light water contamination and to control turbidity excursions.

Moderator purification at the Savannah River reactors takes place at several facilities, including the high activity moderator (HAM) evaporator, the moderator purification facility (MPF), and the heavy water rework facility. The HAM evaporator at $K$ area is used to remove activity and chemical contaminants from degraded moderator. The MPF uses mixed ion exchange resin for removal of oil, turbidity, chloride, and reactor poisons. The heavy water rework facility is used to remove light water contamination from degraded heavy water used in reactor systems. Moderator with a high content of contaminant species is treated at the HAM evaporator or the MPF prior to processing at the heavy water rework facility.

\subsubsection{Heavy Water Distillation Facility}

The heavy water distillation facility consists of two, five stage distillation systems used to remove light water from heavy water. Water can be added at various points in the distillation cycle so that process efficiency is maximized. The highest purity heavy water is around 99.8 mol\% $\mathrm{D}_{2} \mathrm{O}$ with reject water at around 0.45 mol\% $\mathrm{D}_{2} \mathrm{O}$. Reactor systems heavy water-rework is performed in one of the two systems. The other system, Distillation Works, is maintained tritium free and is used for off-plant and newly produced $D_{2} O$ purification. Around 9 to 15 gallons per hour of high purity heavy water are reportedly produced during normal system operations.

\subsection{Analytical Laboratory}

Analytical Laboratory facilities for reactor samples at the Savannah River Site are located primarily at 400-D area, near the heavy water distillation facility. The laboratory function is to provide support to the production facilities for chemical analysis of process water. During very early operating periods, the chemistry information routinely followed included $\mathrm{D}_{2} \mathrm{O}$ content, $\mathrm{pH}$, and conductivity. Analyses for tritium, gross beta-gamma, anions $\left(\mathrm{Cl}_{1} \mathrm{SO}_{4}, \mathrm{NO}_{2}\right.$ and $\mathrm{NO}_{3}$ ), metals, and radionuclides were also traditionally performed. These parameters were followed for trending purposes only at that time. SANSCO procedures were Instituted around 1976. In August, 1989, improvements in communications between the Analytical Laboratories and other areas of the production facility began to take place. The supervisor of the water quality laboratory was established as the interface contact batween the laboratory organization and other areas of the production facility. Since that time, several other organizational and ter hnical changes were instituted. These changes include upgrade of the technical staft, upgrade and optimization of analytical methods, and improved communication of analytical results to operations staff by facsimile machine. in addition, the Analytical Laboratory supported the recent ultrasonic testing activities at $K$ and $P$ area facilities. During routine operations, $50 \%$ of laboratory activity is in support of reactor operations and $40 \%$ is in support of heavy water rework. The Analytical Laboratory also works closely with the Savannah River Laboratory in support of their research activities.

The Analytical Laboratory is organized into Special Laboratories, Central Laboratories, Process Instrument Laboratory, Technical Services Laboratory, Laboratories Projects, and the Waste Analysis Group. Within Special Laboratories, the Materials and Water Quality Laboratories have primary responsibility for reactor samples.

The laboratory employs a supervisor, fifteen analysts, and four chemists. Analysts work three per shift, with each day divided into two shifts. Three analysts are assigned to straight days. With this good analyst suppon, rapid analysis of samples from reactor operations is possible. Upon receipt, samples are entered into a log book to ensure proper analysis performance and tracking. Several types of analyses/analysis techniques are available 
including neutron absorption, lon chromatography, infrared spectroscopy, liquid scintillation counting, alpha, beta, and gamma counting, UVNis spectroscopy, atomic absorption spectroscopy (Fall 1:990), inductively coupled plasma (ICP) spectroscopy (1991), pulse height, flow injection, cold vapor mercury anlysis, turbidity, pH, and conductivity. Wet chemical methods are used for permanganate demand analysis. Several of these methods are common to PWR power plant chemical analysis, in particular, ion chromatography, pH, conductivity, turbidity, beta and gamma counting, liquid scintillation counting, and atomic absorption, UVNis, and IC:P spectroscopy. Methods used for these analyses appear similar to power industry methods. INPO good practice guidelines are used for analyst qualification. Instrument specific training is done on the job with documentation of analytical method qualification on an annual basis. Blind standards are used periodically for quality check's. Future training program goals include institution of a performance based training accreditation program in conformance with DOE order 5480.18 . This is to be implemented by late 1993.

\subsection{Research Activities}

Research activities at the Savannah River Site are performed to investigate corrosion phenomena and methods to control such corrosion. Chemistry control research in the past has focussed on moderator quality control and fuel cladding protection. More recently, activities have concentrated on resolving system piping and component corrosion. Degradation of system materials is a primary cause for reactor decommissioning, as in the case of the $\mathrm{C}$ area reactor. Research activities periormed to address materials degradation include electropotential measurements in the reactor system and constant extension rate tests (CERT) performed in the laboratory.

Electropotential measurements performed at Savannah River indicated that reactor system stainless steel materials are close to or within the cracking potential range. Other observations demonstrate a potential drop during shut down periods. The cause for this has not been determined. Aerated vesseis have been shiown to have an increased electropotential. In addition, the measured stainless ste日l electropotential values are higher than calculated values with oxygen only. This elevation is due to the presence of peroxide species.

CERT tests were performed to investigate cracking corrosion phenomena occurring in the reactor systems. Crack indications have been observed in piping or system components at all operating reartor systems. Intergranular stress corrosion cracking (IGSCC) is believed to have been initiated in the late 1950's 'when reactor power levels were increased and $\mathrm{PD}$ control instituted. Decreases in the cracking rate were observed in the 1960's after oxygen control was adopted.

Cracks have been observed on both inside and outside surfaces of piping. Additional crack locations included heat exchanger heads and the knuckles in " $C$ " tank. Cracks are associated with heat affected zones of welds and are typically circumferentially oriented. A few cracks have been observed in flame washed areas where piping has been heated for ease of pipe fitting.

Statistically designed CERT tests were performed to determine significant parameters involved in the cracking phenomenon. The most significant parameters affecting the corrosion processes include temperarure, peroxide, oxygen, chloride, and sulfate. The peroxide and oxygen effect was defermined to be implivit to the pD chemistry control philosophy and not able to be ameliorated. It was noted that the presence of peroxide was more detrimental than oxygen in inducing failure of test specimens. However, this effect was eliminated when chloride concentration was reduced to below $8 \mathrm{ppb}$ and sulfate concentration was reduced to below $10 \mathrm{ppb}$. The results of the study indicate that reduction of temperature, chloride, and sulfate concentration would lead to reduction in IGSCC initiation. Other test results indicate that transient temperature conditions lead to higher crack growh rate periods and that radiation damage dnes not aggravate SCC in sensitized 304 stainless steel nor induce IGSCC in annealed 304 stainless steel for Savannah River Site irradiation conditions. Similar corrosion effects have been observed in boiling water power reactors which operate with an oxidizing chemistry emvironment.

\subsection{Conclusions and Recommendations}

Personnel responsible for moderator chernistry and corrosion control at the Savannah River Site have made great progress in the past two years in developing a program to address moderator chemistry and system corrosion control issues. They have demonstrated the desire and capability to address and resolve operational deficiencies and to look ahead into ways of continuing performance improvements. All groups responsible for the various moderator chemistry control functions should be commended for their efforts to improve efficiency and reliability. Comments are presented below on various aspects of moderator chemistry and corrosion control management issues.

1. The organization of entities impacting reactor systems chemistry and corrosion control operations is necessarily complex due to the diverse nature of the various functions. Recent efforts at improved communications have 
provided additional mutual understanding among the parties and are leading to the development of comprehensive actions aimed at operations fine tuning and corrosion control.

Recommendation: As future plans deal with the implernentation of system improvements identified in the Moderator Chemistry Program, continued cooperation and participation by all parties in refining chemistry control techniques are necessary to be sure individual requirements and actions are being addressed. The Corrosion Mitigation Committee should continue to meet regularly to review the implementation process, to track performance objectives, and to promote the evolution of further operations refinements.

2. Past communications with entities outside the production reactor field has given additional insight to alternative chemistry control management techniques. The tour of the Vogtle PWR power station and application of EPRI/INPO chemistry management techniques are instances of such interactions.

Recommendation: Participation in activities oriented to other aspects of chemistry and corrosion control should continue to be pursued. Valuable information from various sources such as NACE, EPRI, etc. may be able to be applied at the Savannah River Site.

3. Corrosion tests have indicated that temperature and chloride and suffate concentrations are key controllable variable parameters for reduction of IGSCC in reactor systems. The aggressive nature of peroxide species in the corrosion process appears to be ameliorated to an extent by reducing chloride and sulfate concentrations below 8 and $10 \mathrm{ppb}$, respectively. The moderator chemistry control criteria reviewed during the evaluation place the chloride concentration limit at $30 \mathrm{ppb}$ with no specified limit on sulfate concentration. Sulfate has since been reported to be controlled to less than $50 \mathrm{ppb}$.

Pecommendation: Chloride and sulfate concentration limits should be Instituted in accordance with corrosion test results. Chloride and sulfate limits of 8 and $10 \mathrm{ppb}$, respectively, should be achievable in the closed loop reactor system. Efforts should be made to maintain chloride and sulfate concentrations below $5 \mathrm{ppb}$ during steady state reactor operation.

4. In the power industry, chemistry control perturbations are likely to occur during transient operating conditions, particularly during plant start up when systems have been open to the local environment. No special guidelines for start up chemistry conditions were noted in the review of information from the Savannah River Site. Conductivity and $\mathrm{pH}$ are typically monitored with $\mathrm{PD}$ control established at startup. Corrective action recommendations for high contaminant concentration conditions existing for the power industry were not noted in the Savannah River Site information.

Recommendation: Consideration should be given to upgrading start up control guidelines at the Savannah River Site. These guidelines should include more frequemt sampling to characterize the moderator chemistry environment until steady conditions are established. Corrective action recommendations for off normal chemistry excursions should also be considered. In the power industry, varying degrees of corrective action response, up to and including plant shut down for clean up, are indicated depending upon the extent of chemical contamination experienced.

5. The PD control method employed at the Savannah River Site requires batch addition of nitric acid to maintain moderator conductivity between 1.9 and $3.0 \mu \mathrm{S} / \mathrm{cm}$.

Recommendation: In order to maintain more stable $\mathrm{pD}$ chemistry control, consideration should be glven to develop. ment of a chemical addition metering system which would allow steady moderator conductivity control. This could mitigate potential chemical "shock" to the system and also prevent accidental overdosing of nitric acid to the system.

6. Purification cell demineralizers are prepared manually in the $K$ area deuterization facility. Anion and cation exchange resins are batched into the demineralizer at different rates to attempt approaching homogeneously mixed resin conditicns prior to operation. Heavy water is used to displace the light water in the resin prior to placing the demineralizer in service. Batch addition of lon exchange resins in this manner can result in layering or stratification of the anion and cation exchange resins. Resin stratification reduces demineralizer efficiency and can result in unwanted contaminant leakage.

Pecommendations: Prior to light water displacement, a resin rinse should be performed with demineralized light

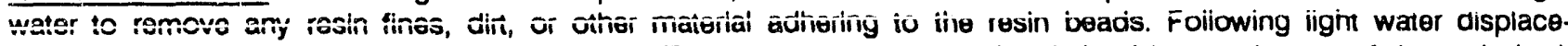
ment, a resin mixing step should be performed. The heavy water should be drained just to the top of the resin bed.

WSRC-TR-90-42-125 
A resin mixing step should be employed at this time to enhance mixed resin homogeneity. Air mixing of the mixed resin slurry has been successfully performed in other water treatment applications to promote intimate mixing of the cation and anion exchange resins. After this mixing step, demineralizers can be filled and sealed for transport to the purification cell.

Consideration should be given to development of a hard plumbed demineralizer purification facility. New demineralizer vessels could be plumbed into the facility where resin batching, deuterization, and mixing could be performed by simple valve and pump manipulation or in an automated process. This could speed the deuterization process and enhance demineralizer preparation quality.

7. Newly installed purification demineralizers are recirculated prior to being placed in service. Demineralizer effluent must meet the conductivity guideline $(<0.3 \mu \mathrm{S} / \mathrm{Cr}$, ) prior to being placed in service. Typical demineralizer effluent conductivity values during operation are in the range of 0.03 tc $0.05 \mathrm{uS} / \mathrm{cm}$. Demineralizers are taken out of service when effluent conductivity increases above $0.3 \mu \mathrm{S} / \mathrm{cm}$.

Recommendation: In order to limit contaminant introduction to the moderator, it is suggested that the demineralizer effluent conductivity specification be reevaluated. During preservice recirculation, demineralizer effluent should be analyzed for chloride and sulfate concentration before placing the bed in service. Effluent conductivity elevation above baseline conditions $(>0.1 \mu \mathrm{S} / \mathrm{cm})$ can be due to increases in chloride and sulfate concentrations at the end of service. If analyses confirm chloride and/or sulfate breakthrough, conductivity limits should be lowered to limit the extent of chloride and sulfate reintroduced to the moderator system. Economics of maintaining low demineralizer effluent conductivity should be evaluated with consideration given to the potential for increased stainless steel corrosion at higher chloride and sulfate concentrations.

8. Current asbestos purification demineralizer fitters are to be replaced with alternate filtration media.

Recommendation. Filter replacement should be part of a complete demineralizer system upgrade plan. Demineralizer after filters typically have limited effectiveness for removal of resin fines. Upgraded resin purchase specifications can improve resin bead particle size distribution and limit the quantity of available resin fines. Addition of a pre-deuterization rinse step during demineralizer preparation can also be effective in limiting resin fine introduction to the moderator system. Conventional resin trap filters can then be used to control resin bead or fragment introduction to the moderator system.

9. $\mathrm{K}$ area purification operators are responsible for preparation of purification demineralizers for all operating the Savannah Piver Site reactors and operation of the HAM evaporator in addition to normal chemistry operations functions. P area operators are also responsible for operation of the MPF.

Recommendation: Additional personnel should be made available at $K$ area to operate the deuterization and dedeuterization facilities as well as the HAM evaporator system so that moderator chemistry control operations are not compromised. Likewise, additional personnel should be available in $F$ area for operation of the MPF.

10. Analytical laboratory personnel receive on the job training for operation of analytical instrumentation. Analysts are qualified annually on instrumertation operation and analytical iechnique. Chemists attend workshops and seminars on technical advances.

Recommendation: While on the job training provides solid, hands on experience in use of sophisticated instrumentation, ongoing industry developments in instrument operation may not be discovered in a timely manner. Instrument manufacturers periodically conduct user seminars or workshops. These can be useful, particularly for the integration of refined and updated analytical techniques. It is suggested inat such seminars and workshops be attended by appropriate analytical personnel, as available.

11. The shield water system contains untreater demineralized light water with conductivity maintained less than 20 $\mathrm{uS} / \mathrm{cm}$ and chloride concentration less than $0.5 \mathrm{pprn}$. Since the shield water system operating maximum temperature is in the range of 70 to $75^{\circ} \mathrm{F}$, little corrosion is anticipated despite the lack of appreciable chemistry control. Investigations into chemistry control options for the shield water system indicate that improved deionization or temperature reduction would minimize the potential for IGSCC in the shield tank system.

Recommendation: it is suggested that a small continuous flow non-regenerable mbed bed demineralizer be installed on the shield water loop to improve shield water purity and limit the potential for development of corrosion in the shieid system. 
Inter-Office Memorandum

October 29, 1990

TU: J. D. Spencer, 773-A

FROM: J. E. Marra, 773-A

Reactor Corrosion Mitigation Committee

RESPONSE TO WESTINGHOUSE NUCLEAR SERVICES DIVISION (WNSD)

"CHEMISTRY OPERATIONS WALKTHROUGH EVALUATION" (U)

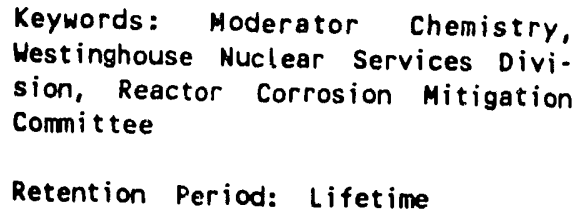

\section{INTRODUCTION \& SUMMARY}

In early 1990, the Reactor Corrosion initigation Committeo (RCMC) commissioned an evaluation of the Savannah River Site (SRS) reactor chemistry operations by the Westinghouse Nuclear Services Division (WNSD). A walkthrough evaluation was performed by J. L. Barkich and J. Roesmer of WNSD in May 1990. This evaluation covered operating practices, enhancements implemented, and plans for future chemistry operation optimization. A final report, "Chemistry Operations Walkthrough Evaluation, " by J. L. Barkich, was received and reviewed by members of the RCMC. Several recommendations were made in the repont to augment the existing Moderator Chemistry Program and to improve control of shield water chemistry. This report documents the recommendations and provides responses from the RCMC in answer to these recommendations.

\section{RECOMMENDATIONS \& RESPONSES}

The final report, "Chemisiry Operations Walkthrough Evaluation" contained eleven recommendations for improving process and shield water control. The RCMC has reviewed and evaluated the recommendations. A brief summary of the recommendations and the responses of the RCMC are given below.

1. Continued cooperation ... by all parties in refining chemistry control is necessary to be sure individual requirements and actions are being addressed. The RCMC should continue to meet regularly...

Response: With the continuing support of management, the RCMC will meet regularly (once a month) to discuss reactor systems chemistry and corrosion mitigation.

2. Participation in activities (NACE, EPRI) oriented to other aspects of chemistry and corrosion control should continue to be pursued.

Response: The RCMC encourages the participation in activities of the National Association of Corrosion Engineers (NACE), the Electric Power Research Institute (EPRI), and other organizations providing information and training pertinent to reactor inemistry and corrosion control. Such participation, however, must be beneficial to the site mission and within budgetary constraints.

3. Chloride and sulfate limits of 8 and $10 \mathrm{ppb}$, respectively, should be achievable in the closed loop reactor system.

Response: As recommended by SRL (WSRC-RP-89-1230), ${ }^{1}$ an attempt to reduce the amount of $\mathrm{Cl}^{-}$and $\mathrm{SO}_{4}=$ in the moderator has already been instituted by Reactor Engineering (RE) Reactor, and Laboratory groups.

To be assured that lower $\left(\mathrm{Cr}\right.$ and $\mathrm{SO}_{4}=$ levels are being achieved, accurate, very low level analyses must be 
performed. Toward that end, the Analytical Laboratory $(A L)$ organization has instituted improved methods that lower the detection limits below that requested (Ion Chromatography, IC).

In August 1990, L-Reactor averaged about 5 ppb Ct, with maximum levels about 8 ppb. K-Reactor moderator averaged about $10 \mathrm{ppb} \mathrm{Cl}$ but went as high as $15 \mathrm{ppb}$. With respect to $\mathrm{SO}_{4}=, L$ averaged about $10 \mathrm{ppb}$ with one large spike over $40 \mathrm{ppb}$ and $K$ averaged about $15 \mathrm{ppb}$ with one spike over $30 \mathrm{ppb}$ and one over $100 \mathrm{ppb}$.

In an attempt to lower extraneous $\mathrm{Cl}$ and $\mathrm{SO}_{4}=$, the asbestos filters on the ion-exchange columns may be replaced with stainless steel screens to reduce chloride and suljate leaching from the asbestos. If sulfonated resin particles are passing through the asbestos filters, it is hoped that stainless steel screens will also reduce the amount of $\mathrm{SO}_{4}=$ observed. In addition to the asbestos filters, some asbestos-containing gaskets are being considered for replacement. These changes should also reduce the extent of $\mathrm{Ct}$ leaching.

The total amounts of $\mathrm{Cr}$ and $\mathrm{SO}_{4}=$ in the moderator at 5 and 10 ppb are small, 1 and 2 grams respectively. However, even to maintain these small 'evels, there must be constant sources for chloride and sulfate in the reactors, because ion exchange should reduce the levels to a few ppb each. The levels currently observed are not believed to be the limits of removal by ion exchange.

4. Consideration should be given to upgrading start-up chemistry control guidelines at the Savannah River Site. ...should include more frequent sampling...

Response: Skis "start-up" chemistry begins with initiation of process water flow, not just reactor start-up. Operating procedures specifically address chemistry considerations during reactor start-up. Reactor Engineering is currenis, in the process of issuing a RTM that will recommend corrective actions for offnormal chemistry contaminants (chloride, sulfate, nitrate, etc.). These corrective actions will also cover the process water "start-up" condition.

5. ...to maintain more stable PD chemistry control, consideration should be given to development of a chemical addition metering system which would allow steady state moderator conductivity control. This could mitigate potential chemical "shock" to the system...

Response: It is doubtful that there is any real chemical "shock" to the reactor system by the present method of $p D$ control because of high flow through the reactor system and the slow addition of small quantities of $\mathrm{DNO}_{3}$. The accidental "overdosing" of the system with acid should not occur if procedures are followed. On-line instruments which read to strip chart recorders follow both the conductivity and the $\mathrm{pH}$ which indicate the presence of excess acid. If either the conductivity or the pH exceeds limits, audible alarms notify the operators.

Nitric acid is currently added to the moderator as a batch process. Under normal operation, about 1.2 gallons (5 liters) of $0.1 \mathrm{~N} \mathrm{DNO}_{3}$ is added in a period of five minutes every eight to sixteen hours. Addition is to loop i, 5, or 6 depending on the valving. The acid is added to the suction side of the Bingham pump which moves approximately 25,000 gal/min in a total reactor volume of 50,000 gallons. The pump therefore moves 2.5 reactor volumes past the acid inlet during addition. In inat scime time period, the six pumps turn the reactor volume over 15 times. One addition will lower the $p D$ about 0.05 unit if the starting point is about $p D=5$. The addition of 1.2 gallons of low concentration acid into a flowing, violently mixed stream of about 50,000 gallons, should not cause chemical "shock" of the system.

The pH is normally maintained at $4.7 \pm 0.1$ by controlling the conductivity of the moderator in the range of 1.9 $(\mathrm{pH}=4.8)$ to $3.0(\mathrm{pH}=4.6) \mu \mathrm{S} / \mathrm{cm}$ (conductivity is the control parameter due to the difficulty in obtaining accurate $\rho H$ measurements in low conductivity water.) If either the $p H$ or the conductivity exceed the limits on either the low or high side, an audible warning is sounded in the purification control room.

If for some reason the system were to receive an "overdose" of $\mathrm{DNO}_{3}$, the flow of the deionizers can be increased (if they are not at maximum flow) or the time between $\mathrm{DNO}_{3}$ additions may be increased to return the system to operating specifications. In any case, the problem would result from procedural violation which may occur equally in the present system or an automated system. Control by an automated metering system has been proposed previously, ${ }^{2}$ but has not been deemed economically beneficial. 
6. Prior to light water displacement, a resin rinse should be performed with demineralized light water to rernove any resin fines, dirt, or other material adhering to the resin beads.

Response: Resin bed preparation has been modified to utilize ultra-high purity deionized water in resin preparation. The resin is thoroughly rinsed and must meet chemistry specifications prior to the deuterization step.

7. In order to limit contaminant introduction to the moderator, ... the demineralizer effluent conductivity specification should be reevaluated.

Response: Revision of the specification for qualifying a demineralizer for service should be contingent upon the installation of reliable in-line monitors. With the current operation of measuring contuctivity off-line on grab samples, it is doubtful that the demineralizer effluent specification can be improved upon without excessive precautions in sampling and analysis.

Off-line samples are biased high because they have been in contact with air and contain dissolved carbon dioxide. In SRL-ADS-90-0504, 3 calculations showed that carbon dioxide can cause conductivity as high as 1 umho/cm. A review of the 1986-1989 Sample Analysis Scheduling Control (SANSCO) data for primary deionizer effluent conductivity (P103A, from purification to reactor), showed that conductivities of 0.3 and $0.4 \mu \mathrm{mho} / \mathrm{cm}$ were most commonly reported; the lowest value reported was $0.2 \mu \mathrm{mho} / \mathrm{cm}$.

The proposed use of Nuclear Grade resins (Recommendation 8) will not eliminate the problems associated with off-line analysis, but may lower the deionizer efluent conductivity below $0.3 \mu \mathrm{mho} / \mathrm{cm}$. The installation of in-line conductivity and $\mathrm{pH}$ meters is discussed below.

Revision of the specification for removing a demineralizer from service will be considered contingent on the performance of the Nuclear Grade resins.

8. Asbestos purification demineralizer filter replacement should be part of a complete demineralizer system upgrade plan. Upgraded resin purchase specifications can improve resin bead particle size distribution and limit the quantity of available resin fines. Addition of a pre-deuterization rinse step during demineralizer preparation can also be effective in limiting resin fine introduction to the moderator system.

Response: A recommendation has already been made to replace the asbestos filter with stainless steel media (WSRC-RP-89-1230).1

Resin bed preparation has also been modified to eliminate the concerns of this recommendation, unintentional layering of resin beds. This possibility has been eliminated by going to a mixed resin at the bottom of the deionizer and the excess anion resin at the top of the deionizer. Other changes that are being made as part of RTM-5039, "Improvements in Prepasing Purification Resin Beds (U)" are:

1.Switching to Nuclear Grade resirss,

2.Utilizing ultrapure, deionized water in resin bed preparation,

3.Installing in-line $\mathrm{pH}$ and conductivity instrumentation for verifying the adequacy of the new resin bed, and 4.Modifying procedures and essential material specification to reflect the current changes.

9. Additional pursonnel should be made available at $K$ area to operate the deuterization and de-deuterization facilities as well as the High Activity Moderator (HAM) evaporator sysiem so that moderator chemistry control operations are not compromised.

Response: As the restart effort continues, additional personnel will be trained and made available for chemistry control operations. Operation of the deuterization and de-deuterization facilities and the HAM evaporator win be included in this added emphasis.

10. It is suggested that Analytical Laboratory (AL) personnel should participate in off-site training and seminars currently offered by equipment manufacturers. 
Response: Historically, AL personnel have routinely attended off-site training for equipment, quality assurance/ quality controh, and National Institute of Standards and Technology (NIST) training as well as tours of off-site nuclear and support facilities. Future training will have to be evaluated against the SRS site mission and budget restrictions.

11. ... a small continuous flow, non-regenerable mixed bed demineralizer (should) be installed on the shield water loop to improve shield water purity and limit the potential for development of corrosion in the shield system.

Response: A recommendation to install an ion exchange system on the shield water loop has already been made (WSRC-RP-89-1230). ${ }^{l}$ Such a system should lower $\mathrm{Cl}^{-}$concentrations to $5 \mathrm{ppb}$ and $\mathrm{SO}_{4}=$ concentrations to 7 ppb.

In addition, a recommendation to increase the flow through the shield system heat exchangers has also been made. This increase in flow should lower the temperature from $70^{\circ} \mathrm{C}$ to $45^{\circ} \mathrm{C}$, thereby lowering the corrosion rate of the shield system components. Implementation of such a recommendation will need to be evaluated against the possibility of increasing the T-weld stresses.

\section{CONCLUSIONS}

The walkthrough evaluation of the SRS reactor chemistry operations was generally complimentary in nature. Personnel from the Westinghouse Nuclear Services Division (WNSD) encouraged implernentation of the programs begun by the Reactor Corrosion Mitigation Committee (RCMC). The specific recommendations made in the WNSD evaluation are currently being addressed and, where possible or practical, implemented. In addition to the WNSD recommendations, the RCMC (though Reactor Engineering) is upgrading procedures and program to enhance chemistry control. In particular, the implementation of the improvements suggested as part of the Moderator Chemistry Program ${ }^{4}$ will further increase the efficiency and effectiveness of the SAS reactor system chemistry control.

\section{REFERENCES}

1. R.S. Ondrejcin and G.R. Caskey, Jr., "Assessment of Susceptibility of Type 304 Stainless Steel to Intergranular Stress Corrosion Cracking in Simulated Savannah River Reactor Environments (U), WSRC-RP-89-1230, Westinghouse Savannah River Company, Savannah River Laboratory, Alken, South Carolina 29808 (Dacember 1989).

2. R. L. Fanning, S. R. Bohrer, S. I. Abdel-Khalik, "Assessment of Methods, Systems, and Procedures for Moderator Chemistry Control at SRS (Task 6 Report) (U)", OPS-RES-900372, Westinghouse Savannah River Company, Savannah Fiver Site, Aiken, South Carolina 29808 (August 1990).

3. E.W. Buumann, "Conductivity of Grah Sarr:jles," SRL-ADS-90-0504, Westinghouse Savarinah River Company, Savannah River Laboratory, Aiken, Soun. Jarolina 29808 (October 29, 1990).

4. L.V. DeWitt, A. Gibbs, and S.I. Abdel-Khalik, "Implementation Plan for Identified Items or Improvement in the Moderator Chemistry Program at SRS (U)," OPS-RES-900531, Westinghouse Savannah River Company, Aiken, South Carolina 29808 (October 1990). 

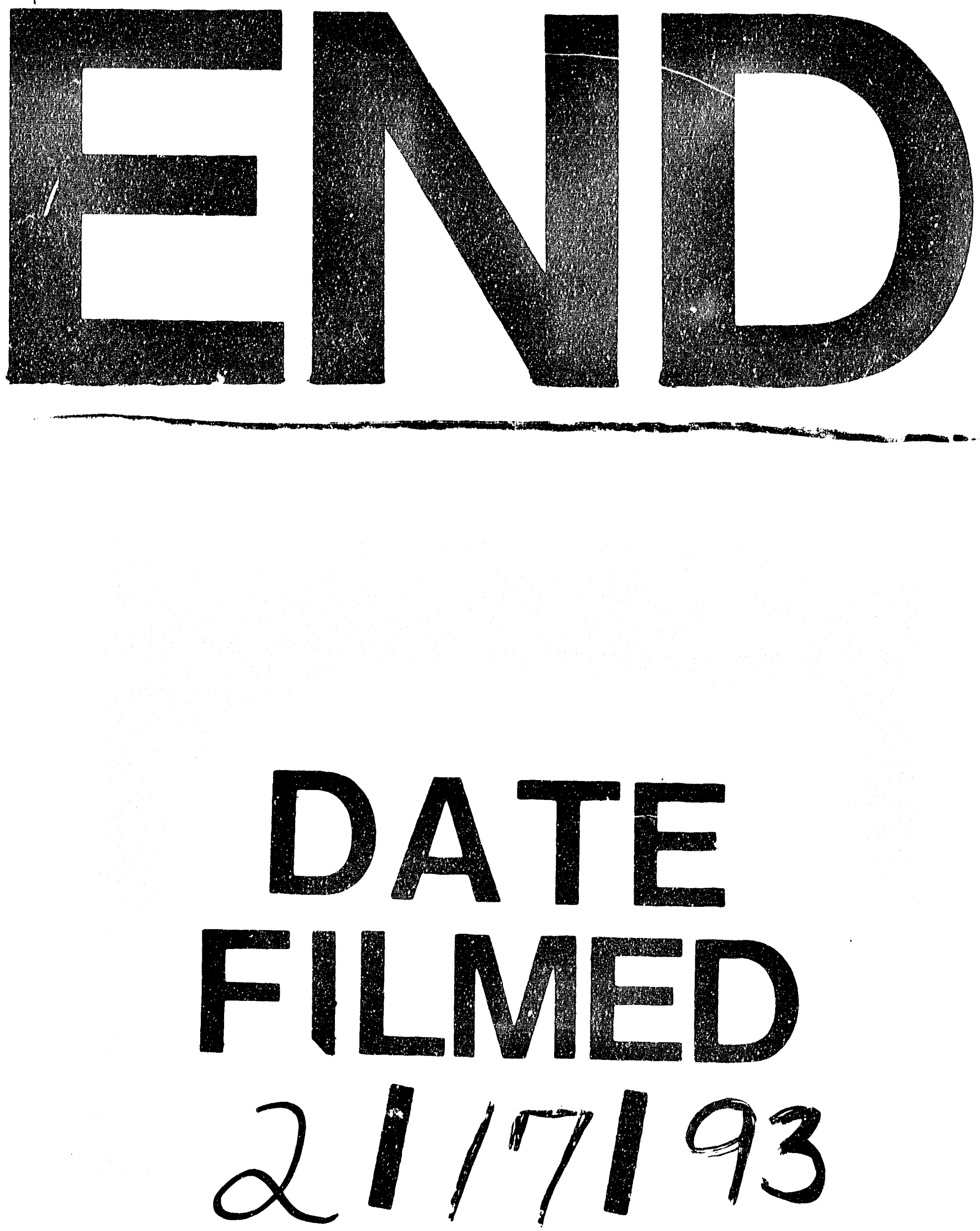